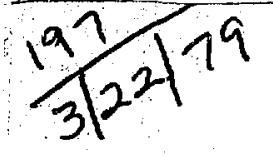

\title{
MASTER
}

$D R$

2364

UCRL-52811

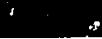

\section{A COMPLETE SYSTEM FOR PORTABLE GAMMA SPECTROSCOPY}

D. A. Fuess

November 15,1978

Work performed under the auspices of the U.S. Department of

Eneroy by the UCLLL under contract number W-7405-ENG.48.

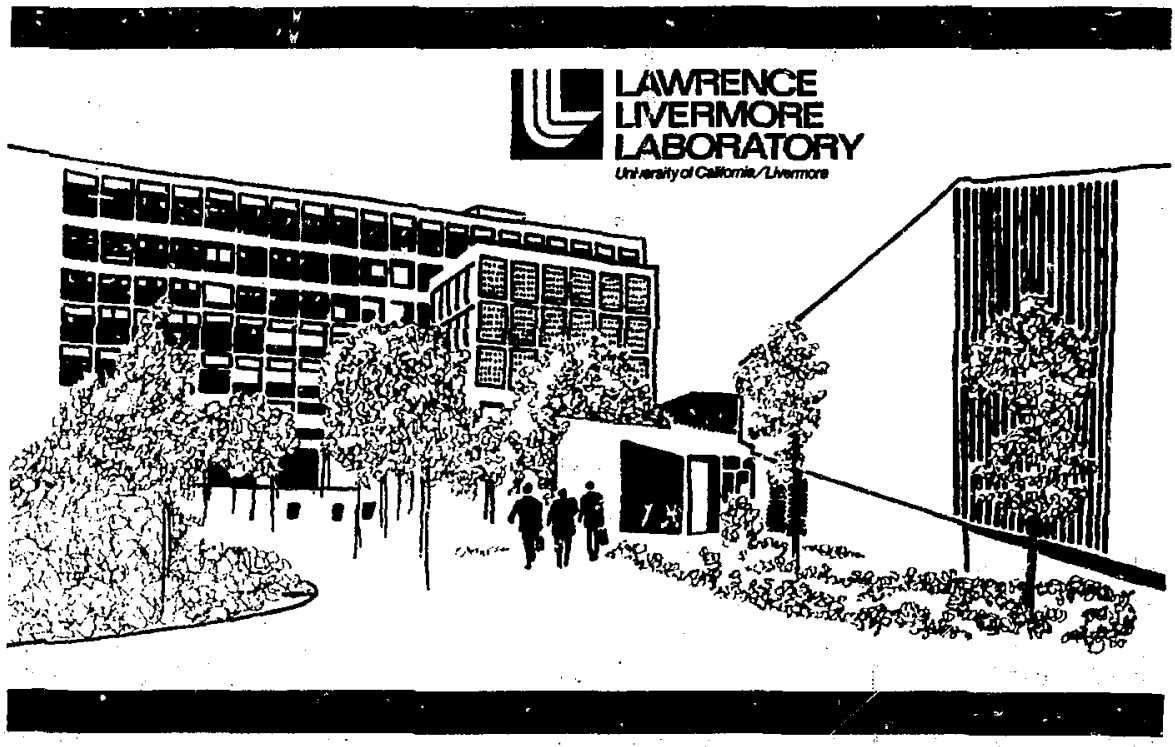




\section{近 \\ LAWRENCE LVERMORE LABORATORY \\ University of Calfornia/Livermore, Calfornia/ 94550}

UCRL-52611

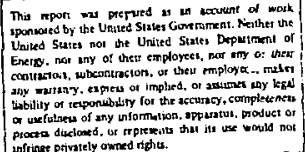

A COMPLETE SYSTEM FOR

PORTABLE GAMMA SPECTROSCOPY

D. A. Fuess

MS. date: November 15, 1978 


\section{A COMPLETE SYSTEM FOR PORTABLE GAMMA SPECTROSCOPY}

\section{ABSTRACT}

This paper describes a system built around the Computing Gamma Spectrometer (PSA) LEA 74-008. The software primarily supports high-resolution gamma-ray spectroscopy using either a high-purity intrinsic germanium detector (HPGe) or a lithiumdrifted germanium detector [Ge(Li)].

\section{INTRODUCTION}

The scientist in the field often needs a rapid, on-the-scene analysis of a sample (the most recent widely known example is Operation Morning Light in response to the inadvertent reentry of the Soviet satellite Cosmos-954). The Computing Gamma Spectrometer (PSA) LEA 74-008 fulfills such a need. It is completely portable: the entire system fits in a vehicle and the multichannel analyzer (PSA) can be hand-earried. Thus, the data can either be analyzed on location or transmitted to a distant processing center via commercial telephone equipment.

\section{SYSTEM OVERVIEW}

The system is divided into two major blocks, data collection and daia analysis, linked through data transmission. A detailed description of the interconnecting hardware can be found in Appen$\operatorname{dix} A$.

\section{DATA COLLECTION}

The data collection function is performed by the PSA and the various gamma detectors (see Refs. 1 and 2 for a complete description). Basically, it is a 1024 channel analyzer with built-in cisplay, power supplies for detectors, single-region-of-interest integration, background subtraction, and a data output function. It has a volatile memory. However, a memory-protect function allows the main power to be tumed off without data loss. In our experience, the internal batteries provide about six hours of fullon operation, and up to several months of memory protection.
The PSA may be used to collect data from numerous detcrtor systems. A series of detectors have been designed specifically for use with the analyzer and are fully supported by $i$. These include a $7 \%$ resolution, $5-\mathrm{cm}$ by $5-\mathrm{cm}$ NAI detector, and side- and down-looking HPGe planner detectors with 11.4-cm ${ }^{2}$-surface, by $1.3-\mathrm{cm}$-thickness active region.

\section{DATA ANALYSIS}

The heart of the data analysis function is the Tektronix 4051 Graphic Terminal. This is a Motorola 6800 microprocessor-based system with a resident-enhanced Basic interpretive languagr. In addition to data analysis, the 4051 recrives transmitted data via the transmission link and stores and retrieves data from data library tupes. See Refs. 3, 4, and 5 ior complete information on the operation and programming of the 4051. The operation of the 4051 with the spectroscopy software is described in a later section of this report. 


\section{DATA TRANSMISSION LINK}

The data transmission link is provided by a Hewlett-Packard 59403A HP-1B/Common Carrier Interface and a Teledynamic 7202D Data Set. Both have been inodified for compatibility with this system.

In this data transmission link, the data are converted from audio frequency shift keyed (FSK) to bit parallel, with an interim conversion to RS232C bit serial. Each step will be detailed in a later section. Audio cassetle tape recorders can store the data directly out of the PSA. The cassettes may be played directly into the 7202 Data Set to complete the data transmission.

Figure $\mathrm{I}$ is a block diagram of the overall system. The audio transmission link (PSAmodem) can consist of any combination of tape deck, telephone, radio, and hardwire, limited only by the amount of noise introduced into the system.

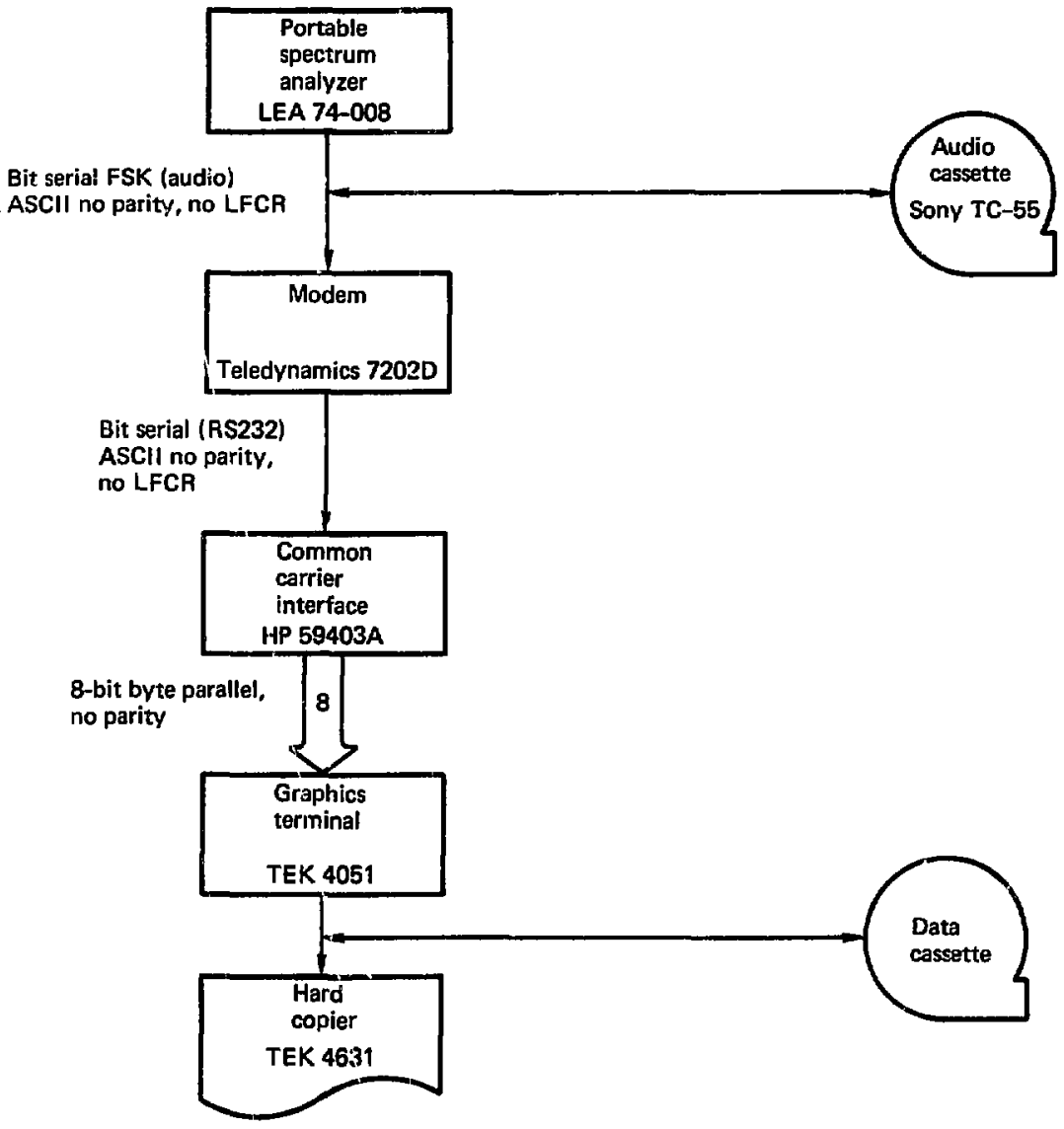

FIG. 1. Portable spectrum analyzer system. 


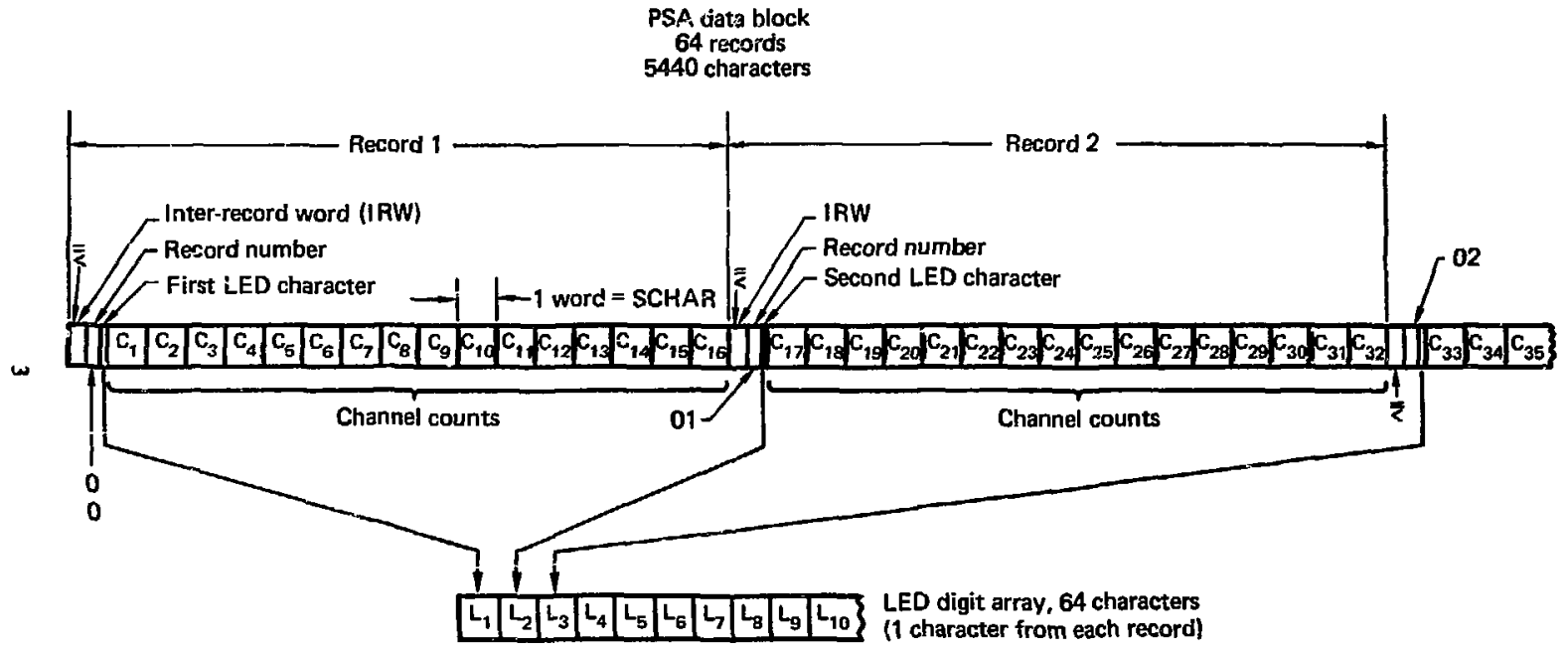

FIG. 2. PSA transmission sequence. 


\section{THE SOFTWARE SYSTEM}

The complete program listing appears in Appendix B. Flow charts for all programs except the primes appear in Appendix C.

\section{PSA DATA TRANSMISSION FORMAT}

The PSA traismits data in a bit-serial, audio FSK (frequency shift key), ASCII character format without parity or control characters. The entire transmission consists of $\mathbf{5 4 4 0}$ characters arranged into 64 records (Fig. 2). Each record is further subdivided into 17 five-character words. The data output sequence is

two beginning-of-record characters $i=<$ )

word 1 two digit record ID, octal

one front panel "LED" digit

+16 words of channel data.

A 5-sec carrier is transmitted before the data begins, followed by 64 cycles of the output sequence, followed by continuous carrier. The carrier is defined as the lower of the two FSK frequencies. If for some reason the transmission begins with the carrier on the high FSK tone (it has been kriown to do so), the transmit sequence must be reset by cycling the analyzer power off for about 30 sec (leaving memory protect or), and then on again. This cycling, should it be necessary, will result in the loss of the clapsed time indication and, for certain analyzers, the calibration information also.

\section{DATA RECEIVING}

The data receiving operation is performed by the $I / O$ program (described in detail later). This is actually a dual function operation, data receiving and data decoding. The decoding function involves establishing the binary arrays of data and LED numbers, and filling the arrays with the proper numbers.

The ASCII characters are counted as they come in. End of transmission is signaled by a character count of 5440 . This is not a highly efficient method for reliable data handling, but because of the absence of control characters, data count is the only available end-of-message indicator.

An interesting data redefinition occurs because of the defined qualities of numerical vs string variables in the 4051 and input of data via the GPIB. Data input via the GPIB is defined internally to the $\mathbf{4 0 5 1}$ as numerical; conversely, the data being presented to the input port is ASCII (string). What we end up with is the numerical value of the ASCII digit. This situation forces a double conversion of the data. Table 1 describes this conversion process.

TABLE 1. How to input the number 25 from the PSA.

\begin{tabular}{|c|c|c|c|c|}
\hline \multirow[t]{2}{*}{ Step } & \multicolumn{3}{|c|}{ Conditions } & \multirow[t]{2}{*}{ Remurks } \\
\hline & $\begin{array}{l}\text { Diglt } \\
\text { numetical } \\
\text { volue }\end{array}$ & $\begin{array}{c}\text { ASCII } \\
\text { atring }\end{array}$ & $\begin{array}{c}\text { Numerical } \\
\text { value }\end{array}$ & \\
\hline 1 & 30 & & & 2 is received \\
\hline 2 & & 2 & & 1st conversion of 2 \\
\hline 3 & 53 & & & 5 is recetved \\
\hline 4 & & 5 & & 1st conversion of 5 \\
\hline $\mathbf{5}$ & & 25 & & Convernion of 2 and 5 \\
\hline 6 & & & $\begin{array}{r}25_{10} \\
00011001_{2}\end{array}$ & Final conversion of 25 \\
\hline
\end{tabular}




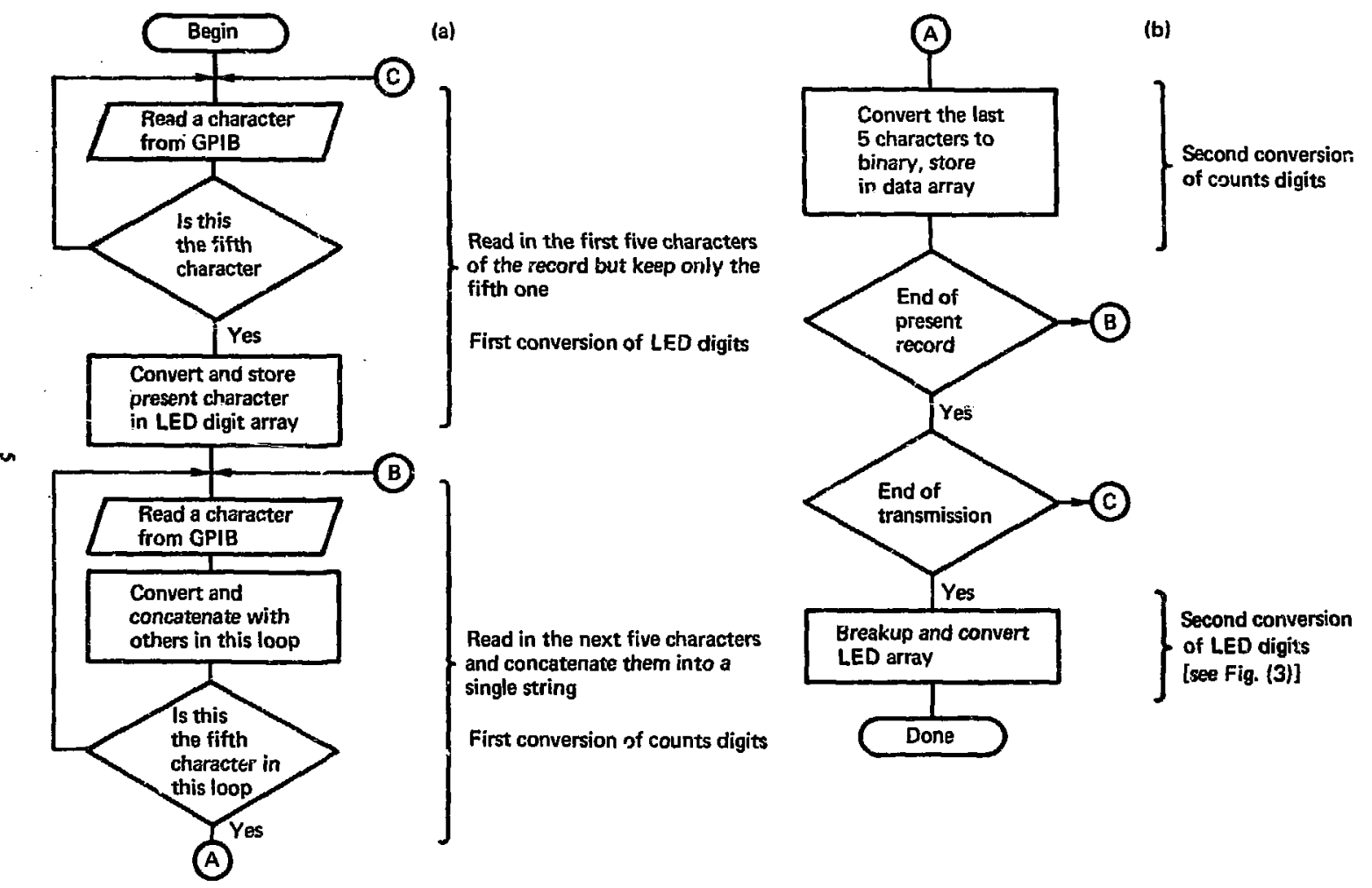

FIG. 3. (a) Data receiving, (b) data receiving (continued). This process takes about 3 min at 300 baud. 


\section{DATA INPUT/DECODE ALGORITHM}

The data input/decode algorithm was written for highest efficiency using the BASIC language. This is done by processing the data as completely as possible as the data are received, leaving very little post-processing. Specifically, the first foui characters of each record are discarded, the LED digit is stored as ASCII for later conversion, and the 16 words of count data are double-converted and stored in the data array.

The algorithm is implemented in a series of nested FOR ... NEXT (DO) loops, and the rate is controller by the incoming data (see Figs. 2 and 3 and Table 2). Thus,

$$
\mathrm{E}(\mathrm{ch})=\mathrm{E} \mathbf{l}^{*} \cdot \mathrm{Cl}+\mathrm{EO}
$$

where ch = channel No.,

$$
\begin{aligned}
& \mathrm{E} 0^{*}=\mathrm{E} 1 \cdot \mathrm{Cl}+\mathrm{EO}^{*}, \\
& \text { Then } \\
& \mathrm{E} 0^{*}=\mathrm{E} 0 \text { if } a<\mathrm{EO}<x \text { or } \\
& \mathrm{EO}^{*}=9 \text { 's complement of } \mathrm{EO} \text { if } \mathrm{x}<\mathrm{EO}<9999 .
\end{aligned}
$$

EO is the contents of a four-digit energy offset register whose maximum value is 4096 . If $E 0$ is

\begin{tabular}{|c|c|c|c|c|}
\hline \multicolumn{3}{|c|}{ Digits in LED array } & \multirow{2}{*}{$\begin{array}{l}\text { Variable name } \\
\text { in progr.m }\end{array}$} & \multirow[t]{2}{*}{ Name } \\
\hline From & To & $\begin{array}{l}\text { No. } \\
\text { digits }\end{array}$ & & \\
\hline $\mathbf{1}$ & 4 & 4 & Po & P mark energ/ \\
\hline 5 & 7 & 3 & F9 & Jullan day number \\
\hline 8 & B & 1 & Q0 & Quadrant number \\
\hline 9 & 10 & 2 & 09 & Semple id, number \\
\hline 11 & 18 & 8 & 89 & Summation $A$ to $B$ \\
\hline 19 & 20 & 2 & $\mathbf{J} 9^{\mathbf{b}}$ & Houn (clock time) \\
\hline 22 & 23 & 2 & $\mathbf{k} \mathbf{g}^{\mathbf{b}}$ & Minutes (clock time) \\
\hline 24 & 28 & $\mathbf{s}$ & B0 & B mack counte \\
\hline 29 & 32 & 4 & B1 & B mark energy \\
\hline 33 & 37 & 5 & 19 & Finpued time (seconds) \\
\hline 38 & 42 & $\mathbf{5}$ & AO & A mark counts \\
\hline 43 & 46 & 4 & Al & A mark energy \\
\hline 49 & s1 & 3 & $\mathbf{E 1}^{\mathbf{c}}$ & Energy calibntion constant (llope) \\
\hline 52 & ss & 4 & $\mathbf{E 0 ^ { C }}$ & Energ calibntion constant (intercept) \\
\hline 56 & 57 & 2 & $\mathrm{C2}^{\mathrm{c}}$ & Analyzer contant \\
\hline
\end{tabular}
negative, its 9's complement is sent. Therefore, I haye set $x$ at 5000 to allow for adequate offet in boti directions.

TABLE 2. Transmitted constants (LED digits).

"Quadrant number (QO) Indicates the status of the mernory puahbuttons at the time of tranamisalon. A $1,2,3$, or 4 means thut a single quadnot was selected, arid an 8 meane that all quadrents were relected. The quadrant number may of may not be a valld indicator of witch poetitions during nequisition. The entire contents of memosy are tranamitted every time, regardless of the position of the memory switches.

bTimes $(39, \mathrm{~K} 9)$ sifonifles that the clock time is the time of day that the data were tranemitted, not the thme of day the data were acquired. If the ame dath are transmitted twice, two different times of day will be listed.

Energy calibntion and analyzer constanta (E0, E1, C2): The meaning of C2 is somewhat nebulus and is not useful. EO and E1 aro used es constants in the linear energy callibration equation. 


\section{DATA STORAGE LIBRARIES}

The IO program stores data for later analysis or historical purposes. These libraries are maintained separately from the program tape. The following definitions apply throughout the remainder of this document:

- Litiary tape: A tar (scotch 500A or equivalent) on which data are stored.

- Data library: Refers to all of the information stored on a library tape.

- File: A physical file on the library tape.

- Data set: The data stored on tape or in the 4051 from one specific spectrum and its parameters.

- Data file: A file in which a data set is stored.

- Library i.d.: A unique designation/name for a library tape.
- Data set i.d.: A unique name for a data set.

- Index: A listing of data set i.d.'s for this library tape.

- Index file: The first file, it contains the library i.d. and the index.

The library tape format was established to meet the following criteria:

- Machine recognizable as a library tape.

- Avoid data set i.d. duplications.

- Facilitate automatic data storage, i.e., the 4051 can figure out where to write the data set.

- Protect the data against inadvertent loss or destruction (as much as possible).

The tape is structured by files. The first file contains the word "DATA," followed by the library i.d., followed by tine index. The remainder of the files contain the data sets referred to in the index.

\section{SAFIPLE SPECTRUIA}

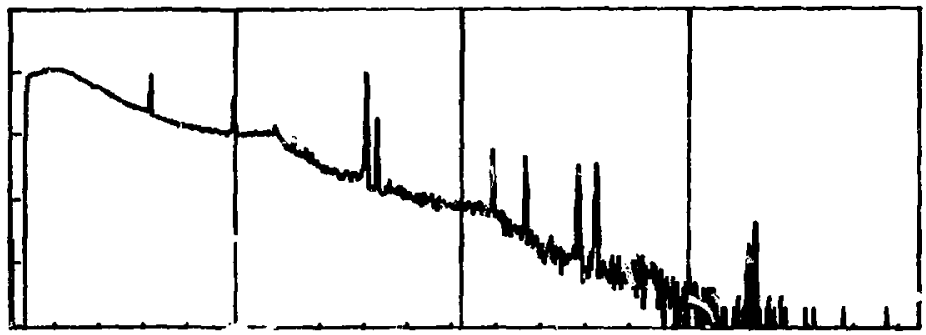

P MARK. ENERGY

$$
\text { DAY BUAD }
$$

TIME

15.27

LIUE TIHE 360

\section{SAAPLE}

20

B MARK COUHTS

351

A MARK COLHTS
INTEGRAL $A_{\theta}$ TO $E$

B MARK EHERGY 1291

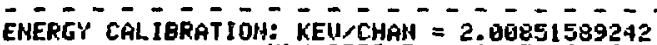

KEU OFFSET $=-1.17155256722$

KEU FULL SCALE $=2655.54872127$

FIG. 4. Sample spectrum. 
The library creation operation sets up File 1, and writes the word "DATA" and the library i.d. Thereafter, the user conducts only read and write operations on the library tape.

\section{INITIAL DATA DISPLAY}

The I/O program plots the incoming data after receipt and decoding. The plotting format duplicates the PSA display in log mode to allow the sender and receiver to compare readings. $A$ dashed line is drawn across the lower portion of the screen, and energy calibration calculations are made and displayed below the dashed line (see Fig. 4). This display can be called manual!y to display data retrieved from a data library tape.

\section{DATA ANALYSIS PROGRAM PHILOSOPHY}

There is no established technique for gamma spectrum analysis. Generally, those involved in this area have devised their own specific techniques. The analysis functions rovided in this program are intended to complement all the various techniques by carrying out the computations common to them. That is, the functions provide the physicist with the necessary baseline data upon which he may apply his analysis technique. These functions include:

- Plotting the data.

- Energy calibration.

- Peak locatió..

- Peak net area intezration.

- Background determination.

- Listing of photo peaks with their properties.

- Listing of the raw data.

These functions are presented in a variety of fashions, ranging from nearly fully automatic processing of the entire spectrum to a fully manual processing controlled entirely by the operator.

A functional description of the program is given later in the program listing; only the calculational methods will be discussed here.

\section{ENERGY CALIBRATION}

The calibration procedure employed assunes that ener $y$ is a perfectly linear function of the chan- nel numbers and can be fully defined on the basis of two points.

Given two-channel energy pairs $P_{1}\left(C_{1}, E_{1}\right)$ and $P_{2}\left(C_{2}, E_{2}\right)$, then

$$
E 1=\frac{E_{2}-E_{1}}{C_{2}-C_{1}}
$$

and

$$
\mathbf{E} 0=\mathbf{E}_{2}-\mathbf{E} 1 \cdot \mathbf{C}_{2} \text {; }
$$

the energy associated with a given channel $\mathbf{N}$ is

$$
E_{N}=E 1 \cdot N+E 0 .
$$

Equation (1) is the energy calibration equation. The constants EO and El may be re-evaluated as often as desired during processing. Any output obtained after a recalibration will contain the updated energy calibration.

\section{PEAK LOCATION}

Peaks are defined by three points: upper and lower channel extremities and $\mathrm{d}$ crest. The crest is located first and is defined as a channel whose count is greater than the counts of the adjacent channels. The lower extremity is defined as the highest channel below the crest where the slope of the data changes from negative to positive. The upper extremity is the lowest channel above the crest where the slope changes from negative to positive. These location criteria would define every ripple and bump in the data (Poisson noise, counting statistics, eti.) as a peak, if no other criteria were applied.

\section{PEAK DETERMINATION}

The peak determination criteria are set by the operator as he processes the data. This is usually done on the basis of deviation from background. Thie basic criterion applied is that a peak exists if and only if the operator says it exists. Given a channel ntaber between the upper and lower bound, the program applies the described peak lccation criteria to define the peak.

In 'he automatic mode the program locates and classifies peaks according to their deviation from background. That is, the net peak area must be 


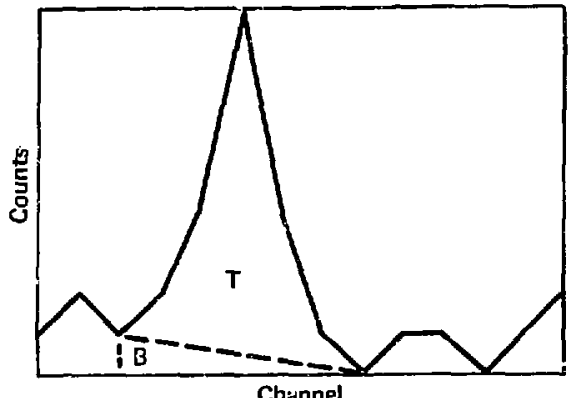

Both $T$ and $B$ are good approximations of the areas. Sigma calculation is valid.

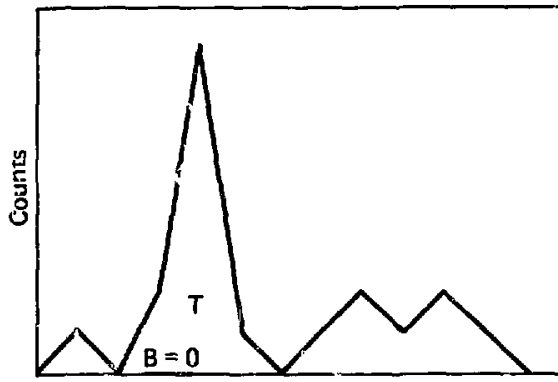

$T$ is a good approximation of net peak area, but sigma cannot be calculated $\langle\sqrt{B}=0\rangle$.

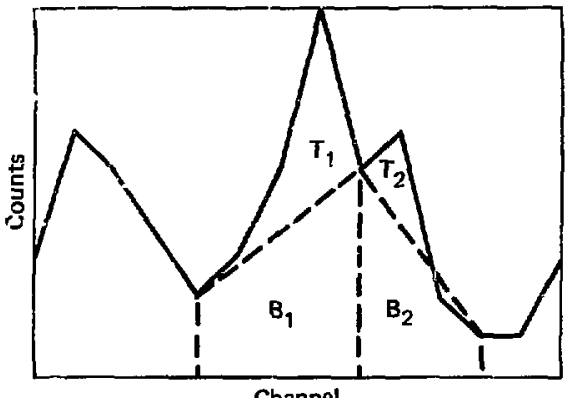

Peaks are piled up. $T_{1}$ and $T_{2}$ win! ur.derestimate the net peak areas, Sigmas will be small. $B_{1}$ and $B_{2}$ overestimiso background areas.

FIG. 5. Peak location end determination. 
greater than a specified number of standard deviations above the background area " $B$," where a standard deviation is defined to be $\sqrt{B}$.

A possible source of error occurs if the net background area is zero. Peaks faling into this category must be processed manually [Fig. 5(b)].

Errors may also result because of peak pileup or peaks standing on the crest of a Compton edge [Fig. 5(c)]. These errors are illustrated in the figures following this section.

\section{AREA CALCULATIONS}

Peak and background areas are calculated using the classical method (trapezoidal rule), Given the upper and lower channel limits $C_{2}$ and $C_{1}$ for a peak, then

$$
\text { Total Area }=\sum_{i=c_{1}}^{C_{z}} D_{i}
$$

where $\mathrm{D}_{\mathrm{i}}$ is the contents of channel $\mathrm{C}_{\mathrm{i}}$.

Then

$$
\begin{aligned}
\text { background area } & =\frac{D\left(C_{1}\right)+D\left(C_{2}\right)}{2} \\
& \times\left(C_{2}-C_{1}+1\right)
\end{aligned}
$$

and

net peak area $=\mathrm{T}=$ total area $-\mathrm{B}[$ Fig. $5(\mathrm{~b})]$.

\section{SYSTEM SETUP AND OPERATION}

\section{CALIBRATION OF PSA}

If at all possible, the PSA should be used in the full memory mode (1024 channels). The resolution for smaller memory increments (256 channels) is not generally adequate for spectrum analysis. Furthermore, the energy calibration for a 256-channel spectrum may be incorrect when displayed on the 4051 .

Digital offsets should not be used. The ofisetting procedure for the PSA is somewhat complicated, increasing the operator's opportunity for error. For greatest indicated accuracy, the spectrum should range from 0 to $4 \mathrm{MeV}$. (The PSA energy register range is 0 to 4096; therefore, a 0 to $5 \mathrm{MeV}$ spectrum would be indicated as 0-05.00, giving only two-place $(10-\mathrm{KaV})$ accuracy when 3-place is generally desired.) follows:

The procedure for calibration is outlined as

(I) Select full memory.

(2) Move A marker to lowest channel (channel 1).

(3) Move B marker to highest channel (channel 1024).

(4) Using "ECAL OFFSET," adjust "A MARK ENERGY" to zero.

(5) Using "ECAL KeV," adjust "B MARK ENERGY" as close as possible to desired ful" scale energy.

(6) Move the A marker to the calibration source's low energy.

(7) Move the B marker to the celibration source's high energy.

(8) While aequiring the calibration source, adjust the ZERO and GAIN NORM controls to place 'he appropriate peaks in the marked channels.

The calibration spectrum should be recorded on the cassette recorder before the sample spectrum is taken. If this cannot be done, then at the very least, the calibration parameters (channels and energies) should be recorded.

\section{DATA STORAGE ON CASSETTE}

This would seem a simple enough task to perf $m$, however it does have its pitfalls. First and foremost, each spectium must be fully identified, before it is recorded, as to time, place, configuration, source description, and all of the PSA front panel display numbers. This typ: of identification allows for error checking when the tape is read into the 405t.

As an aid to the operator, who may have to read the data later, all of the leading carrier and about $15 \mathrm{sec}$ of trailing carrier should be recorded. Thus, the tape deck must be started before pressing DATA OUT, and the recorder stopped about $15 \mathrm{sec}$ after completing transmission before releasing the DATA OUT key. (The DATA OUT key is a latching type.) 
The recording should begin eight revolutions from the physical beginning of the tape. To locate this point, press rewind until the tape stops; set the counter to zero; run the tape forward to 8 on the counter: and reset the counter to zero again. This ensures that the clear leader is past the tape head beforis recurding is attempted.

\section{OPERATIONS GUIDE}

This section provides an outline of instructions for receiving the data. It is intended only to get you started and not as a substitute for experience.
Set Up the Hardware

(i) Make up all the cable connections illustrated in Fig. 6 for the 405I, CCl, modem, and 4631 (if you have one).

(2) Turn on the 4631, 4051, and modem. Leave the $\mathrm{CCI}$ off for now.

Set Up the Software

(1) Insert the "FIELD ANALYSIS" program tape in the 4051 tape slot.

(2) Press "AuTO loAD."

(3) After the first page (or however many you wish to read), type "RUN" followed by ("RETURN"). The I/O program will be loaded.

\section{Cable descriptions}

$\therefore-$ RG58 or equivalent, BNC to spade clips (BNC end is made adaptable to cassette recorder by a BNC to appropriate plug-type pigtail).

B - 25 Pin, RS232C, standard cable, both ends male.

C - HPIB standard cable, stackable male/female both ends.

D - TEK 012-0547-00 or TEK 012-0630-01.

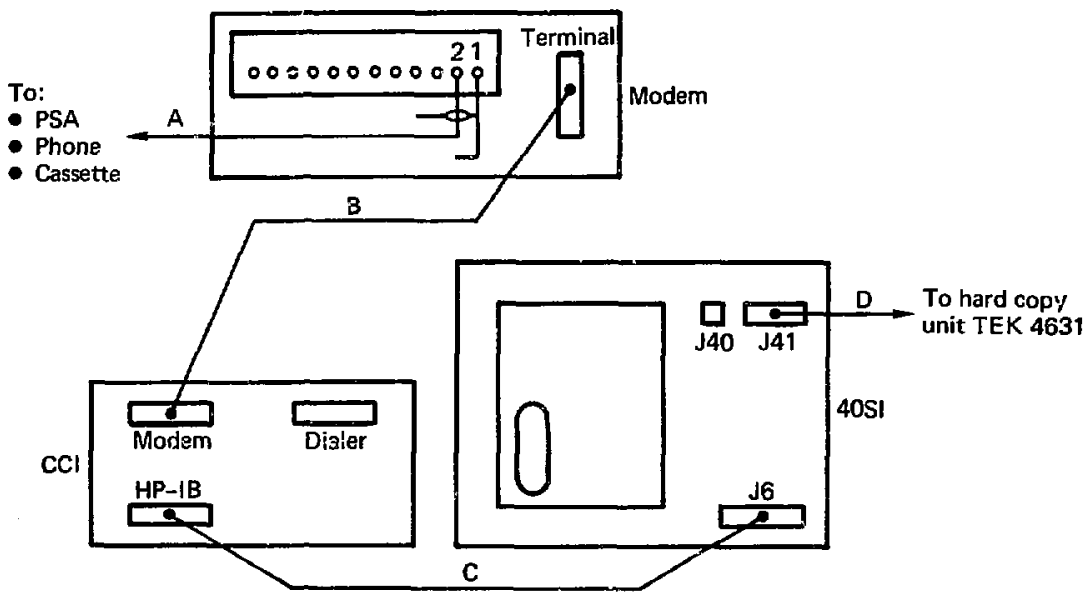

FIG. 6. Data transfer system interconnections. 


\section{Data Output Level Adjust}

This adjustment may not always be necessary. It should be done if the modem carrier light will not stay on resulting in numerous interruptions in transmission, or the data looks like $1 / 4$ stick of dynamite may have been used on it (this happens when the data out level is too high and saturates the modem input).

Either of these indications could also be the result of a noisy phone line; if so, the data output level adjust may or may not improve the situation.

Over-the-phone adjustment is best accomplished using two phone lines, one for the cquipmerit and one for the operators. With only one phone line available the user may have to resort to trial and error by listening for distortions himself:

(1) Set up the desired data link from the PSA to the modem.

(2) Depress "DATA OUT" on the PSA.

(3) Decrease "DATA OUT LEVEL" (CCW) on the PSA until the modem light gcas out.

(4) Increase "DATA OUT LEV EL" until the modem light renains on steudy. (This indication may be affected by line isoise.)

(5) Wait for the completion of the data out cycle ( $3 \mathrm{~min}$ ) and release "DATA OUT."

\section{Data Receiving}

(1) Set up the desired data link from the PSA to the modem.

(2) Turn on CCI

(3) Press "CLEAR CCI" (user key No. 7 un $4051)$.

(4) Press "RECEIVE" (user key No. 6 on $4051)$.

(5) When the modem light goes on, press the return key on the 4051 .

The 1/O light on the 4051 should coine on solid then begin to blink as the data are received. If an error (SRQ) occurs, see the section entitled Error Recovery.

(6) When data transmission is completed (about $3 \mathrm{~min}$ ), the $405 \mathrm{I}$ will signal (heep). Turn off the $\mathrm{CCI}$, respond to the requests on the display screen of the 4051. A plot will automatically be generated for you.

\section{Error Recovery}

An internal error recovery routine will handle most small, nonfatal errors. However, an extended series of errors may result in total failure of the receive algorithm.

As long as the 4051 keeps running, leave it alone. If, howe:er, it is necessary to stop the transmission, the following procedure should be used:

(1) Press "CLEAR ON ERROR", turn off CCI (User Key No. 8).*

(2) Wait until present transmission completes.

(3) Start over from step Dauz Receiving step 2.

\section{Data Analysis}

The primer defines each function of each overlay, and each overlay lists the user-defined key assignments specific to it when called. This arrangement results in a guided tour through the program during execution. The best way to learn the program is by running it. If the user sticks with the defined functions and follows the lead of the program, neither the tape nor the data can be destroyed. A complete processing should take less than $15 \mathrm{~min}$; however, longer times may be required, depending on the nature of the data.

The user gains access to the analysis overlay by pressing the user ney marked "Load Analyze" while in the $1 / 0$ overlay. Before calling the analysis overlay, the user should have completed all input/output operations. The program assumes that the last data set read into the $\mathbf{4 0 5 1}$ is the one on which the user wishes to operate.

No attempt is made here to instruct the user in spectrum data analysis techniques. It is suggested that the user become familiar with the techniques employed in general and with the functions supplied in the analysis program. He is then free to employ his own analysis method.

To permanently record changes the user may make in the data set (calibrations, elapsed time, data modification, etc.), the user must return to the $I / O$ overlay and use the library overwite function.

\footnotetext{
"You may have to press "BREAK" several times and/or tum off the $\mathrm{CCI}$
} 


\section{REFERENCES}

1. A. MoGibbon, Lawrence Livermore Laborato;y, Internal Document M-079. Readers outside the Laboratory who desire further information on LLL internal documents should address their inquiries to the Technical Information Department, Lawrence Livermore Laboratory, Livermore, California 94550.

2. K. Crase, Lawrence Livermore Laboratory, private commınication (1978).

3. Tele-Dynamics Instruction Manual for the 7202D/E-2P, Tele-Dynamics Division of AMBAC, Fort Washington, Peinsylvania.

4. Operating and Service Manual, Model 59403A Common Carrier Interface, Hewlett-Packard Co., Loveland, Colorado.

5. Tektronix 4051 Graphic System Reference Mantal, Tektronix, Beaverton, Oregon (Jan., 1976). 


\section{APPENDIX A \\ DETAILED DESCRIPTION OF INTERCONNECTING HARDWARE}

Teledynamics 72020 Data Set (Modem)

This particular modem was selected on the basis of its ability to accept the nonstandard audio frequency output of the PSA. The PSA frequencies are $2184.5 \mathrm{~Hz}$ and $1191.5 \mathrm{~Hz}$. Other modems were tried and failed.

The modifications deseribed below produce a one-way (i.e., incoming only) communication as neither the PSA nor the tape recorder can function in a two-way mode.

The straps are set as follows (up = removed):

$$
\begin{aligned}
& \text { A-DOWN } \\
& \text { B-UP } \\
& \text { C-UP } \\
& \text { D-DOWN } \\
& \text { E-DOWN } \\
& \text { F-UP } \\
& \text { G-UP } \\
& \text { H-UP } \\
& \text { J-DOWN }
\end{aligned}
$$

$$
\begin{aligned}
& \text { K-UP } \\
& \text { L-UP } \\
& \text { M-DOWN } \\
& \text { N-DOWN } \\
& \text { P-UP } \\
& \text { R-DOWN } \\
& \text { S-UP } \\
& \text {-8-DOWN } \\
& \text { All others straps-UP }
\end{aligned}
$$

Internal switch positions:

$$
\begin{aligned}
& \text { AUTO/MAN-MAN } \\
& \text { NORM/LOC-NORM } \\
& \text { NORM/REM-NORM }
\end{aligned}
$$

Traces cut on the RS2:? connector board:

TRACES FROM RS232 CONNECTOR

PINS 4 AND 11

Jumpers on rear terminal strip:

$\begin{array}{ll}\text { FROM } & \text { TO } \\ 5 & 6 \\ 6 & 7 \\ 9 & 12\end{array}$


Audio input connections (rear terminal strip):

$$
\begin{aligned}
& \text { Signal } 2 \\
& \text { shield-1 }
\end{aligned}
$$

RS232, 25 Pin connector from terminal jack to common carrier interface 'MODEM' jack.

\section{Common Carrier Interface, HP $59403 \mathrm{~A}$}

The common carrier interface (CCI) is needed to compensate for the lack of control characters in the PSA transmission. As shown in Fig. 2, no LFCR's are transmitted. Standard RS232C devices cannot generally receive the data without termination characters, therefore the data must be connected for reception oyer the GPIB (HPIB).

The CCI performs the conversion from bit serial to bit parallel. No parity checking can take place, however, because the PSA does not transmit parity bits. The parity bit from the modem is random, requiring a modification in the $\mathrm{CCI}$ to prevent unwarted error interruptions.

In general, HPIB devices (CCI) and GPIB devices (4051) are compatible. However, this is not always the case with the CCl's. There is enough variation between the handshake timing specifications to allow both devices to be in specification yet be unable to communicate. Although the degree of compatability can be determined with a logic analyzer, we resolved the problem by associating matched pairs of devices, i.e., a compatible $\mathrm{CCI}$ and 4051 .

The common carrier interface is set up as follows:

Address (DIP switch inside):

$$
\begin{aligned}
& \text { 1-OFF } \\
& 2-O N \\
& 3-O N \\
& 4-O N \\
& 5-O F F \\
& 6-O F F \\
& 7-O N
\end{aligned}
$$

The lead from the HPIB connector pin 16 (data bit 8 ) is disconnected. This can be done by removing the sockel insert from internal plug P3 pin 6.

Front panel push buttons:

BAND RATE-300

INTERFACE-ASYN

PARITY-NONE 
Cable connections:

FROM

CCI, MODEM (RS232C)

CCI, HP-1B
TO

MODEM, TERMINAL 4051, GPIB

When turned on, only the ON-LINE indicator should light. 


\section{APPIENDIX B PROGRAMMIN CONSIDERATIONS \\ OVERALL PROGRAM CONTROL}

The program tape FIELD ANALYSIS onsists of four files. The first file is the initiaization and primer program. It is in fact the ouly real program on the tape. The remaining three files contain overlays, designated I/O, ANALYSIS, and PEAK SEARCII AUTO.

All program variables are essentially global. This means that a variabla, once defined, is accessible in all other overlays unless it is specifically deleted. This tends to cause a problem because the memcry tables may become filled with unused or forgotten variables that will result in hardware errors and program termination. I have tried to follow the basic rule that any variable not intended to be shared with the other overlays is deleted before releasing the overlay present.

\section{THE WHY AND HOW OF OVERLAY}

The full memory capability of the 4051 is 32,000 bytes, 30,000 of which are available for program and data storage an: $\geq 2,000$ of which are claimed by the system for the operating tables. The present size of the entire program is 84,744 bytes for program alone?

Now for the How. The Injtialize program supplies the first three lines of code, which remain constant throughout all overlays. These lines arc:

1 GO TO 100

2 DELETE 5, 10000

3 APPEND 4

All overlays begin with line 4 , which always reads

\section{GO TO 100}

Lines $8-80$ are available for user lefinable key definitions. The actual programming for the overlay begins on line 100 .

The overlay procedure is implemented in the main body of the overlay present. A jump (Go To) line $\mathrm{N}$ begins the process....

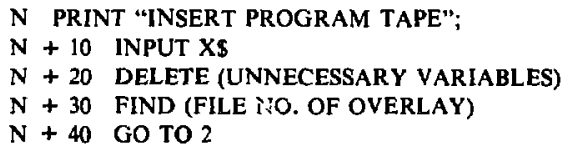

\section{GLOBAL VARIABLES}

The global variables are specified; they either control program flow, or relate to the present data set. These variables have been defined as follows:

A0 A mark counts

Al A mark energy

B0 B mark counts 
B1 B mark energy

C2 An analyzer constant

D Data yector (1024 elements)

E0 Energy calibration constant (Intercept)

E1 Energy calibration constant (slope)

F9 Julian day number

J9 Hours (clock time)

K9 Minutes (clock time)

L9 Elapsed time

O9 Sample i.d. number

PO P mark energy

P1 Overlay i.d. number

P2 Data present sentinal

Q0 Quadrant number

\$9 Summation between markers

TS Data set title

\section{GENERAL AND SHARED VARIABLES}

Sonne variables, by either tradition or by assignment, itave special uses.

I, J, K General index variables

$X \$$, I\$ General string input variables

N3, iN4 General limit variable (beginning and ending)

$X$ Ganeral temporary store 


\section{APPENDIX C \\ FLOW CHARTS FOR PROGRAMS}

FIELD AMALYSIS PROGRAMS

D. A. FUESS

SEPTEMBER 1, 1978

PROERAAM LISTINGS IN TEK BASIC

LANGUAGE FOR THE TEK 4051 . 
TAFE: FIELD AHHL YSIS

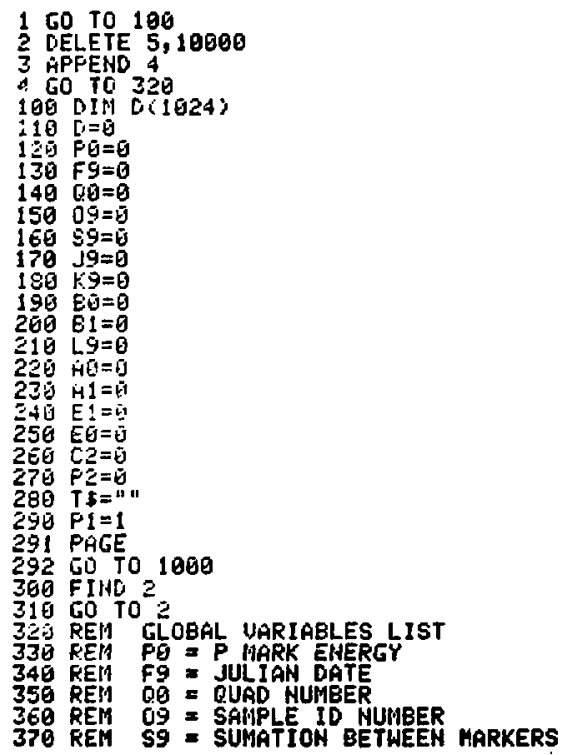

150 TO 100

2 DELETE 5,10000

3 APFEND 4

460 T0 320

100 DIM D(1024)

$1190=0$

$120 \mathrm{~PB}=0$

$130 \quad F G=0$

$14 B Q \bar{Q}=\mathrm{B}^{3}$

$150 \quad 09=0$

$160 \$ 9=0$

$170 \mathrm{J9}=0$

$180+9=0$

$19 \bar{E} \mathrm{E} \overline{\mathrm{U}}=\mathrm{O}$

$200 \quad 51=0$

$210 \quad L 9=0$

225 -

$230 \quad H !=\bar{G}$

$2,401=0$

250 E $=\bar{\theta}$

$200 \quad \mathrm{C} 2=0$

270 P2 $=5$

$280 T \$=41$

$25 \bar{B} \mathrm{P} 1=1$ 


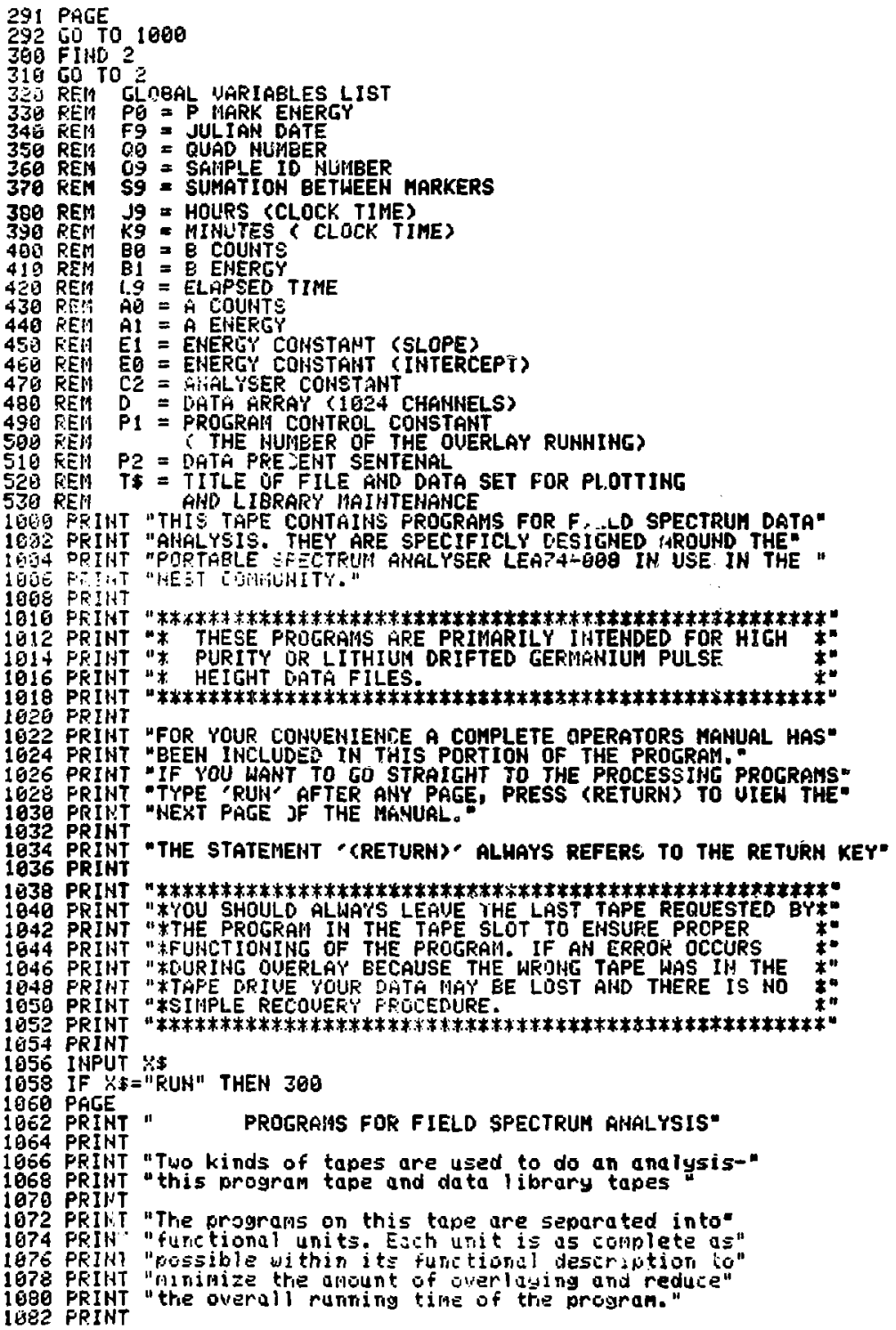




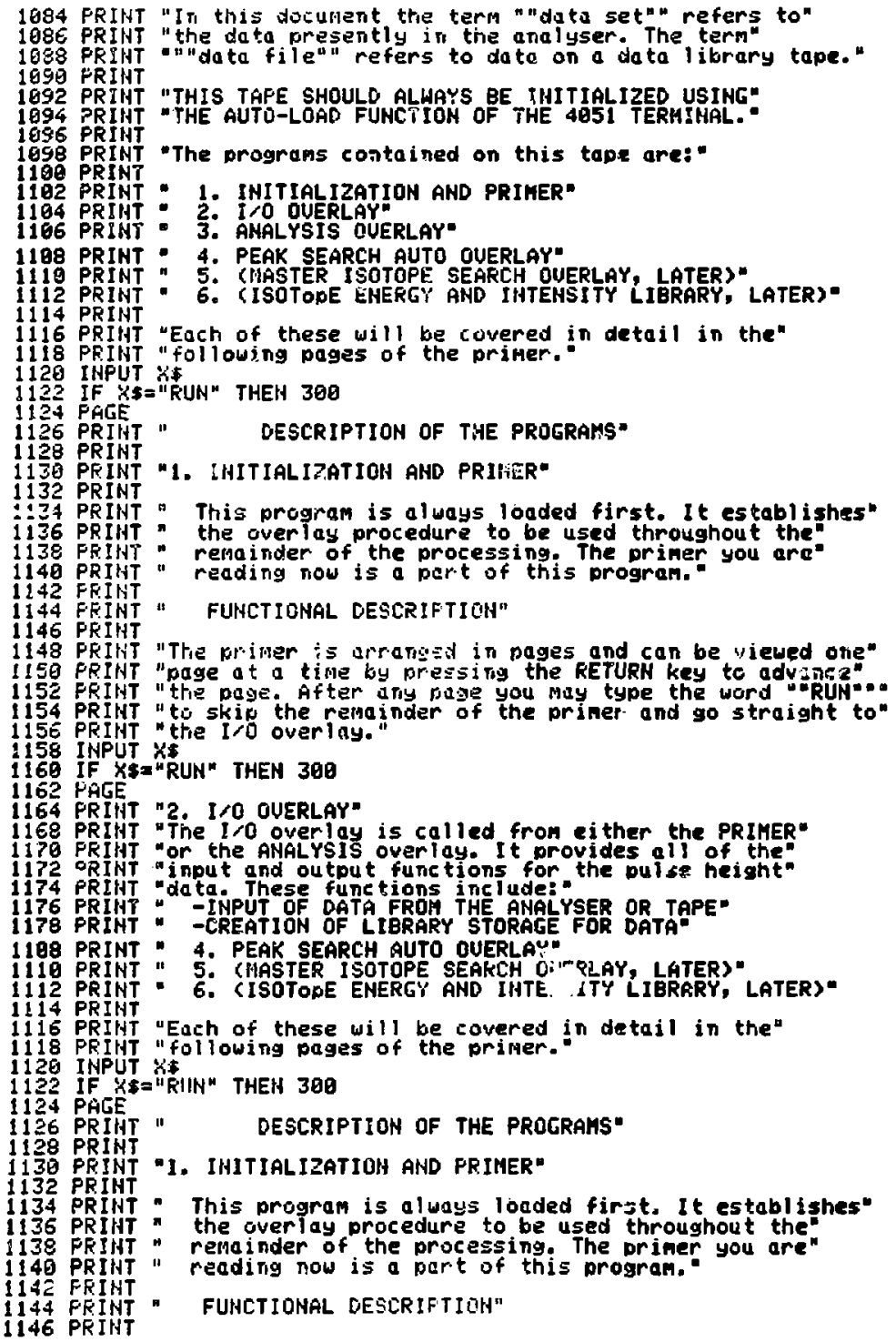


1148 PRIHi "The orimer is sararizat in pases and con be vieued one" 1150 PRINT "page of a tine by bresis tho the RETURN key to advance" 1152 FRIHT "the puge. After atiy pase you may type the word "RUN" 1154 PRIHT "to skin the renainder of the priner ind go straight to" 1156 PRIST "the I>0 overlay."

1158 INFUT $2 \%$

1160 IF $X \$=" R U N "$ THEN 300

1162 FAGE

1164 FRIHT "2. I/O QUERLAY"

IIES PRIHT "The I 0 overlay is called from either the PQXMER"

1170 PRIHT "or the AHALYSIS overloy. It provides all of the?

1172 PRINT input and output functions for the oulse height"

1174 FRIitT "data. These functions include:

1176 PRINT " -IHPUT OF DATA FROH THE ANALYSE OR TAPE*

178 PRINT * -CREATIOH OF LIBRARY STGRAEE FOR DATA

1180 PRINT " -DECODING DF DATA FROM THE AHALYSER"

1182 PRINT "-READING AHD WRITINC OF DATAA LIERARIES"

1184 PRIHT " -PLOTTIHE THE DATA IN THE PSA FRONT PANEL FORMAT"

II 8 E RIHT

IIES PRINT "FUNCTIOHAL OESLRIPTION*

1195 PRIKT

1192 PRINT

1194 PRINT

1196 PRIHT

1190 FRINT

I $2 G E$ PRINT

120 PRINT

I2E4 PRIHT

1206 PRIN"

$12 G E$ PRINT

1210 PRIHT

1212 PRIHT

1214 PRIHT

1210 FRINT

1210 FFIINT

IIE FRIHT

iz: FOIT "C

1234 PRINT

"A. RECEIUE DATA FFOM NOPEI"

" Data is received uia the modem and comon carriem" interface ard laded into a receiving array. After. all data is received it is automatically decoded" to produce the bi riary form used in further processing." The enersy Cinstants transmitted by the PSA are" used to arri.e at the prelininary energy calibration."

"B. PLOT DATA"

The data is plotted in a format which resembies the" front purei display of the PSA in las node. The energy" calibration of the PSA is shown below a dotted 1 ise" arross the lower wortion of the Ecreen."

$122 E$ FRIST

1228 FRIHT

1230 PRINT "

1232 PRINT

1234 IIPPUT $\mathrm{X}$

IZZE IF $\mathrm{XS}=$ "RUN" THEN 300

1238 FHGE

1240 PRINT

1242 PRINT

I244 PRINT

1246 PRINT

1248 PRINT

1249 PRINT

1256 PRIHT

1252 PRIHT

1254 PRIHT

1256 FEI ITT

1258 PRIHT

1200 PRIHT

1262 FRIHT

1264 FRINT

1266 PRINT

1263 PRINT

İ7G FRIHT

IET2 PRINT

1274 PRIHT

1276 FRINT

1278 PRIHT

1280 PRIHT

IEES FRIHT

1284 PRINT

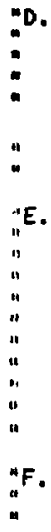

CREPTE HEW DATA LIBRARY"

This function estailishes the proper file structuren on 4 BLAkK tope for future data storage."

IF THIS FUHCTION IS USED ON"

A PREUIOUSLY WRITTEN TAPE ALL PREUIOUSLY HRITTEN FILES* HILL BE FOREUER LOST!";

\section{LIST A DATA LIERARY INDEX"}

This function lists all of the data file" index numbers and the data file name for all" files on the library tape. The file names are" assigned at the time the data is received."

A protective feature provides that no two data" file rities in any one library can be duplicated."

"E. WRITE DATA INTO Aं DATA LIBRARY"

This function Etores the present data set in" the library inserted into the tape slot. "Dato" files are stared and retrieved in sequential" order. If the data set you are attempting to urita" already exisis (ky file name) you can ei ther" type "WRI IE" to overwnite the data file or" assign a new (different) name underwhich the" data can be stored. The overwrite feoture allous" for storage of recalibrated data, undated data" or datu in which overflows etr. have been correcked."

READ DATA FROM a DATA LIBRARY"

Files are reauested by file index nuaber (see 2.D above)" The data and all descriotive constants sexceot for" 


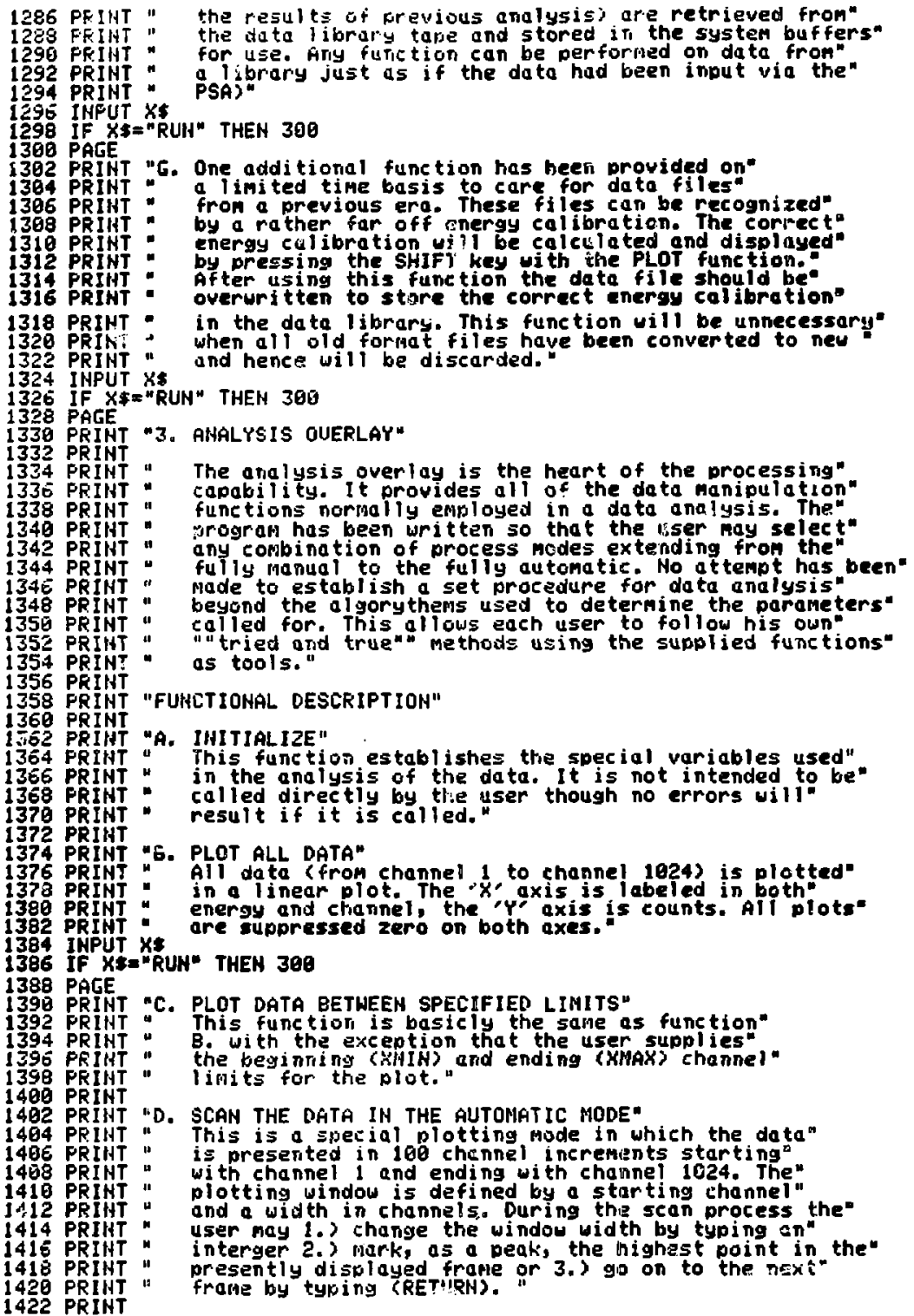




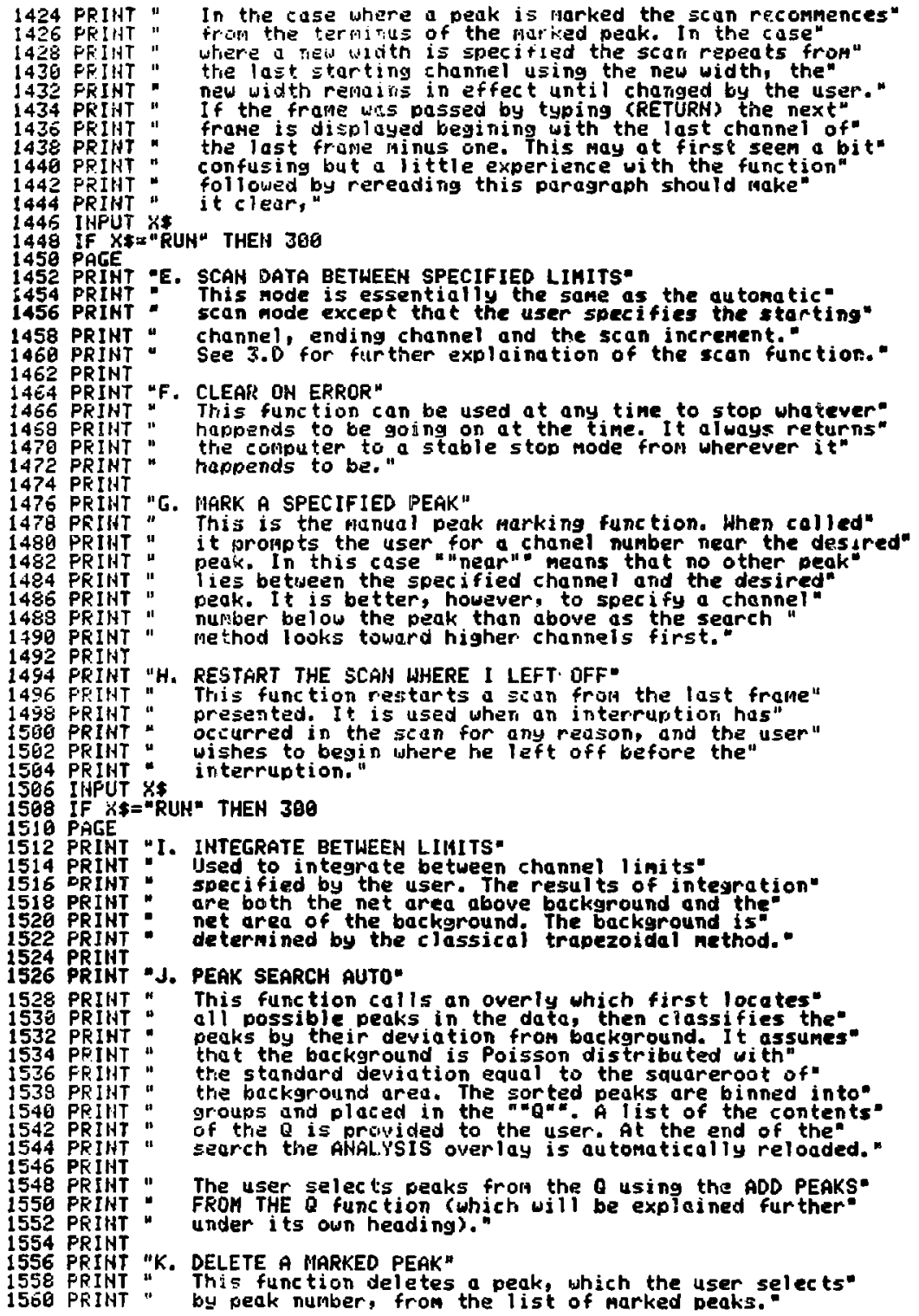




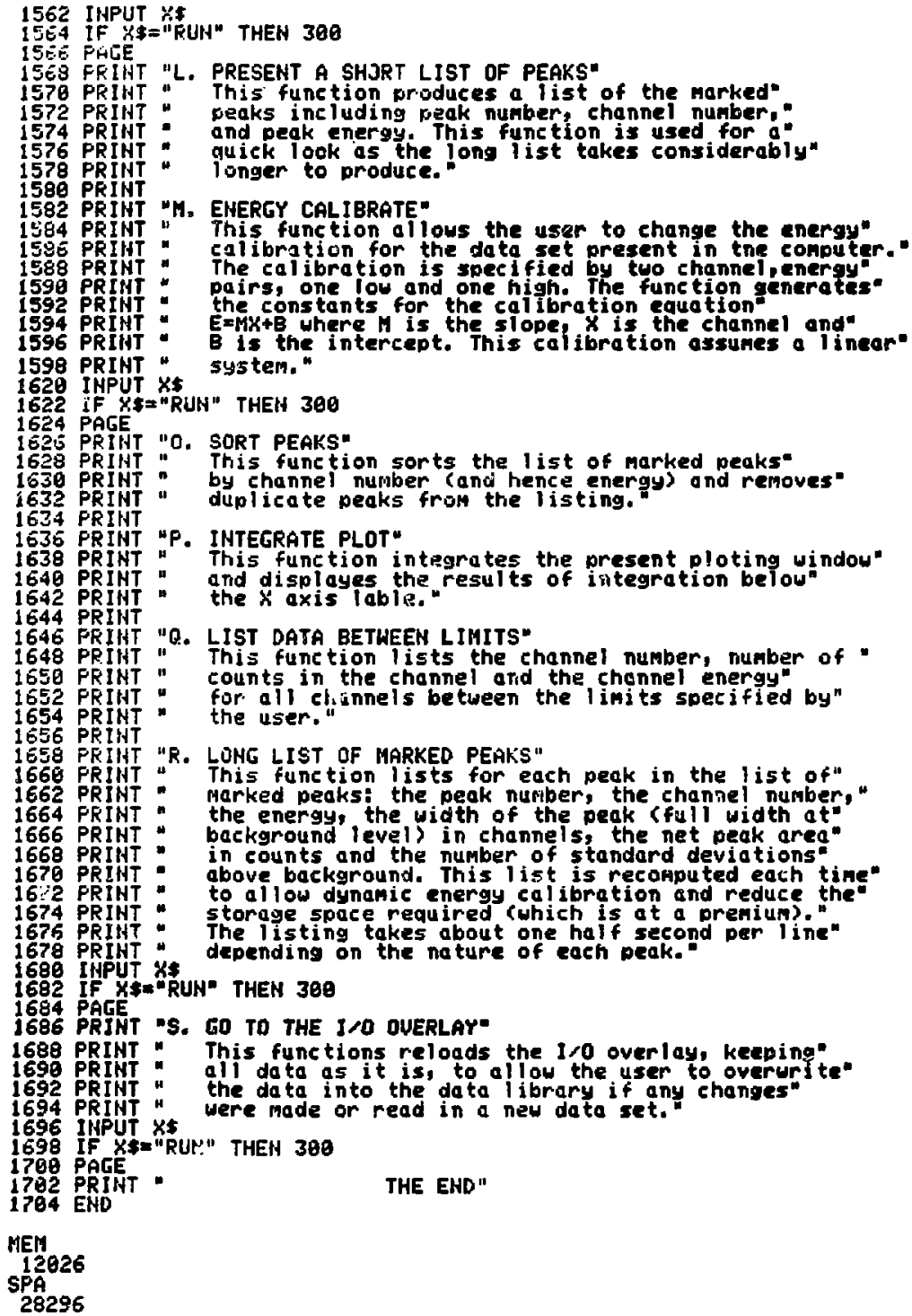


PROGRAM: INPUT , OUTPUT

TAPE: FIELD ANALYSIS

FILE: 2

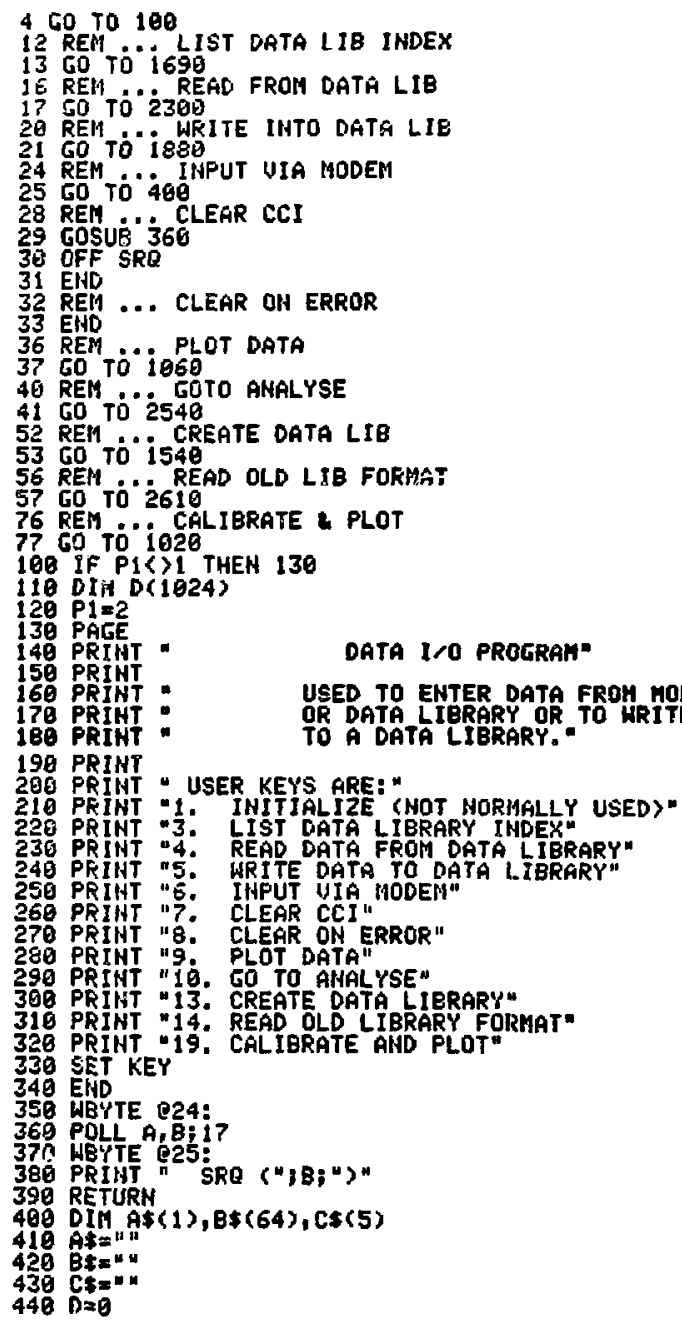




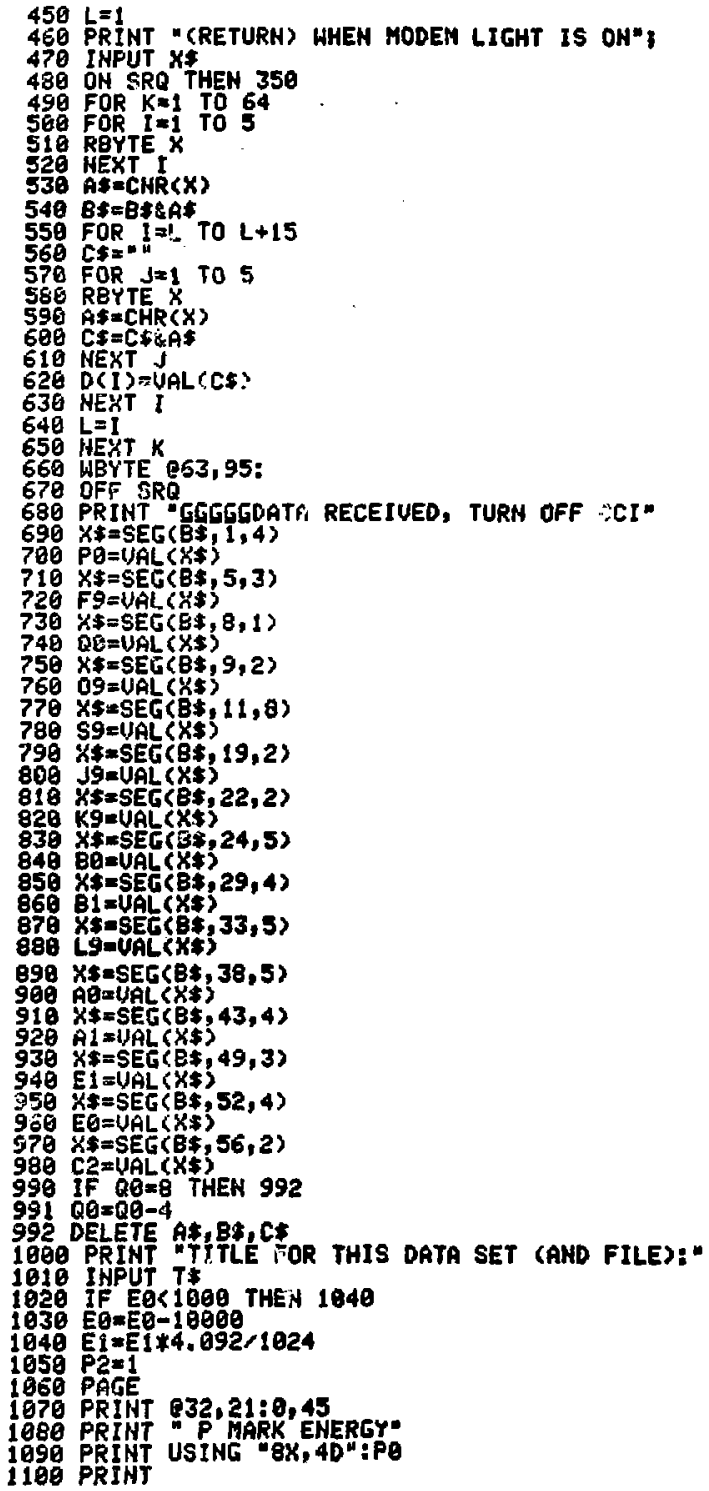




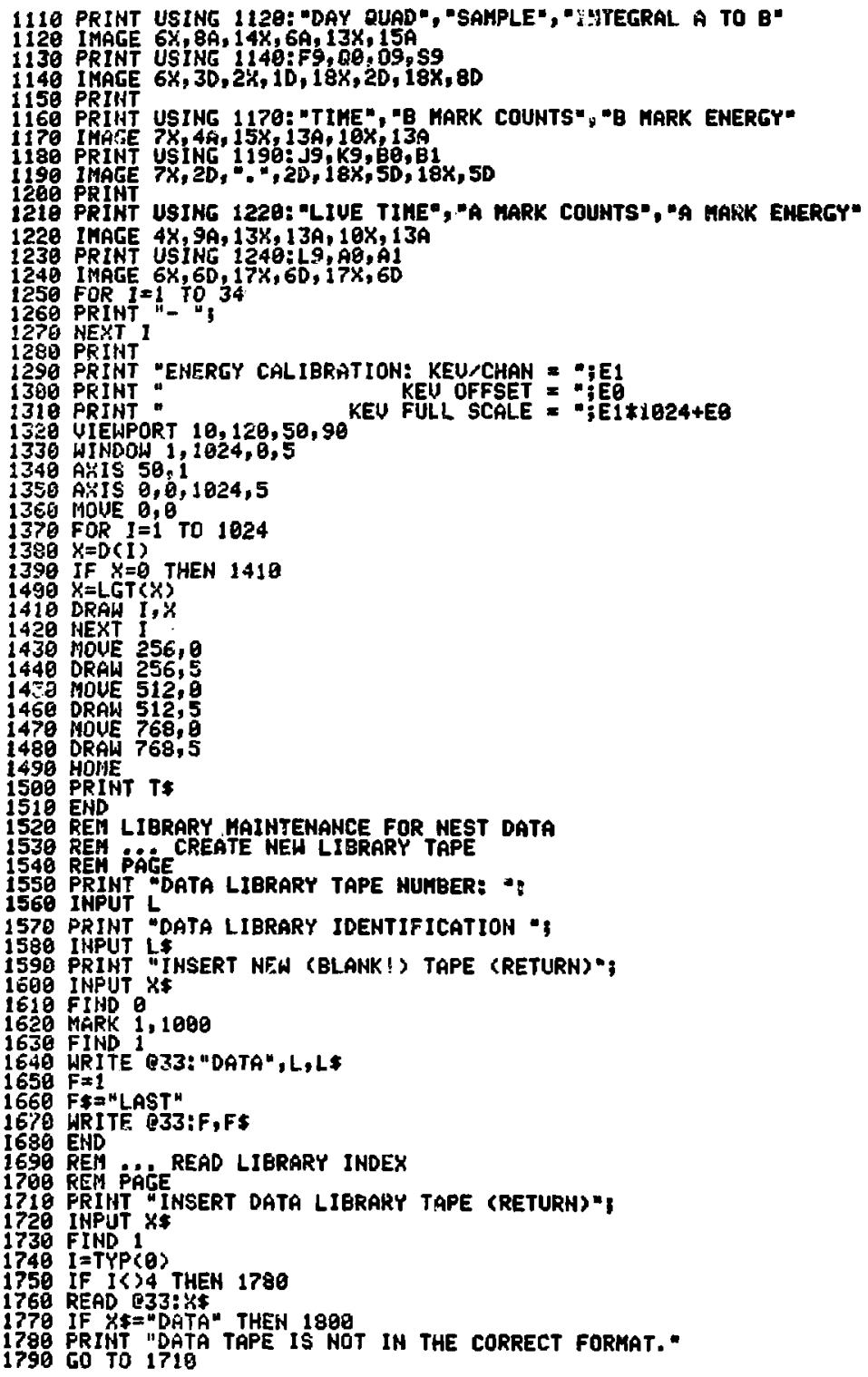




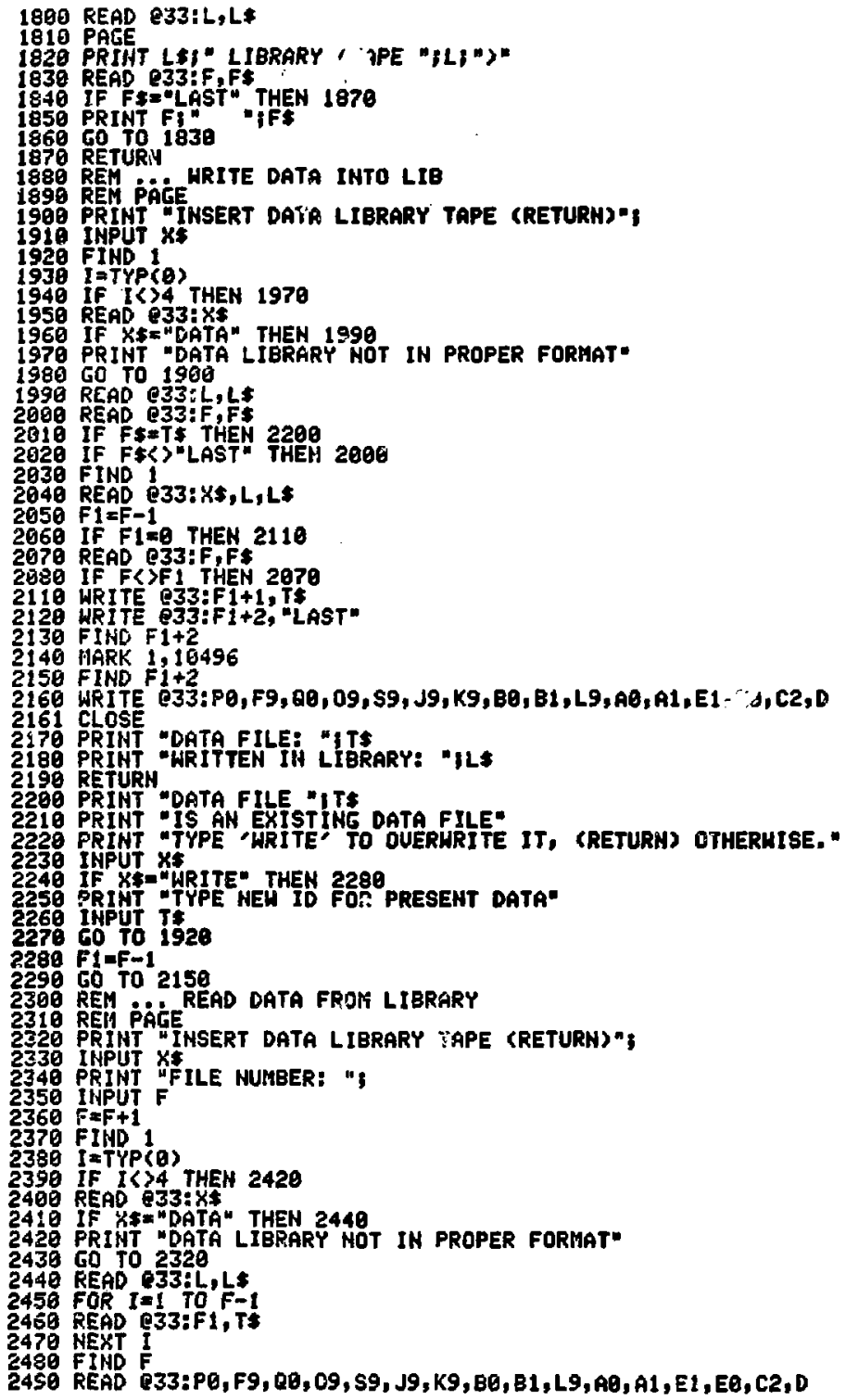




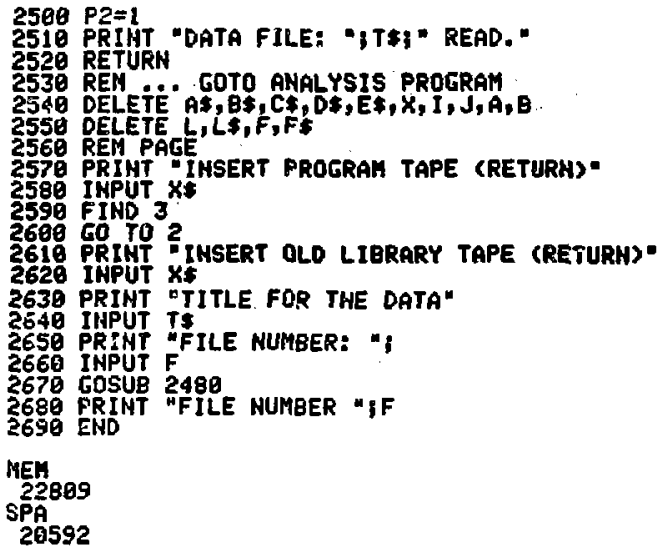


PROIJRAI4: ANALYSE

TAPE: FIELD ALR: SS

FILE: 3

4 Go TO 100

8 REM ... PLOT ALL (2)

$9 \mathrm{~N} 1=1$

$18 \mathrm{N2}=1024$

i1 60 Tó 530

12 REM PLOT LIMITS (3)

1360 TO 4 ?

16 REM... SCAN AUTO (4)

17 60 TO 3080

20 VEM ... SCAN LIMITS (5)

21 CO TO 2986

24 REM ... CLEAR ON ERROR (6)

25 EHD

29 REHI $\cdots$ MARK LIMITS (7)

29 Cु TS 1940

32 REM ... SCAN RESET

33 GO TO 3140

36 REM ... INTEGRATE LIMITS (9)

3760 TO 1400

40 REM L LCATE PEAKS AUTO (10)

41 GO TO 3460

44 REM ... DELETE MARKEC PEAK (11)

45 GO TO 2120

48 REM ... LIST PEAKS SHORT (12)

49 GO TO 2430

52 REM . ENERGY CALIBRATE (13)

53 CO TO' 3290

60 REM . SORT PEAKS (15)

61 Go TÖ 2230

64 REM . INTEG'ATE AUTO (16)

65 GO TÓ 1490

68 REM ... LIST LIMITS (17)

69 CO TO 1650

72 REM ... LIST PEAKS LONG (18)

73 GO TO 2640

26 REM ... GO TO IPO PROGRAM (19)

$37 \mathrm{GO} \mathrm{TO}^{\circ} 3400$

BO REM ... GO TO STANDARD PEAKS LIBRARY (20)

100 IF $\mathrm{P} 2 \mathrm{a}=3$ THEN 170

$110 \quad P 2=3$

120 DIM D(1024)

130 DI $R(3)$

140 DIt P(100)

$150 \mathrm{Mg}=\mathrm{O}$

$160 \quad L \neq 0$

170 SET KEY

180 IF P2=4 THEN 3530

190 REM

200 PAGE

$210 \quad P 9=0$

220 PRINT *

230 PRINT

240 PRINT

250 PRINT

260 PRINT

270 PRINT

280 PRINT

290 PRINT

300 PRINT "4:" SCAM AUTO S TO IOZ4 INC IOBS"

USER DEFINED KEYS:

PLOTTING RND DATA MaNIPULATION"

D. A. FUESS* 


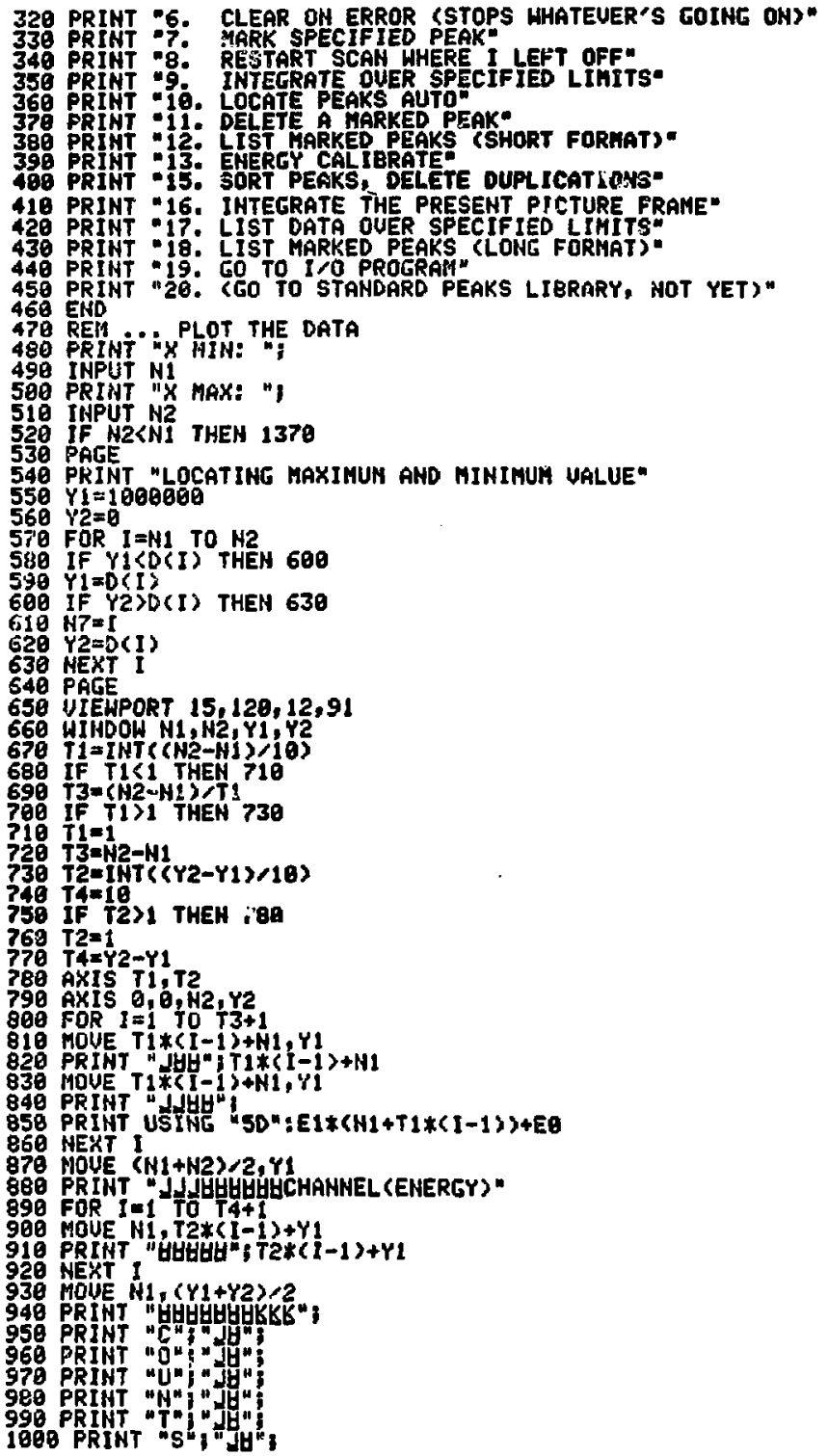




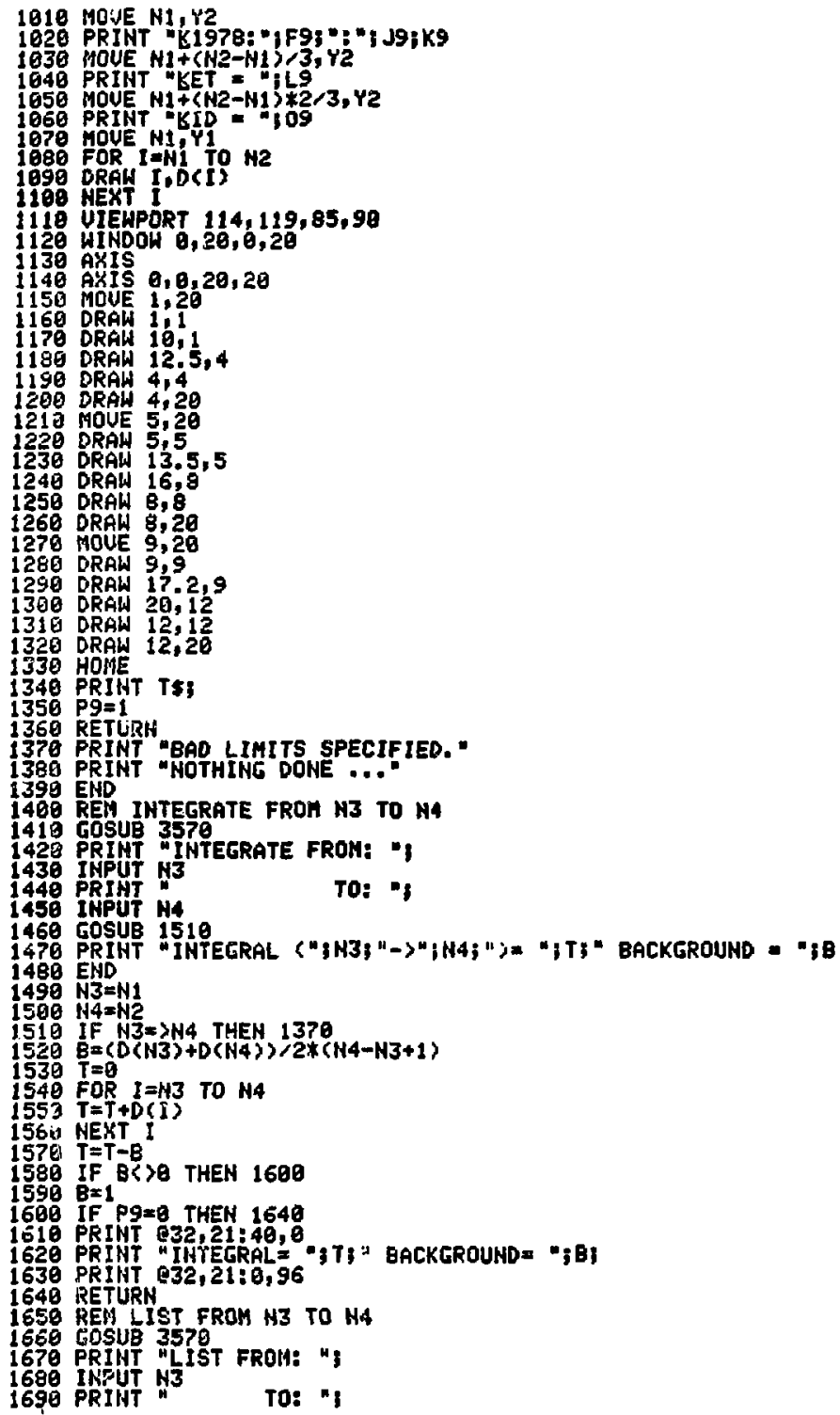




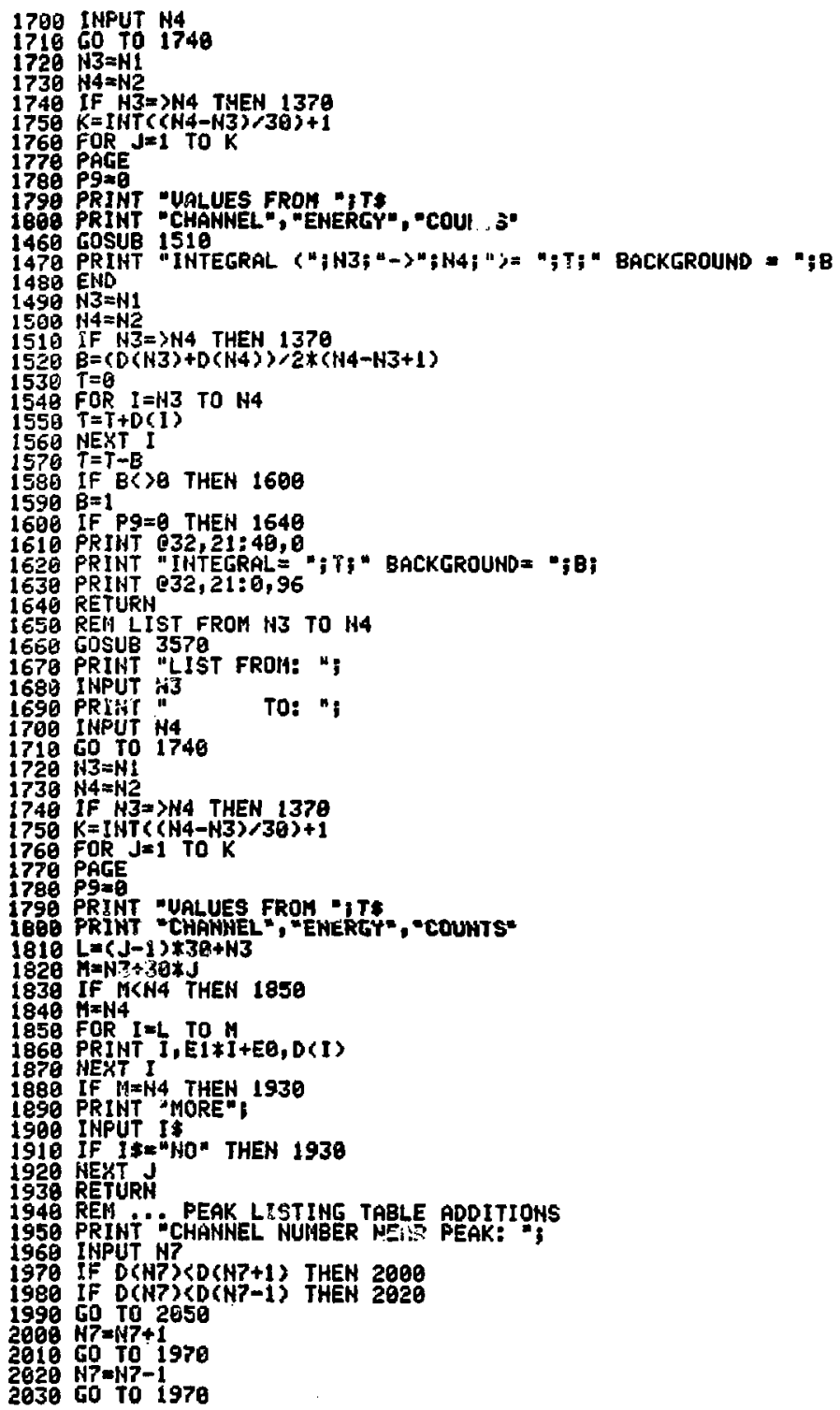


2049 REM 17 SET PRIOR TO CALLING

$2050 \mathrm{Ng}=\mathrm{Ng}+1$

2860 IF $N 9=101$ THEN 2090

2870 P(N9) $=N$ ?

2880 RETURN

2090 PRINT "PEAKS TABLE IS FULL P("IHP\}") NOT LISTED."

$2100 \mathrm{NG}=169$

2110 END

2120 tosuB 3570

2T30 PRINT NUMBER OF PEAK TO $8 E$ DELETED: *

2140 INPUT $N 3$

2150 If $H 9=B$ THEN 2220

2168 IF N9=1 THEN 2218

2179 IF $N 3=N 9$ THEN 2210

$218 \mathrm{FOR}^{\mathrm{I}} \mathrm{I}=\mathrm{H}$ TO $\mathrm{Ng}-1$

ट190 $P(I)=P(I+1)$

2200 iHEXT I

$2310 \mathrm{HA}=\mathrm{Ng}-1$

2220 RETURN

2230 REM $\ldots$ SORT rEAKS - DELETE DUPLICATES

2249 IF $N 9=\dot{\theta}$ THEN 2350

2250 IF $199=1$ THEN 2350

2260 REM ... SORT PEAKS

2270 FOR J=N9-1 TO 1 STEP -1

2289 FOR $I=1$ TO $\mathrm{J}$

2290 IF $P(I)<P(I+1)$ THEN 2330

$2300 \quad x=P(I)$

$2310 P(I)=P(I+1)$

$2320 \mathrm{P}(\mathfrak{1}+1)=\mathscr{X}$

2330 HEKT I

2340 HEXT J

2350 REH ... DELETE DUPLICATES

2360 FOR J=N9-1 TO 1 STEP -1

2370 IF $J=1,9$ THEN 2420

2380 IF $P(J)\langle P(J+1)$ THEN 2410

2390 N3 $=\mathrm{J}+1$

2406 GOSUB 2160

2410 NEKT $J$

2420 RETURN

2430 REM $\ldots$.. SHORT LISTING OF PEAKS

2440 PAGE

2450 P9:O

2460 PRINT PPEAKS IN IT:

2470 IF N9=O THEN 2620

$2480 \mathrm{~J}=9$

2490 PRINT "HUMBER" "CHANNEL", "ENERGY"

2500 FOR I-1 TO N9

2510 PRINT I,P(I),EI*P(I)+r.e

$2520 \mathrm{Jl} J+1$

2539 IF J 39 THEN 2600

2548 PRIHI "MORE";

2550 INPUT $X \$$

2560 PAGE

25 P PRINT "PEAKS IN ": TS

2580 PRINT "TiUMBER", "CHANHEL", "ENERGY"

$2590 \mathrm{~J}=0$

2600 NEXT I

2638 END

2620 PRINT "NO PEAKS LISTED"

2630 RETURN

2649 REM ... PEAKS LIST LONG

2650 PAGE

2660 P9*0

2670 PRINT "PEAKS IN "i T\$

2680 IF N9 $\times 0$ THEN 2620

2690 PRI USI 2700: "MU WBER" "CHAMMEL", "ENERGY" "HIDTH" "INTEGRAL" "SIGMA"

2700 IHAGE $6 A, 2 X, 7 A, 2 X, 6 A, 2 X, 5 A, 2 X, 8 A, 2 X, 5 A$

$2710 \mathrm{j}=\mathrm{g}$

2720 FOR $K=1$ TO N9 


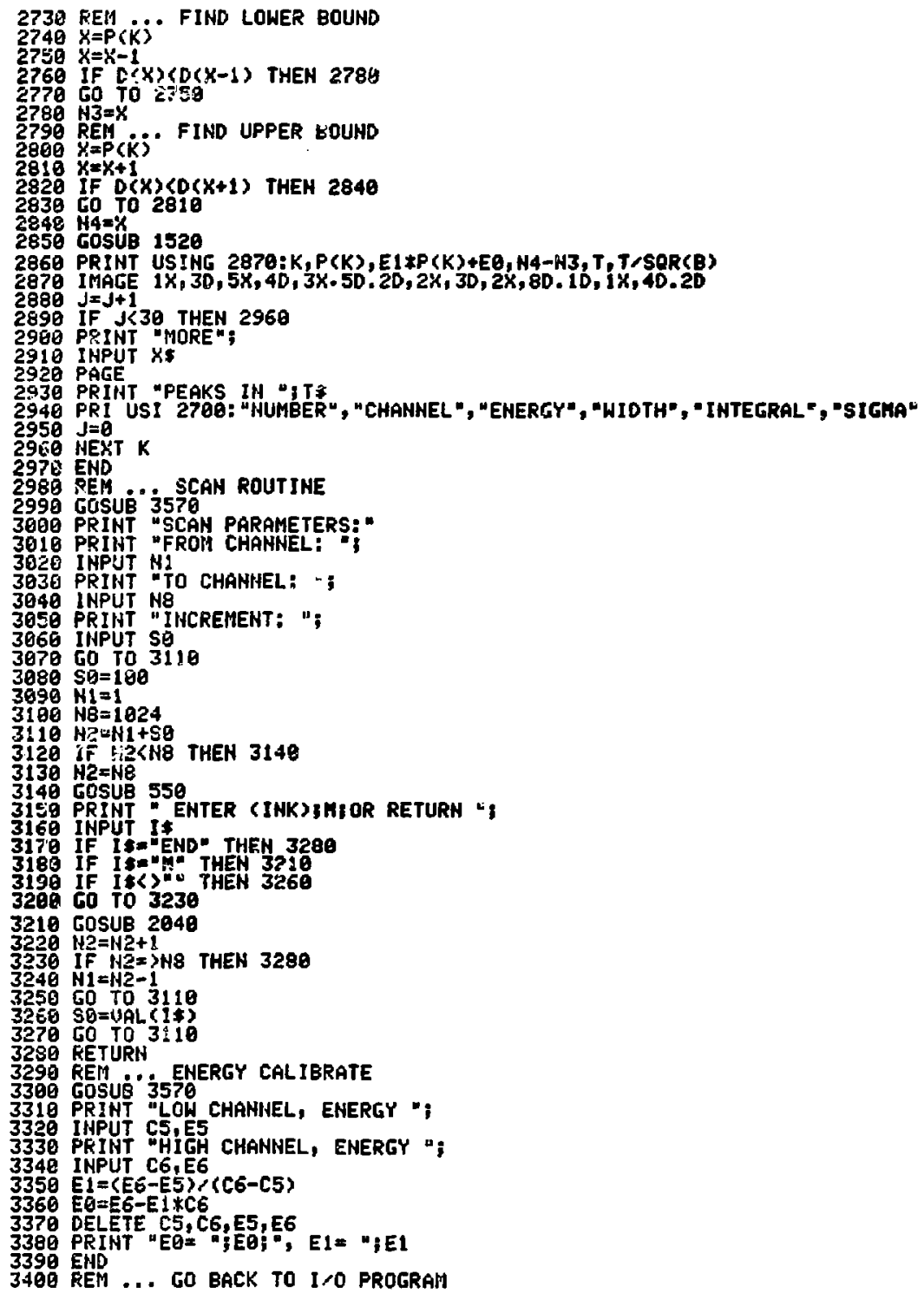


3410 GOSUB 3570

3420 PRINT "INSERT PROGRAM TAPE (RETURN) -

3430 INFUT X\$

3440 FIND 2

3450 GO TO 2

3460 REM ... GO TO PEAK SEARCH AUTO

3470 GOSUB 3570

3480 PRINT "INSERT PROGRAM TAPE (RETURN)"

3490 INPUT $X \$$

3500 P2=4

3510 FIND 4

3520 Go TO 2

3530 REM... ADD PEAKS FROM THE 0

3558 GOSUB 2238

$3568 \mathrm{GO}$ TO 2640

3570 If P9.0 THEN 3600

3580 PACE

3590 Pg=0

36BB RETURN

MEM

20298

SPA

28003 
4 CO TO 100

160 REM THIS IS a TEST PROGRAH TO LOCATE PEAKS IN A HPGE

110 REN SPECTRAL OATA FILE ANO CLASSIFY THE PEAKS LOCATEO

120 REM BY SIGHA LEUEL. OELY THE 1 GU HTOHEST SIGHA PEAKS

130 REM ARE REPORTED. STHE PEAK STORAGE SPACE IN THE ANALYSIS

140 REM PRUERAM ALLUWS FOR A MAXIMUN OF 100 PEAKS.)

15 REM

160 SET NOKEY

170 PAGE

180 PRIHT "CHAHNEL NUMBER FOR BEGIH SEARCH: "i

190 IHPUT 21

200 IF $Z 1>10$ THEN 220

$210 \quad z 1=19$

220 PRIN" "CHANMEL NUMBER FOR END OF SEARCH: ";

230 INPUT $\geq 2$

240 PRINT "LOWEST ACCEPTABLE SIGMA LEUEL: ";

250 IHPUT 23

ZË IF Z2र1E14 THEN 280

$270 \quad 22=1014$

280 FRIHT "PEAK SEARCH OF ";T\$

$290 \quad 26=21$

$30020=20+1$

310 If $20=322$ THEH 670

320 IF $0(20)<D(20+1)$ THEN 390

330 IF $D(20)<D(20-1)$ THEN 300

$340 \mathrm{~N} 3=20$

$350 \quad N 4=20$

360 N3 $=N 3-1$

370 IF H3=1 THEN 498

380 If D(H3)<D(N3-1) THEN 490

390 G0 To 368

400 M4xH4+1

410 IF N4=1024 THEH 440

420 IF DENS) $(\mathrm{D}$ (M+1) THEN 440

438 Go TO 408

$440 \mathrm{~B}=(\mathrm{C}(\mathrm{N} 3)+\mathrm{D}(\mathrm{N} 4)) / 2 *(N 4-\mathrm{N3}+1)$

$450 t=0$.

460 FOR I=N3 TO H4

$470 T=T+D(I)$

480 NEXT I

$490 T=T-B$

$5 B 0$ IF B>B THEN S20

510 8=1

526 IF T/SQRCB $<23$ THEH 560

$530 N 9 \times+9+1$

540 IF H9x101 THEN 580

$550 \quad P(19)=20$

$56020=144$

570 GO TO 300

580 PRINT "NO MORE ROOM IN PEAKS ARRAY, (100 MAX)"

590 PRINT "PEAKS EEYOND CHANNEL "ZZ6; 'HAUE NOT BEEN LISTEO."

600 PRINT "TYPE NEW SIGMA LEUEL OR O CO=END LIST)"

610 INPUT 23

620 IF $23=0$ THEN 650

$630 \mathrm{Ng}=0$

640 G0 TO 290

$650 \mathrm{Ng}=100$

660 . SET KEY

6PE PRINT H9; " PEAKS LISTED FOR THIS SPECTRUM* 
680 PRINT "RETURHING TO AHALYSIS FOR SORTIHE"

698 DELETE $21,22,23$

700 FINO 3

710 6O TO 2

MEM

28226

SPA

4536 


\section{PROGRAM: SPECTRA MATH FUNCTIOHS}

TRPE: FIELD AHALYSIS

FILE: 5

NOTE: NOT CALLED DIRECTLY, MUST BE MANUALLY OUERLAYED IN THE AMALYSE PROERAM. DESTPOY GFTER USE AS IT MAY CAUSE

MACHINE ERTORS DUE TO MEMORY OUERFLON. 


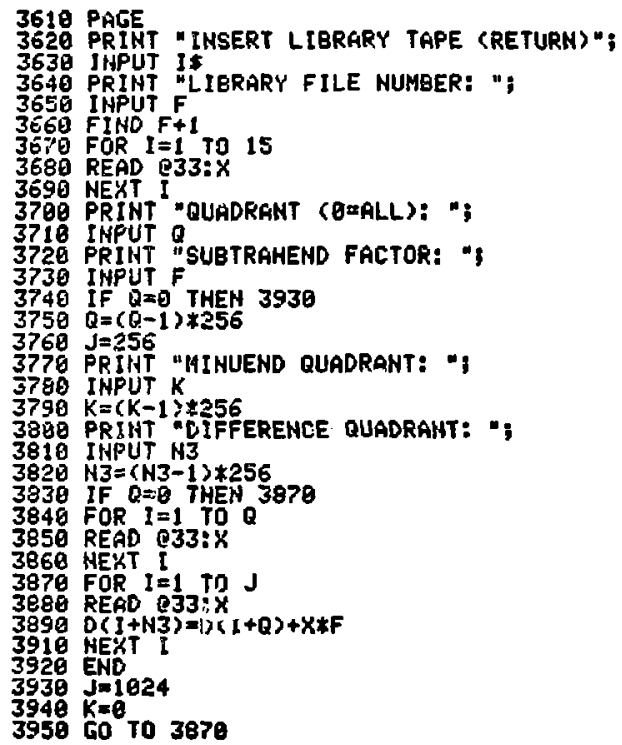

MEN

SPA

2449

$\begin{array}{llll}1 & \text { ASCII } & \text { PROGRAM } & 30208 \\ 2 & \text { ASCII } & \text { PROGRAM } & 30208 \\ 3 & \text { ASCII } & \text { PROGRAM } & 30208 \\ 4 & \text { ASCII } & \text { PROGRAM } & 30308 \\ 5 & \text { ASCII } & \text { PROGRAM } & 36208 \\ 6 & \text { LAST } & & 768\end{array}$

TAPE LIST INDEX FROM FIELD ANALYSIS TAPE SEP 1, 1978 


\section{APPENDIX C \\ FLOW CHARTS FOR PROGRAMS}

FLOWCHART SYMBOLS

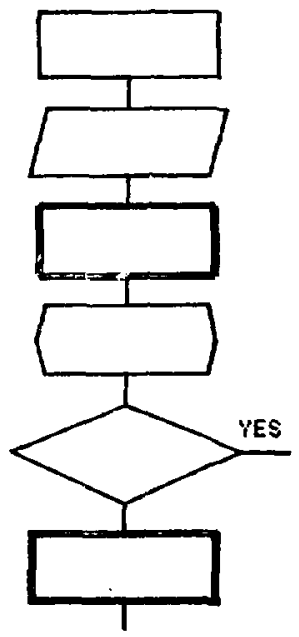

CalCULATIOH.

IHPUT OUTPUT OPERATIOH.

GRAPHICS.

HISC.

COHDITIOHAL BRAHCH.

SUBROUTI IHE CALL. 
0

4

12

13

16

17

20

21

24

25

28

29

A

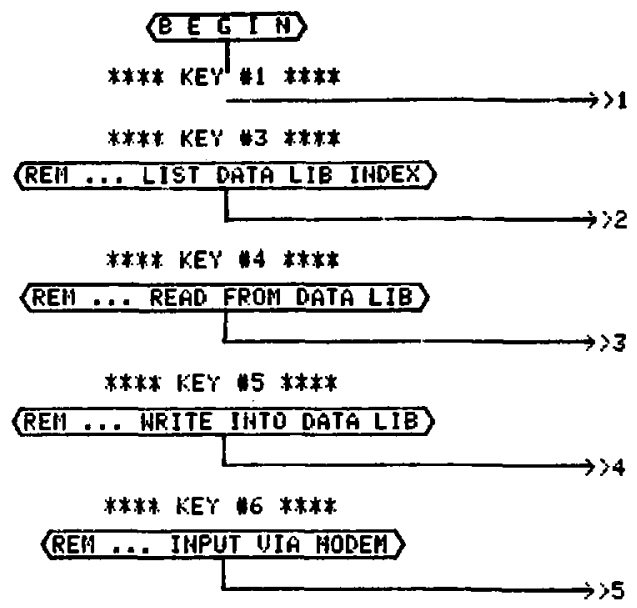

**** KEY *7 ****

REI ... CLEAR CCI

GOSUE 3EO $\rightarrow>6$ 
A

30

31

32

33

36

37

40

41

52

53

56

57

B

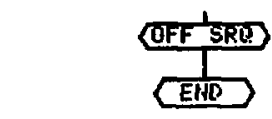

**** KEY 18 *\$**

REII... CLEAR OH ERROR

(ETDD

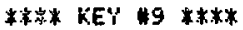

REM... PLOT DATA

**** KEY \#10 ****

REII ... GOTO ANAL"YSE

才末** KEY \#13 t*\#***

REH ‥ EREATE DATA LIB

**** KEY \#14 ****

REM ... READ OLD LIE FORHAT 
$\theta$

76

37

100

110

120

130

140

$15 \overline{0}$

$1 \in \bar{B}$

170

180

190

208

210

220

236

240

250
**** K.EY' 19 ****

(REN... CALIBRATE \& PLOT

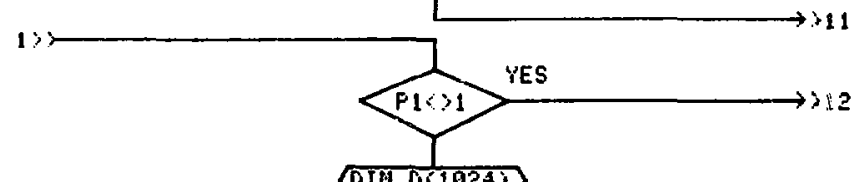

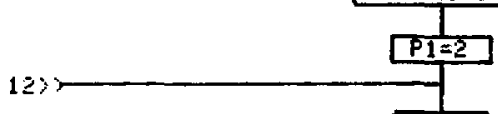

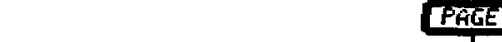

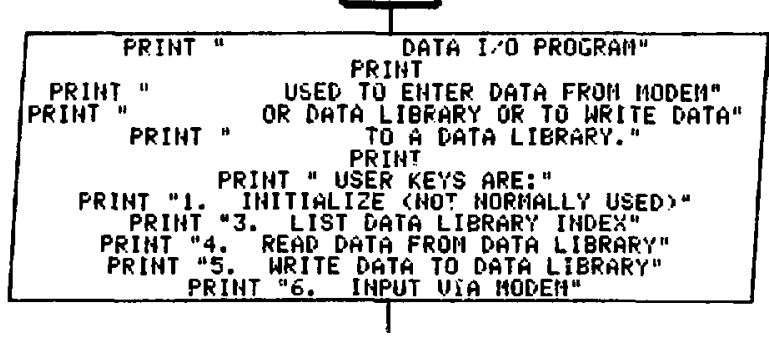

C 
C

360

370

$38 \overline{0}$

390

400

410

o

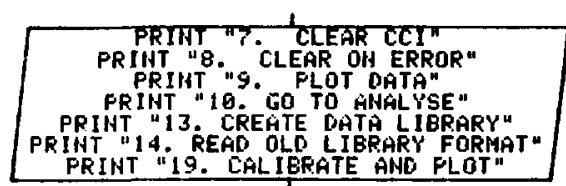

SETKEY

Ek+0

13:IINTERRUFT

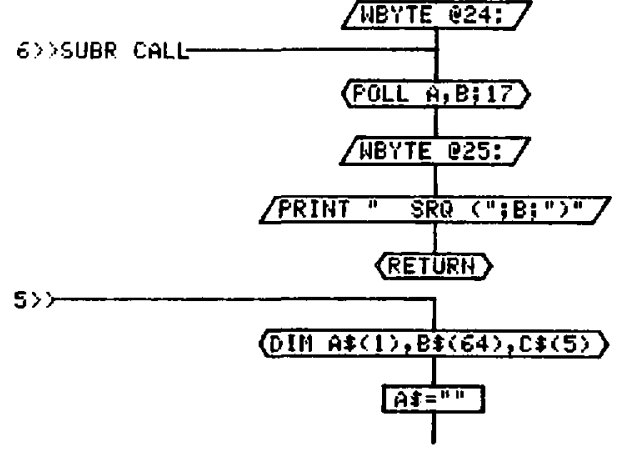


0

460

470

$48 e$

490

500

510

520

530

540

550

560

570

E

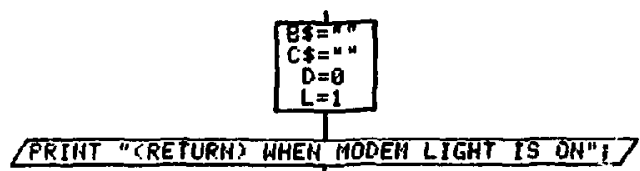

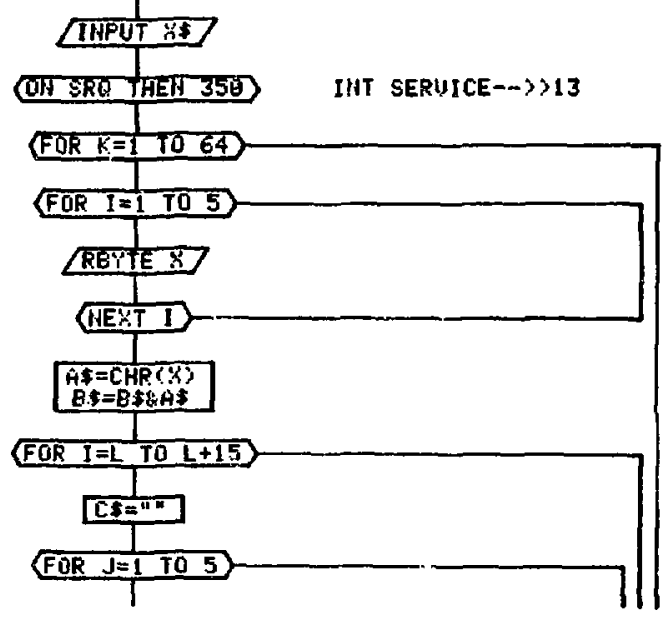

IHT SERUICE- $\rightarrow>13$ 
E

588

590

600

616

626

630

640

650

660

670

680

690

710

726

730

F
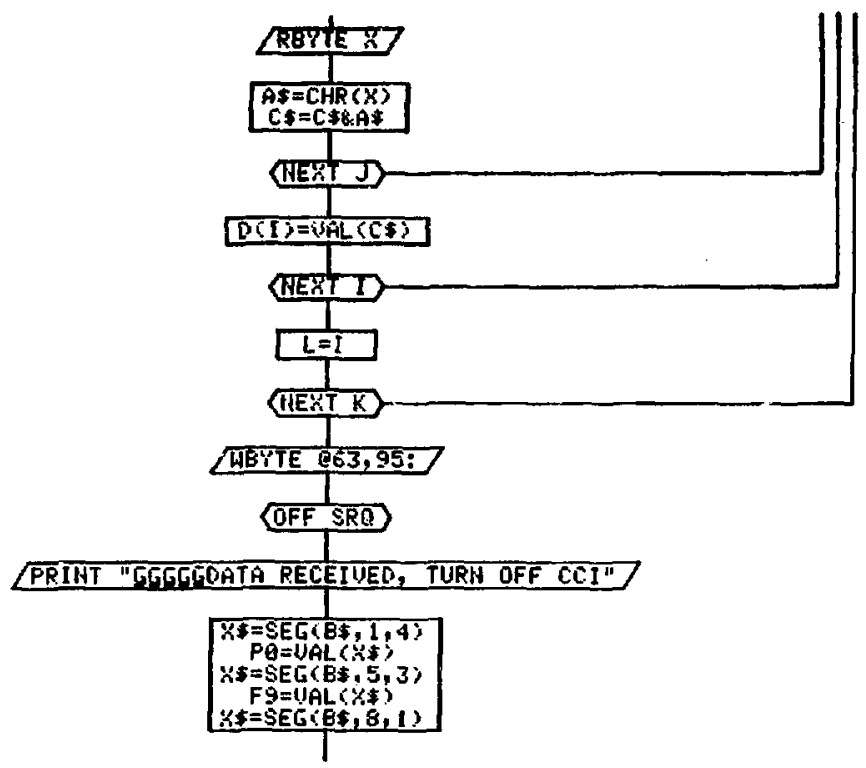


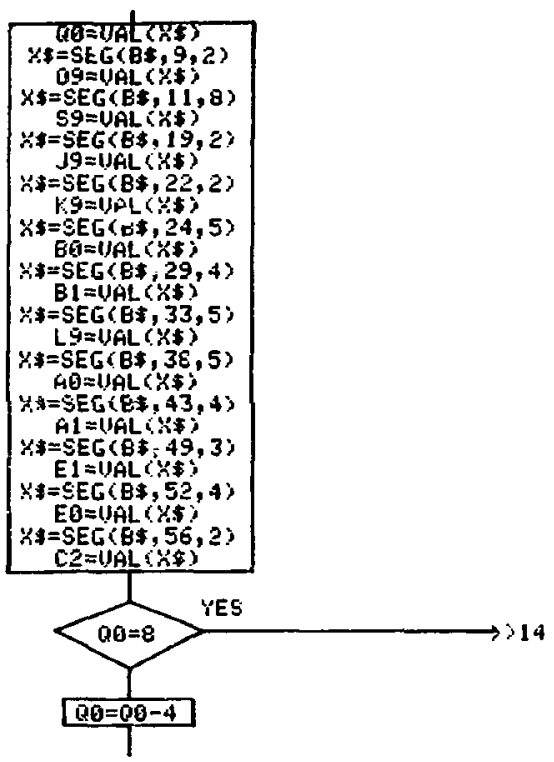

$G$ 
G

992

1068

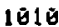

1020

1030

1040

1050

1868

1070

1086

1090

1100

i116
14)

QEEETE AS,BS,CS

PRITT "TITLE FOR THIS DATA SET CAIND FILES:"

Mipगt T3

113

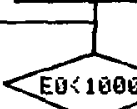

YES

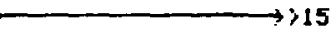

15)

EQEE0-10008

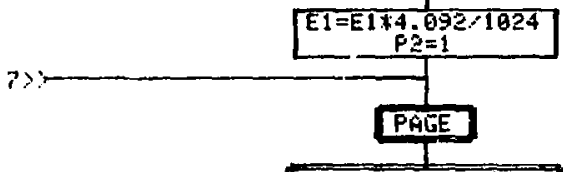

PRIAT 032,21:0,45

PRIIHT "P MARK EHERGY"

PRIHT USING " $8 \%, 40 ": P G$

PRIHT USING 1129: "DAY QUAD", "SAMPLE", "IHIEGRAL A TO B"

H 
H

IMAGE $6 \%, 8 f, 14 \%, 6 A, 13 \%, 15 A$

$11 \mathrm{jg}$

PRINT USIHG 1140:F9,00,09,59

1140

IHAGE $6 \%, 30,2 \%, 10,18 x, 20,18 x, 80$

1150

1160

PRINT USIHE MTO: "TIME" PRIAT

1170

IMAGE $7 \%, 4 A, 15 \%, 13 A, 10 \%, 13 A$

1180

PRIITT USING 1190: J9, K9, BG,BI

1190

IMAGE $7 K, 20, " ., 20,18 K, 50,18 \%, 50$

1210

1228

IHACE $4 K, 9 A, 13 K, 13 A, 10 K, 13 A$

1230

PRINT USING 1240:L9,AG,AI

1249

IMAGE $6 \mathrm{~K}, 60,17 \%, 60,17 \%, 60$

1250

FOR I=I TO 34

I 
I

1260

1270

1280

1300

1310

1320

1330

1340

1350

$1 \geq 60$

1370

1380

1390

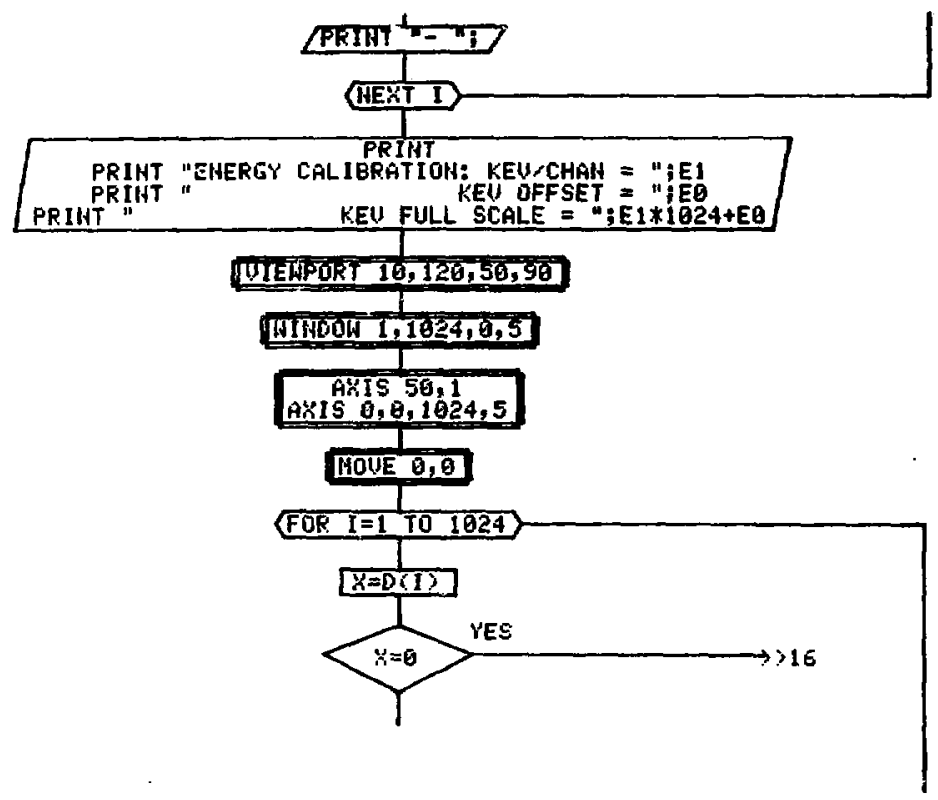




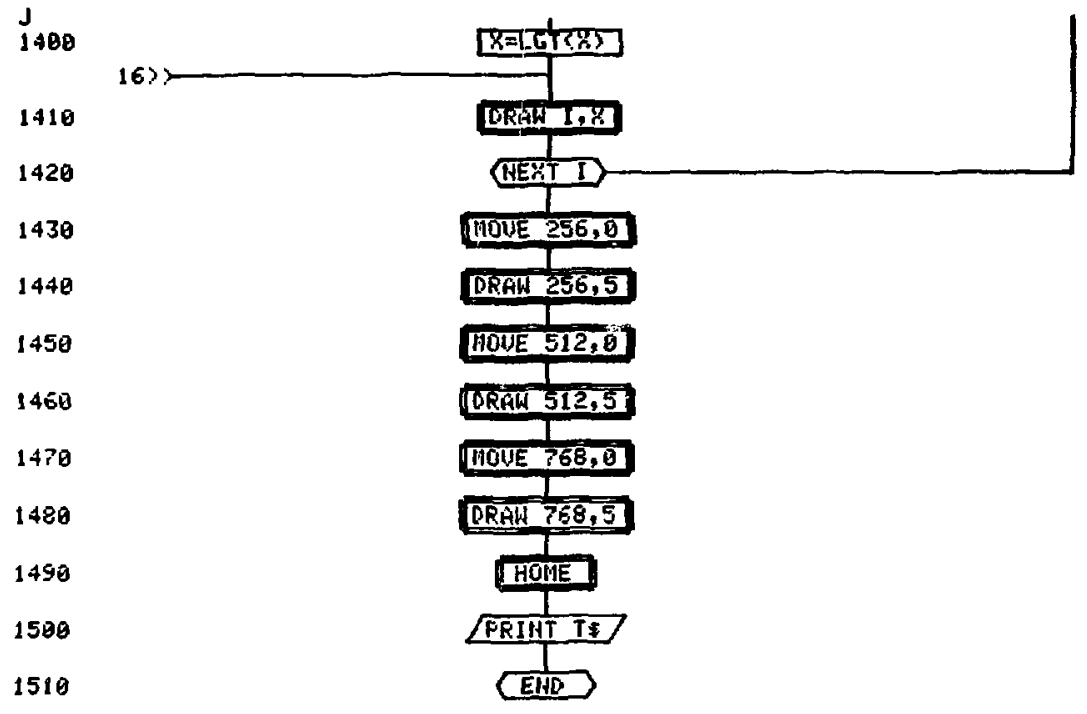

1520

$k$ 


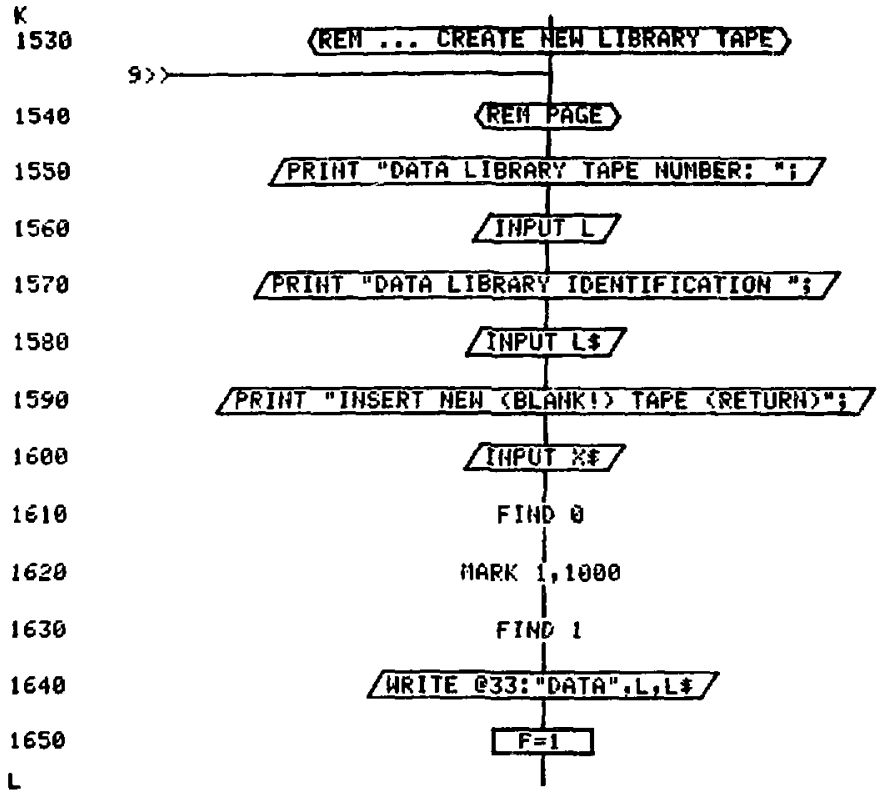




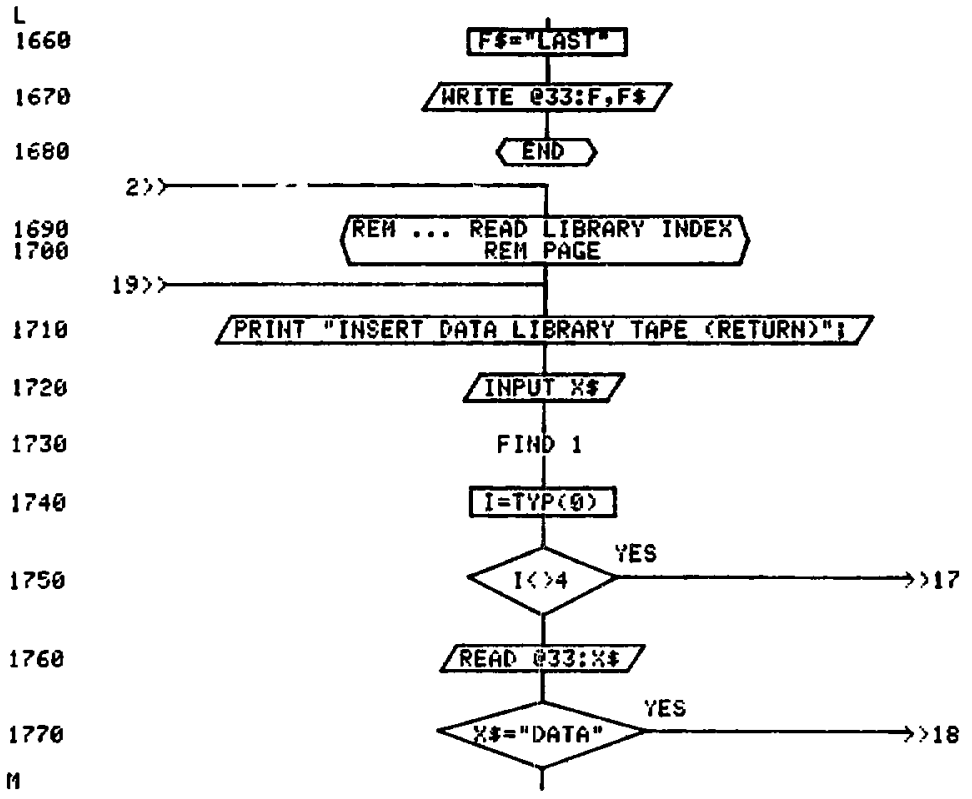




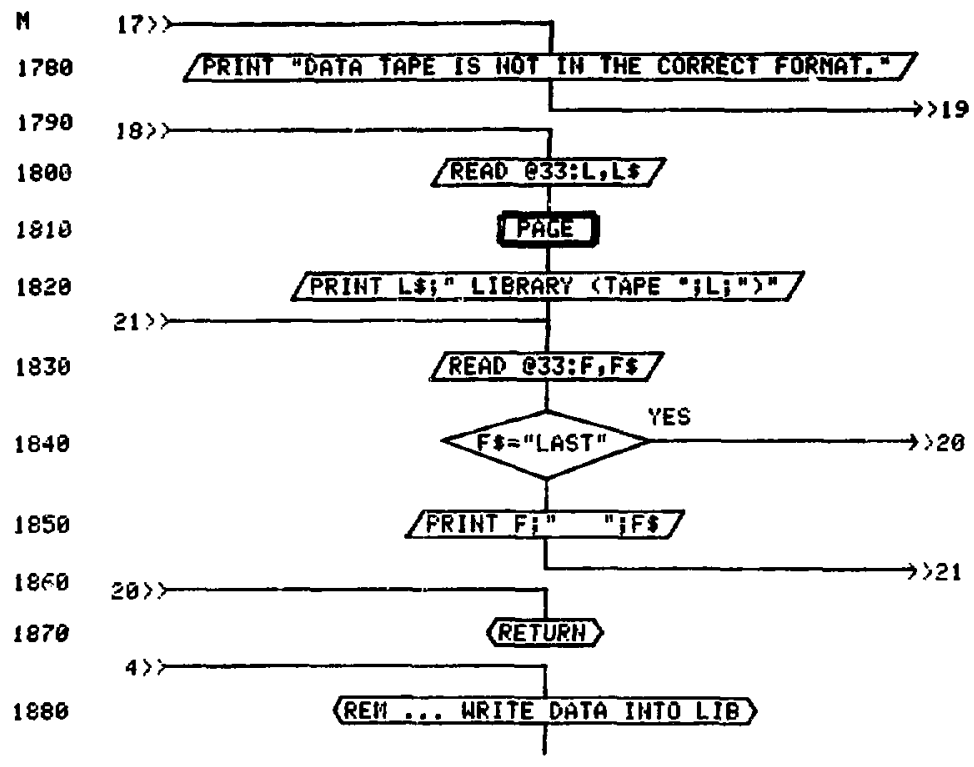

H 


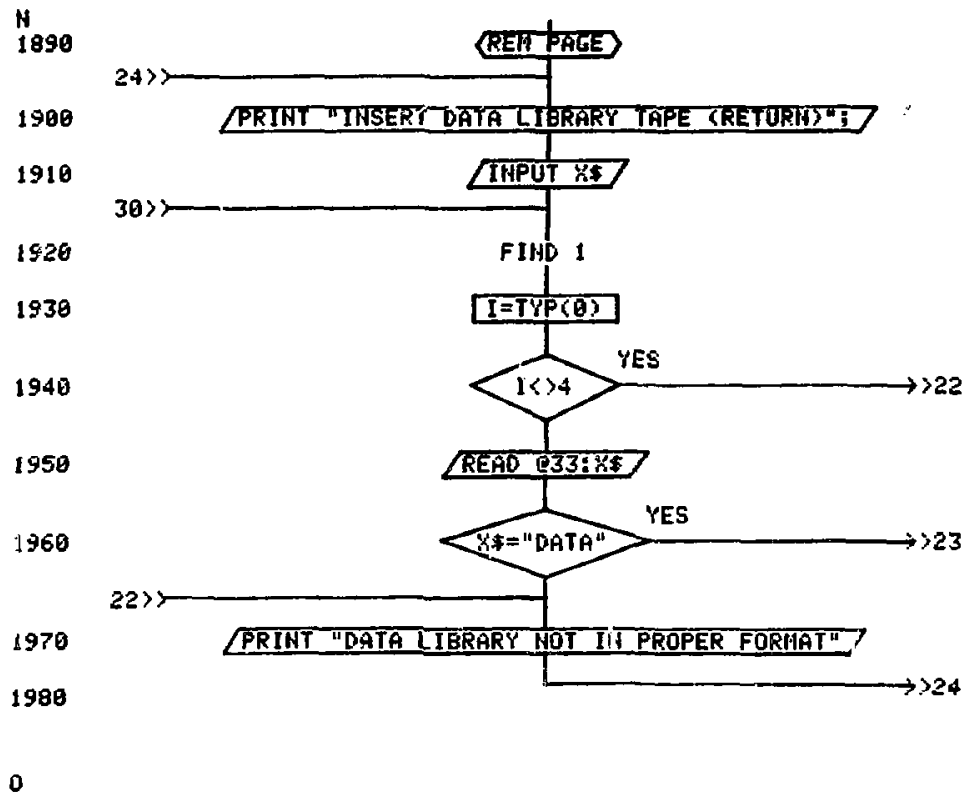




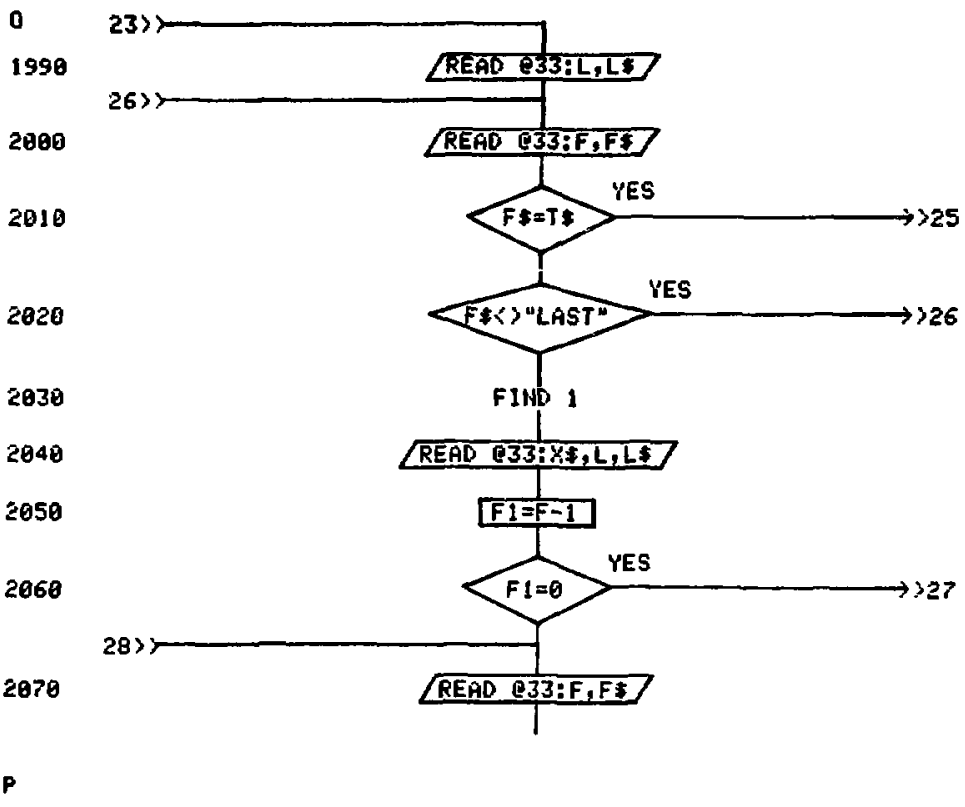




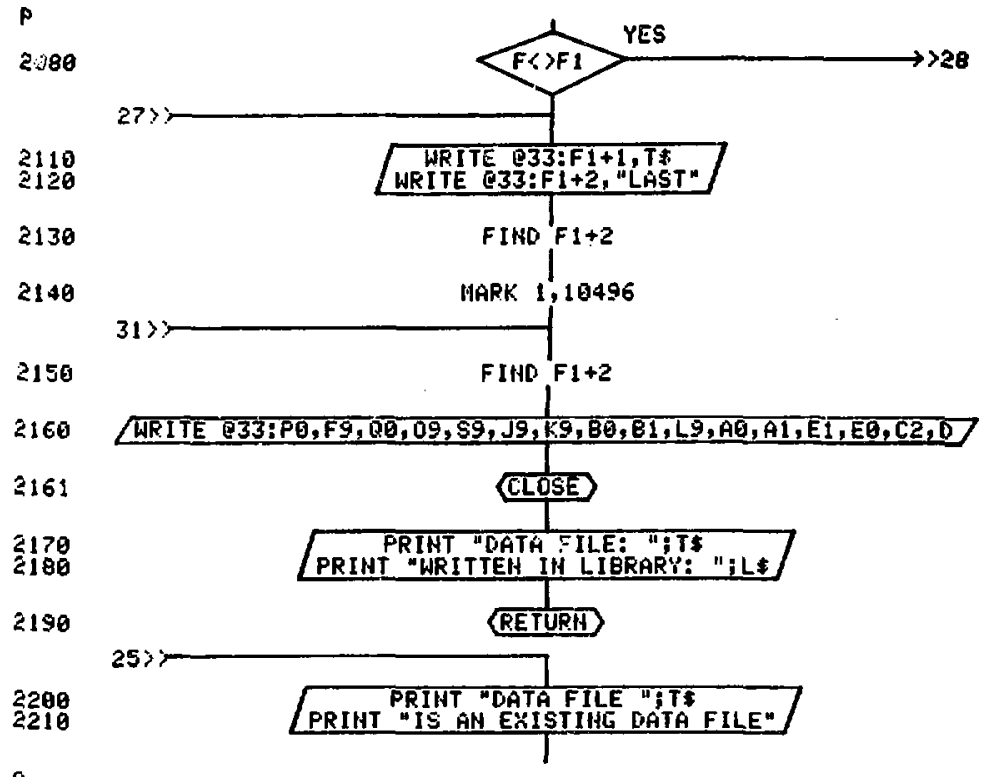

0 


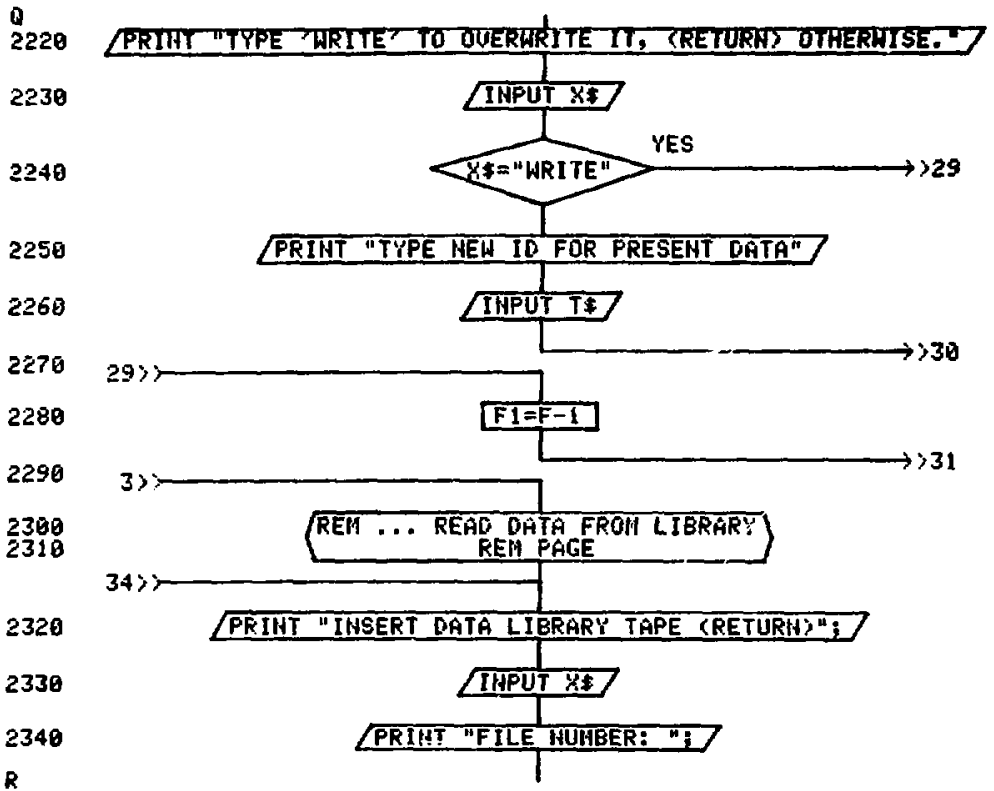




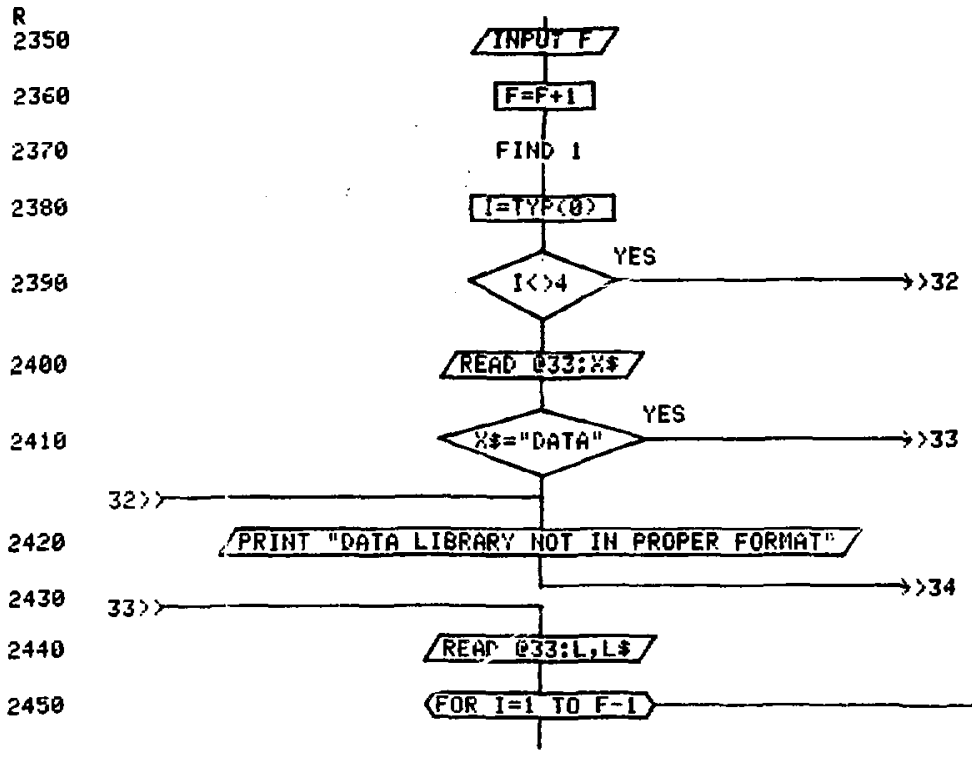

S 
5

2470

2480

36) PSUBR

CALL

2496

READ Q33:PO,F9,00,09,S9,J9,K9,BO,G1,L9,AG,A1,E1,EO,C2,D

2586

2510

2520

$P 2=1$

HEXT 1

2530

REM ... GOTO AMALYSIS PROGRAM

8)

2540

2550

2560

2570

FEIHT "DATA FILE: "IT\$" READ."

RETURT

2580

PRINT "IHSERT PROGRAM TAPE (RETURH)"

T

INPUT ถ้\% 


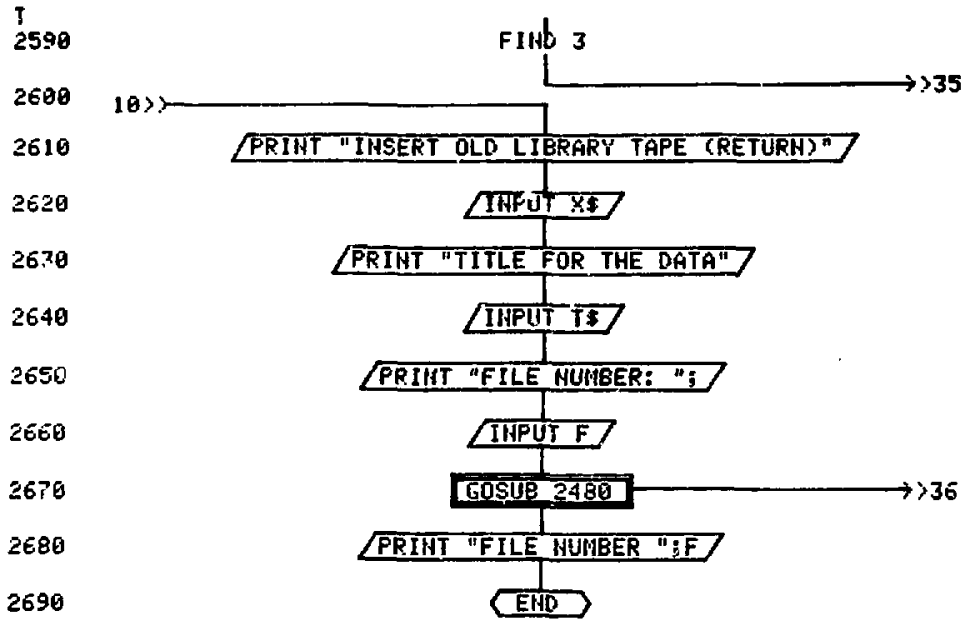

\begin{tabular}{|c|c|c|c|c|c|c|}
\hline $\begin{array}{l}\text { BR: } \\
====\end{array}$ & FROH & T0 & 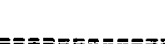 & BR: & FROH & 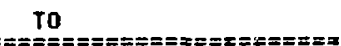 \\
\hline $\begin{array}{l}1 \\
2 \\
3 \\
4 \\
5 \\
6 \\
7 \\
8 \\
9 \\
10 \\
11 \\
12 \\
13 \\
14 \\
15 \\
16 \\
17 \\
18\end{array}$ & $\begin{array}{r}4 \\
13 \\
17 \\
21 \\
25 \\
29 \\
37 \\
41 \\
53 \\
57 \\
77 \\
100 \\
480 \\
990 \\
1020 \\
1390 \\
1750 \\
1770\end{array}$ & $\begin{array}{r}100 \\
1690 \\
2300 \\
1890 \\
490 \\
360 \\
1060 \\
2540 \\
1540 \\
2610 \\
1020 \\
130 \\
350 \\
992 \\
1640 \\
1410 \\
1780 \\
1890\end{array}$ & 更 & $\begin{array}{l}19 \\
20 \\
21 \\
22 \\
23 \\
24 \\
25 \\
26 \\
27 \\
28 \\
29 \\
35 \\
31 \\
32 \\
33 \\
34 \\
35 \\
36\end{array}$ & $\begin{array}{l}1790 \\
1840 \\
1860 \\
1940 \\
1960 \\
1980 \\
2010 \\
2920 \\
2060 \\
2980 \\
2240 \\
2270 \\
2290 \\
2350 \\
2410 \\
2430 \\
2600 \\
2670\end{array}$ & $\begin{array}{l}1710 \\
1870 \\
1830 \\
1970 \\
1990 \\
1900 \\
2200 \\
2000 \\
2110 \\
2970 \\
2280 \\
1920 \\
2150 \\
2420 \\
2440 \\
2320 \\
2400\end{array}$ \\
\hline
\end{tabular}


-

4

8

9

io

11

12

13

16

17

20

21

24

A $\frac{\text { BEGID }}{\text { E*** KEY } 1 \text { **** }}$

***** KEY U2 ****

REM ... PLUT GLL (2)

$H 1=1$

$42=1024$

\#*** KEY \#3 ****

REM... FLOT LIMITS (3)

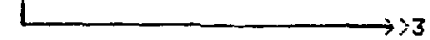

2*** KEY H4 ****

(REN ... SCAN FUTO (4)

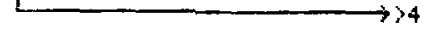

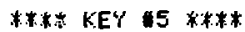

(REH ... SCAH LIHITS (5)

**\#* KEY U6 ****

GEEN... CLEAR OH ERROR (6) 
A

25

28

29

32

33

36

37

40

41

44

45

48

B
Eस]ए

**** KEY IP ****

(REA ... IIARK LIAITS (T)

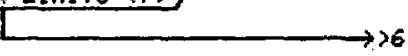

**** KEY \$8 ****

(REM .... SCANT RESET (8)

**** KEY 19 ***k

REM... INTEGRATE LIMITS (9)

\#*** KEY \#16 *स**

REM ... LOCATE PEAKS AUTO (10)

*末** KEY \#11 *⿻**

REM... DELETE MARKEE PEFK (11)

**** KEY H12 t*k*

(REM ... LIST PEAKS SHORT (1.2) 
8

49

52

53

66

61

64

65

158

49

$7:$

73

76

C

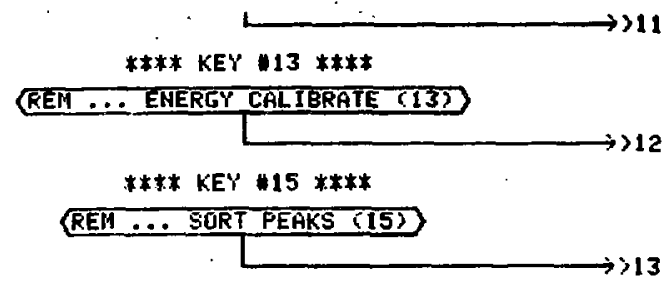

स*t* KEY \#16 *t*t

REII... IHTEGRATE AUTO (16)

**** KEY 17 ****

REH .... LIST LIMITS (17)

**** KEY \#18 *\#**

REW ... LIST PEAKS LONG (18)

K*** KEY \#19 **\$*

REII ... GO TO IOO PROGRAM (19) 


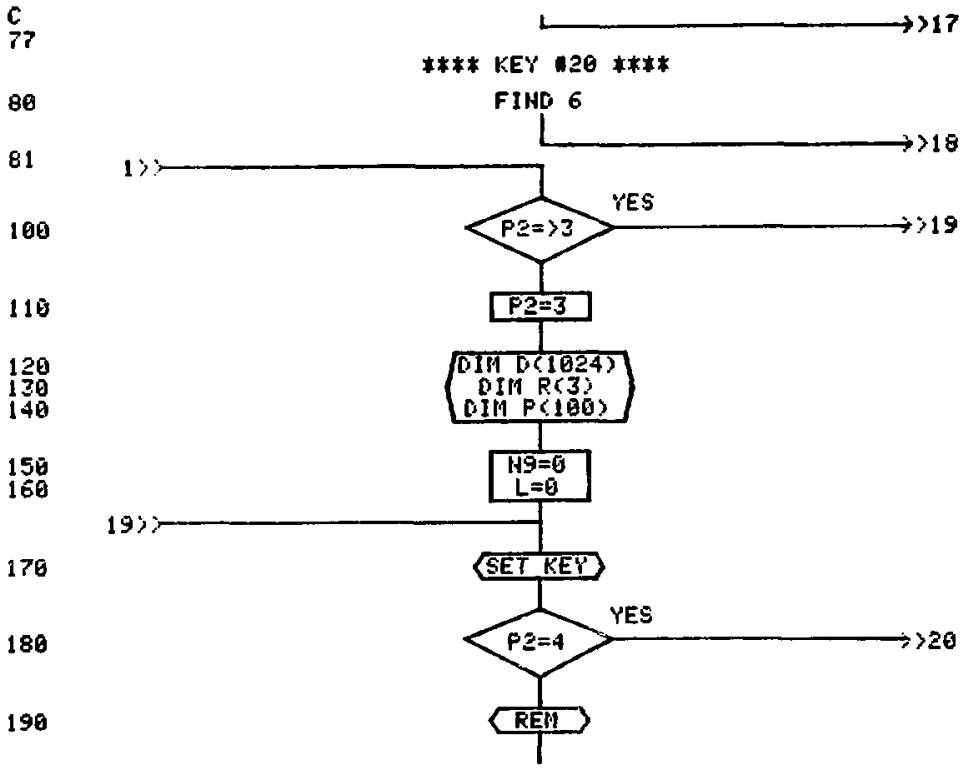

D 
D

266

210

220

230

240

250

260

270

280

290

300

310

320

330

340

350

360

370

380

390

400

416

420

430

440

450

460

\section{PAt}

P9=0

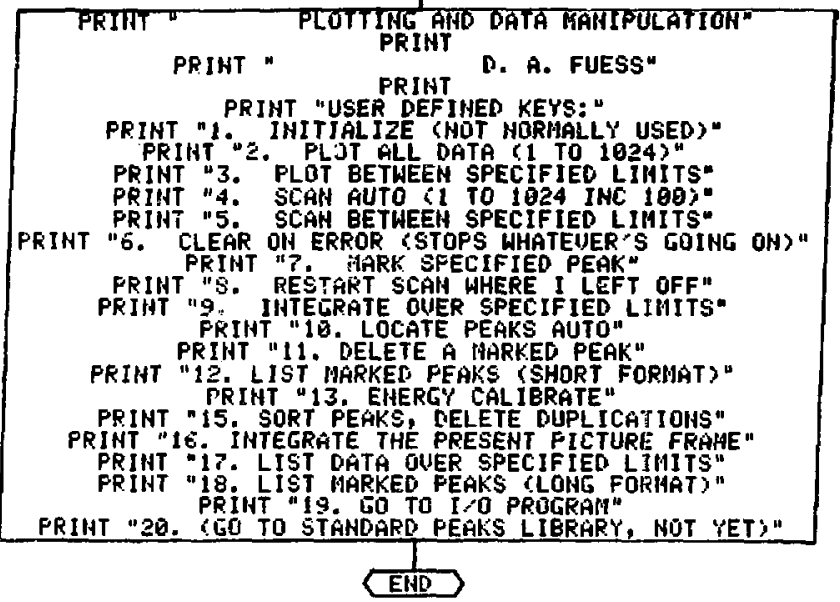

E 


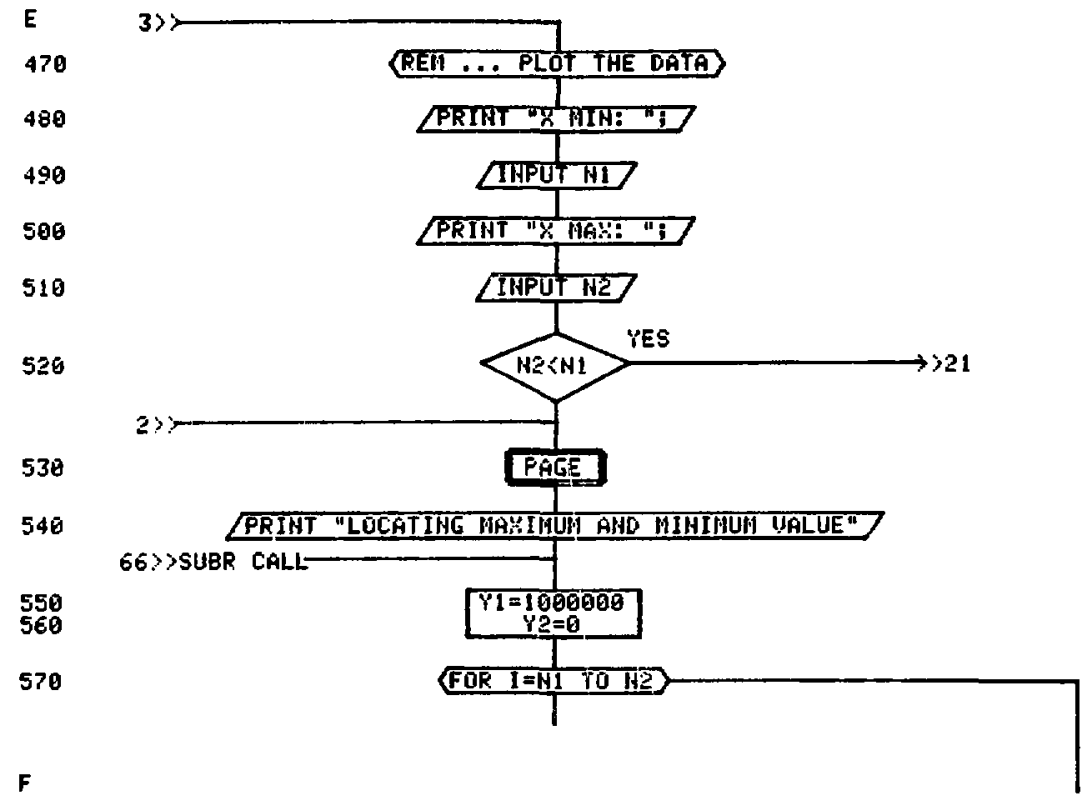




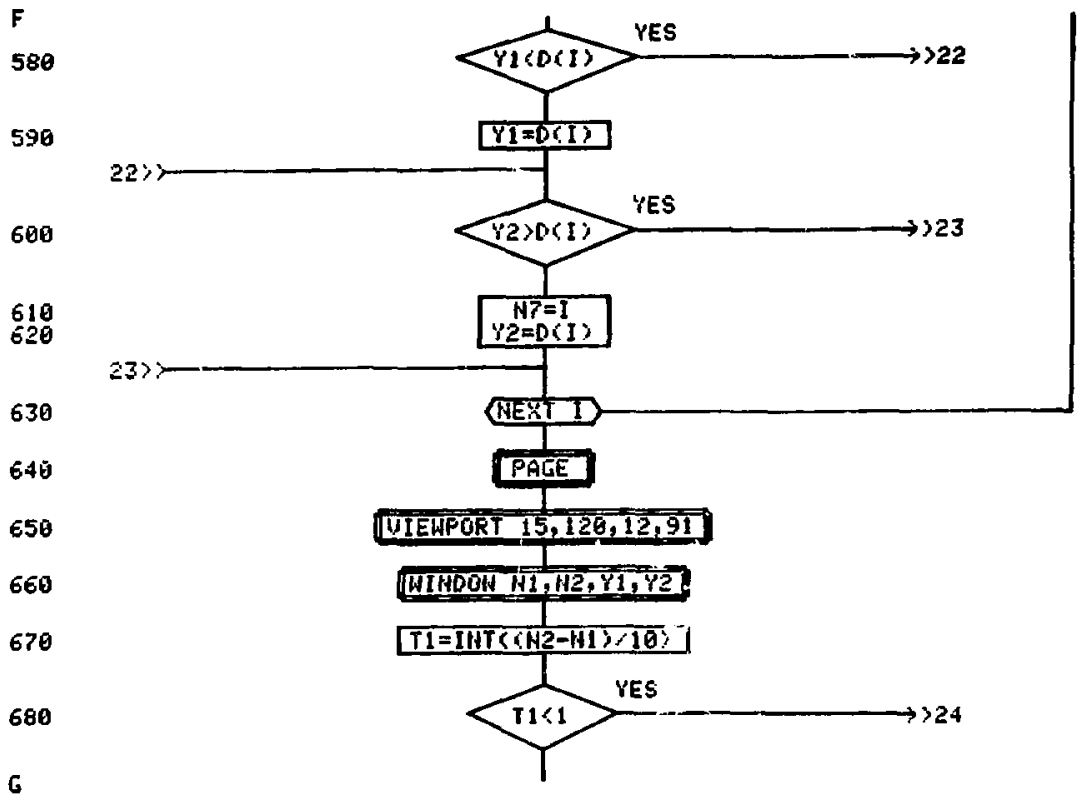




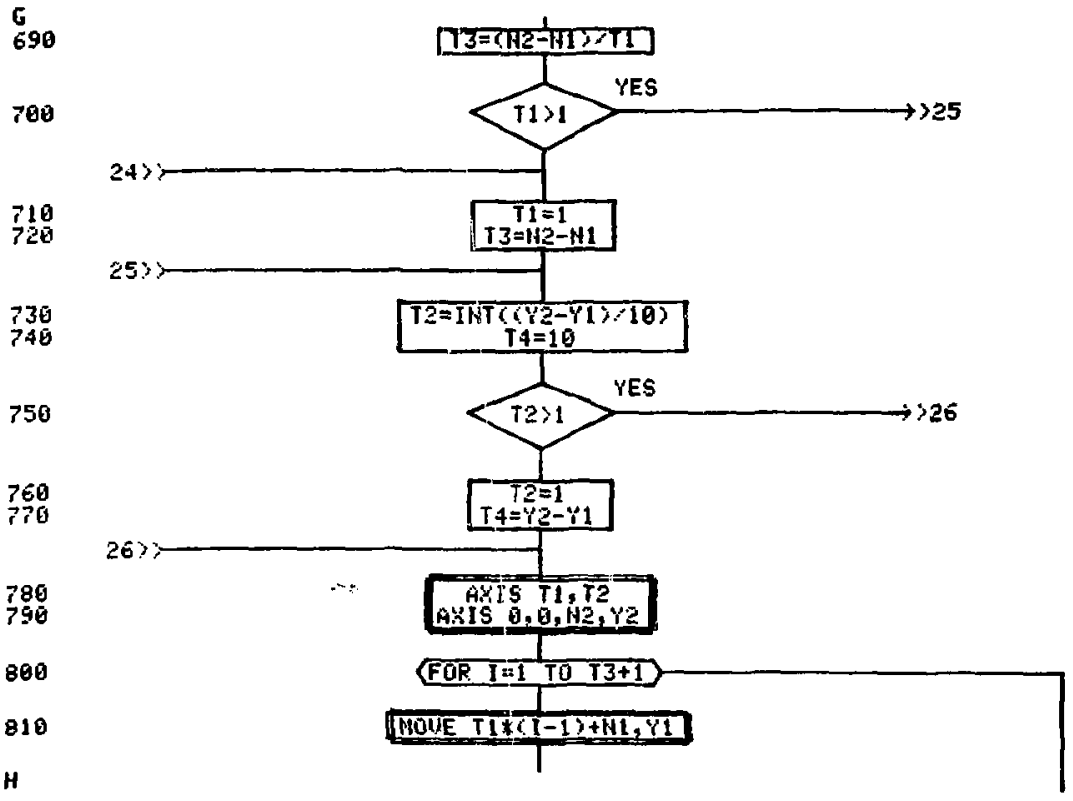


H

820

830

840

856

8E0

870

880

ธิติธี

900

910

930

930

940

950

I

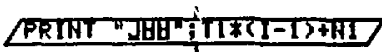

MOUE $I I *(I-T)+N L, Y 1$

PRIHT USING "FRIN" "EIX

NEXT I

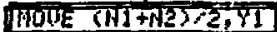

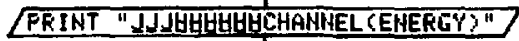

FOF $I=1$ TO $\mathrm{TA+1}$

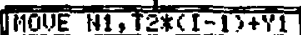

$\angle$ PRIAT "HUHHH"; TZK(I-1)+Y1

(NEYTT 1

HOUE $\mathrm{N1},(\overline{1+Y 2) / 2}$

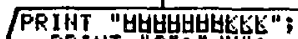

PRINT "C" "NH": 


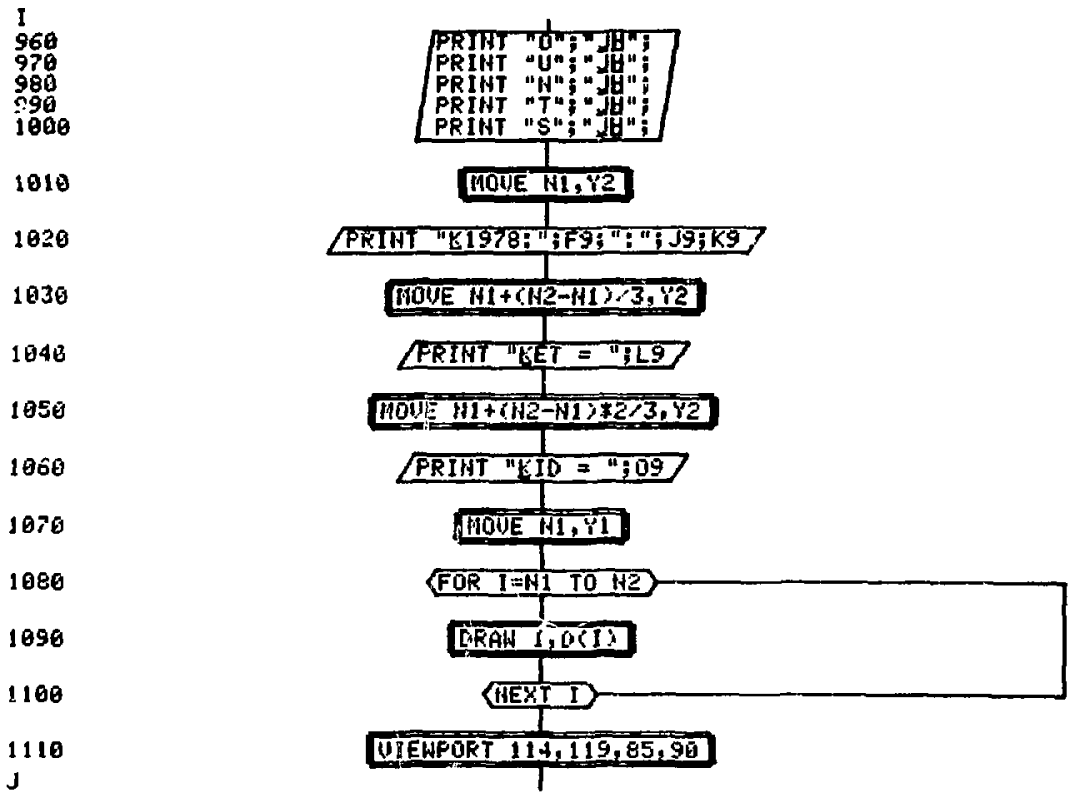




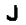

1120

1130

1140

1154

1160

1170

1180

1190

1200

1210

1226

1236

1246

$1 \geq 56$

1260

1270

1280

1296

136

1310

1320

K
WHWOH ह120, 0,20]

Ar.TS

A\% IS $0,0,20,20$

HoUE 1,26]

\begin{tabular}{c} 
DRAW 1,1 \\
ORAH 10,1 \\
ORAW $12.5,4$ \\
DRAH 4,4 \\
DRAW 4,20 \\
\hline
\end{tabular}

MOUE 5.20

DRÂH 5.5 DRAN 13.5.5

DRAH I6,8

DRAN 8,8

[RAL 8,29

\section{MDUE 9,20}

ORAW 9,9

ORAIN $17.2,9$

DRAN 20, 12

ORAW 12,12

DRAN 12,20 
K

1330

1340

1350

1360

1370

$138 \overline{0}$

1390

1400

1410

1420

1430

1440

$L$

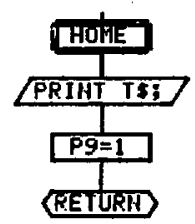

21 ;

39

34 ?

PRIYT "BAD LIMITS SPECIFIED."

PRINT "NOTHIHG DONE

ENHD

$8 ;$

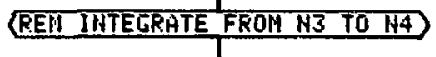

GDSUE 35rg

PRINT "IMTEGRATE FROM: "I

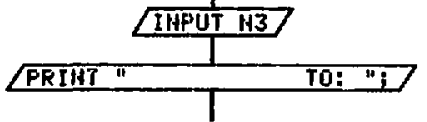




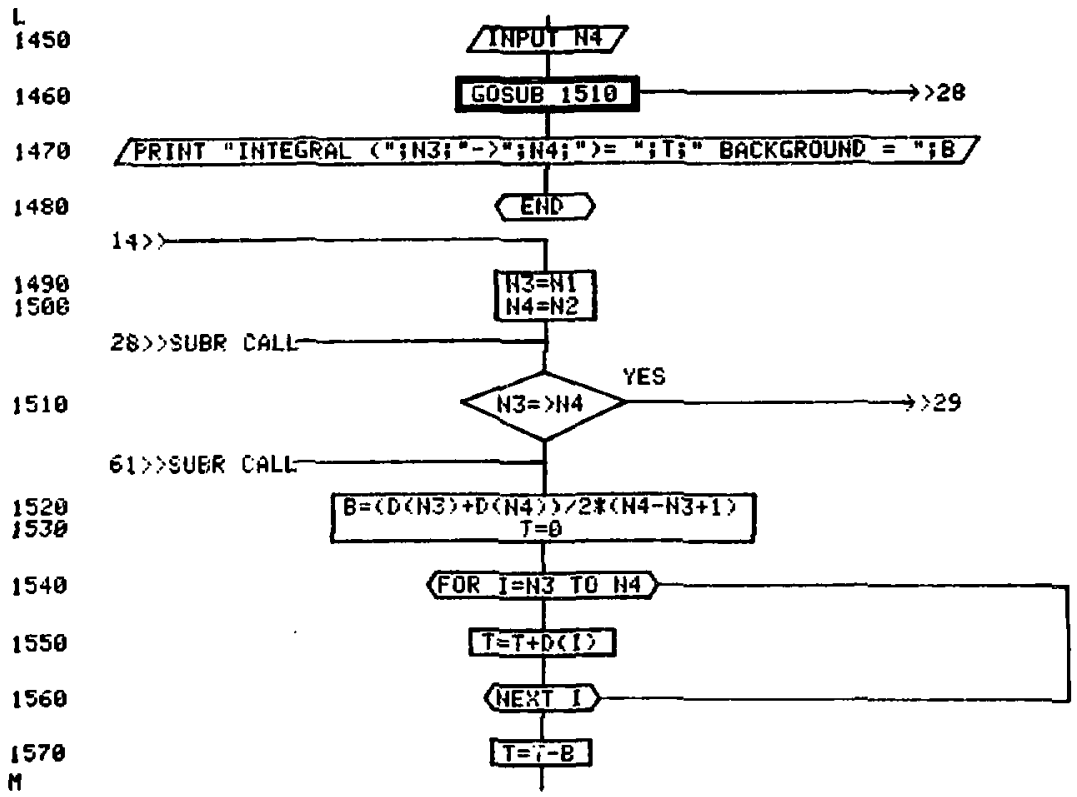




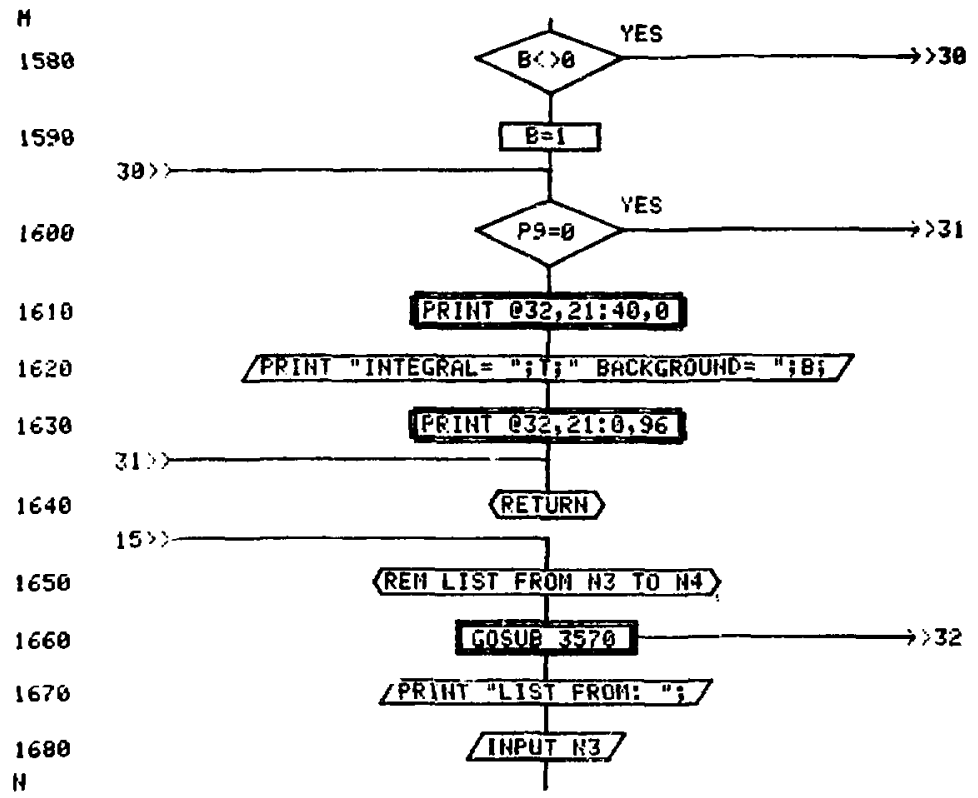


H

1690

1700

1718

1720

1738

1740

1750

1760

1770

1780

1790

1800

1810

IBटि

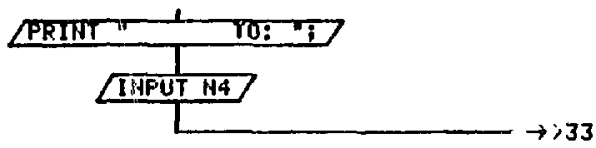

$N 3=N 1$

$N_{4}=H_{2}$

3)

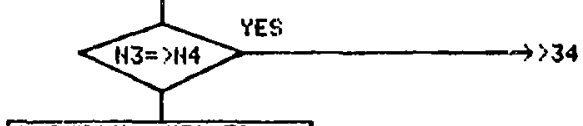

$A=I+T(2 \mathrm{N4}-1+3), 30)+1$

FCR $\mathrm{J}=1$ TO $\mathrm{K}$

\section{PÁGE}

$P 9=9$

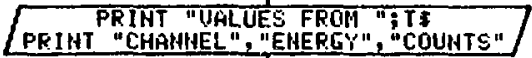

$L=(J-1) * 30+113$

$14=143+30 * \mathrm{~J}$

0 
0

1830

1840

35)

1859

1860

PRIIIT I,EIKI+EO,BCI)

1870

1880

1890

PREIHT IHORE":

1900

1910

1920
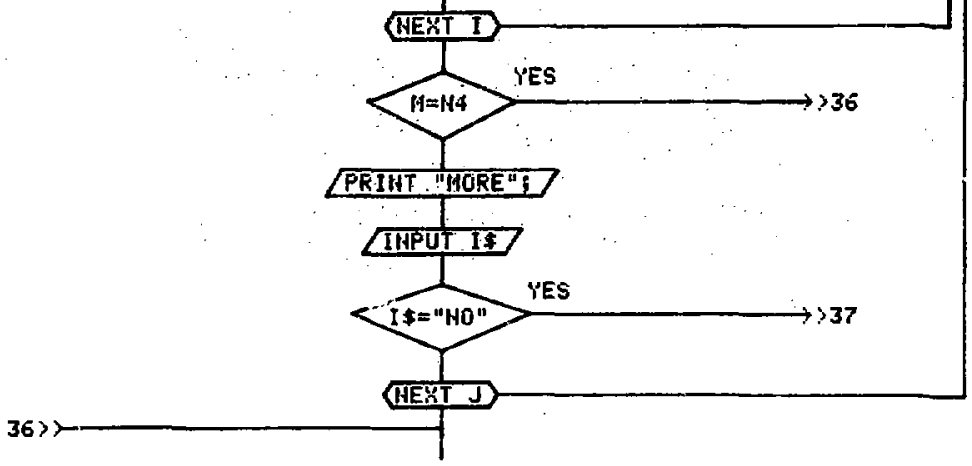

$p$ 


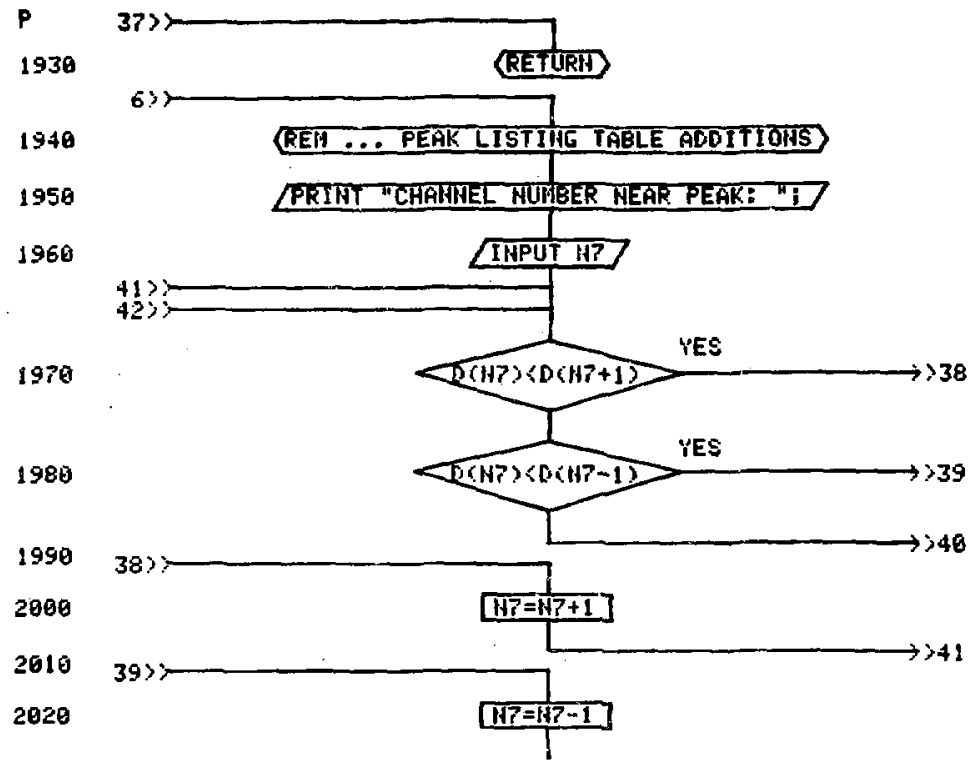

$a$ 


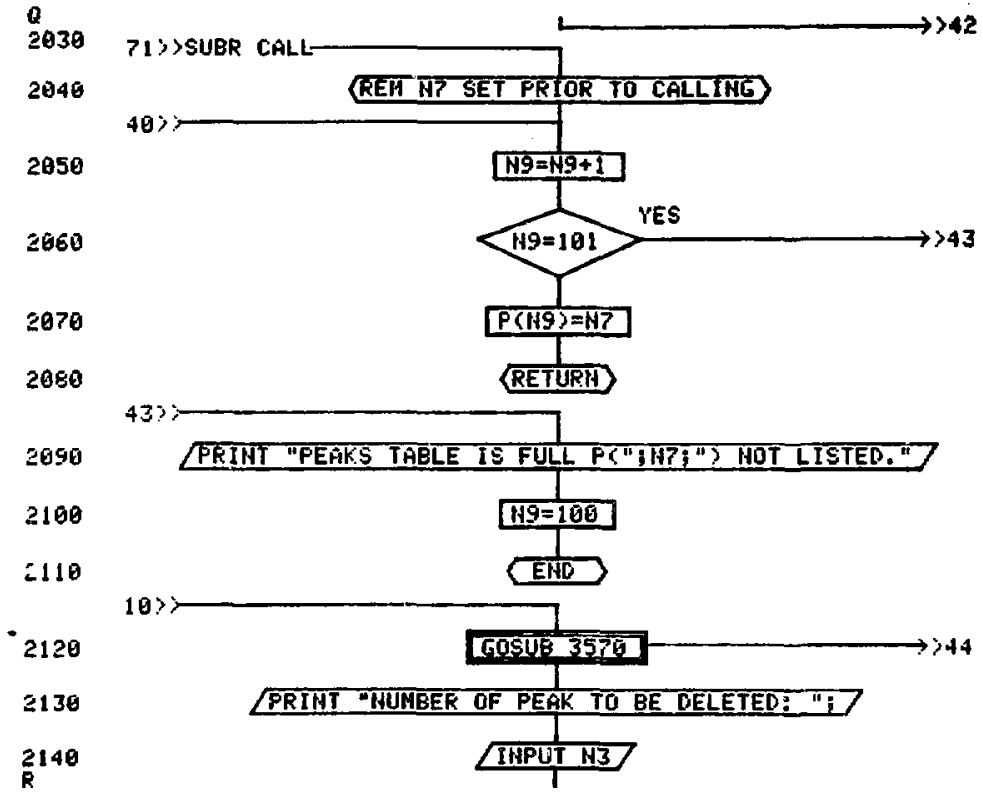




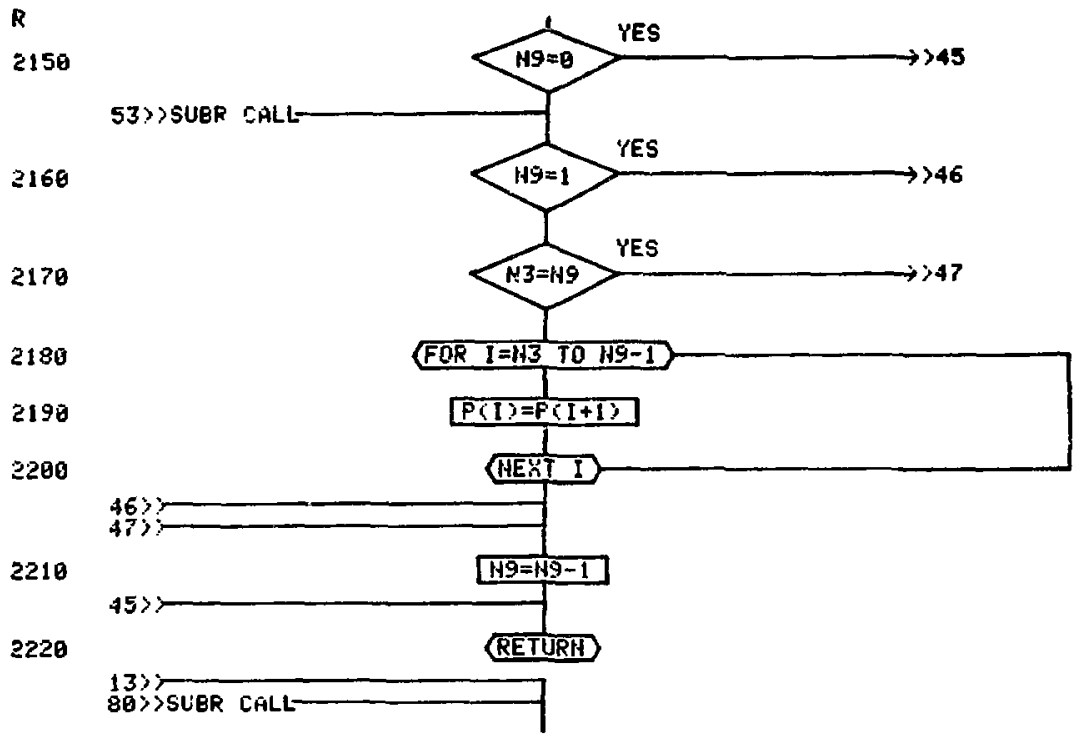

s 


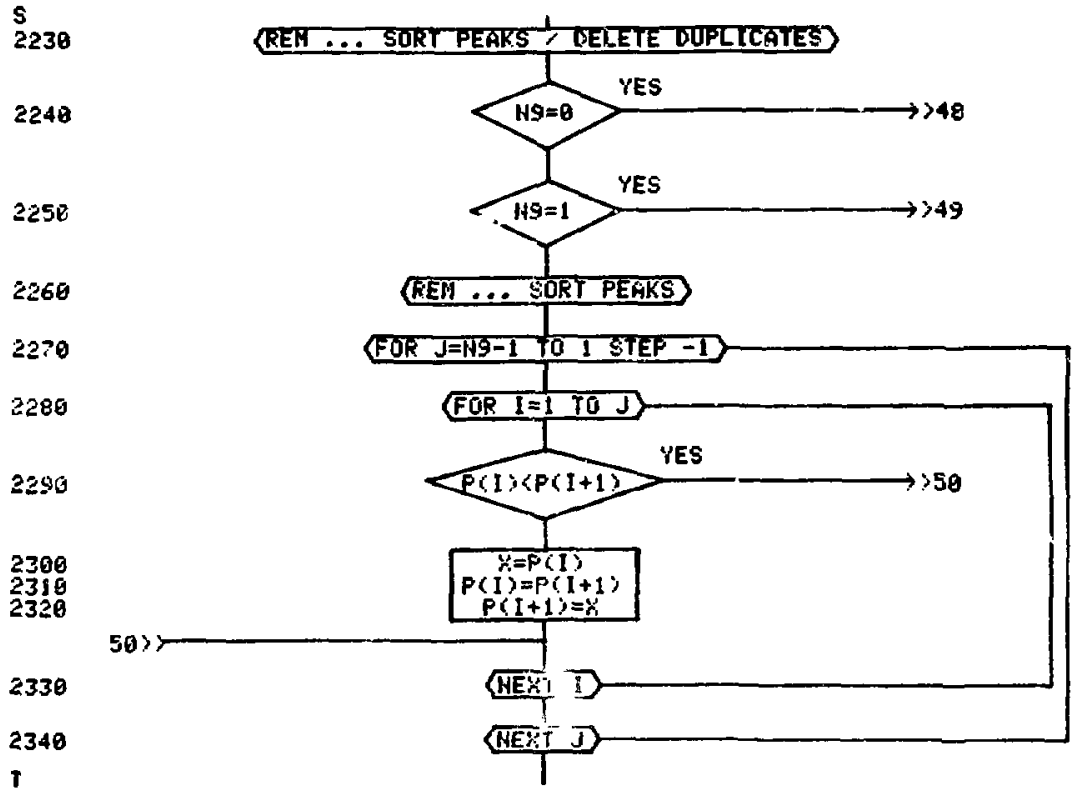




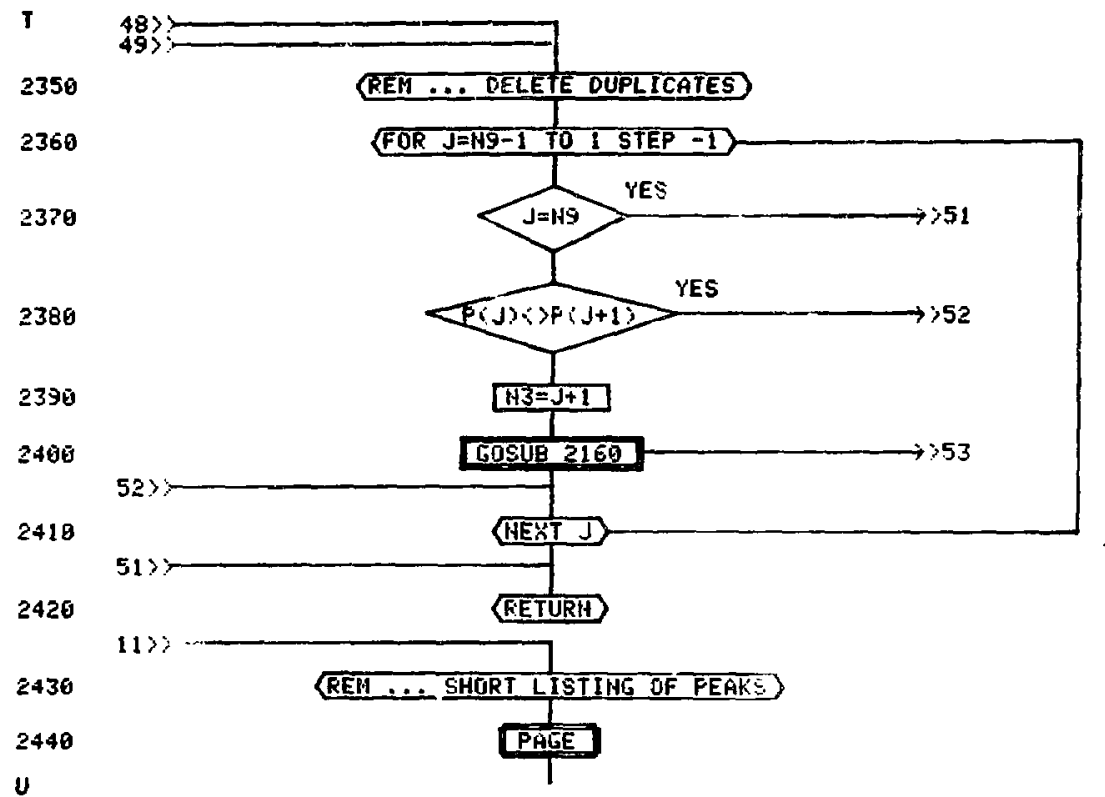


U

2450

2463

2470

2480

2490

2500

2510

2520

2530

$254 \theta$

2550

2560

v

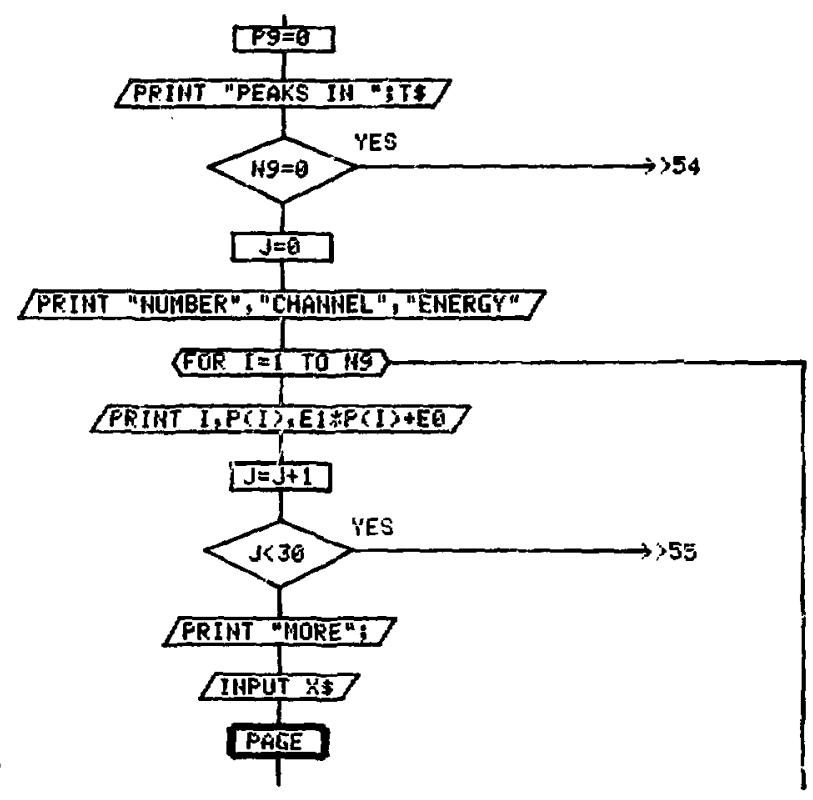


2590

2600

2610

2626

2630

2640

543

55)

FRINT "HLMBER", "CHAMHEL" "ENERGY"
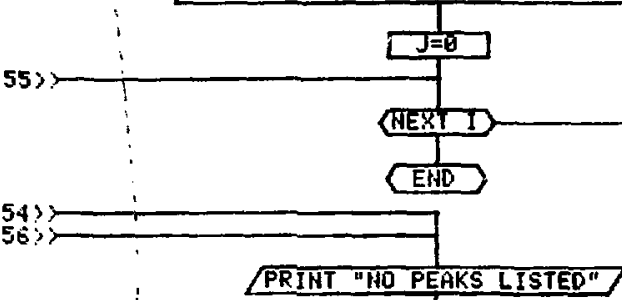

2650

2660

2670

BHEXI I

EHD

RETURA

$16 \%$

81 ?

REN ... PEAKS LIST LONG

FAGE

$p 9=0$

PRINT "PEAKS IH "IT

W 


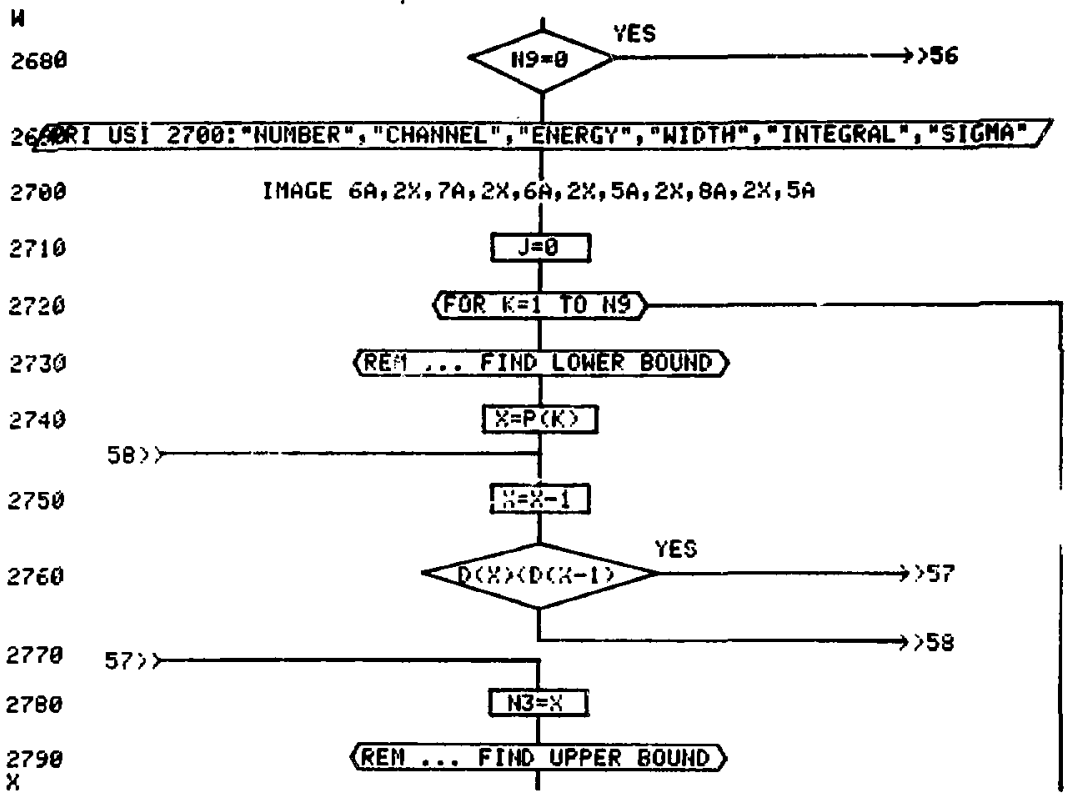




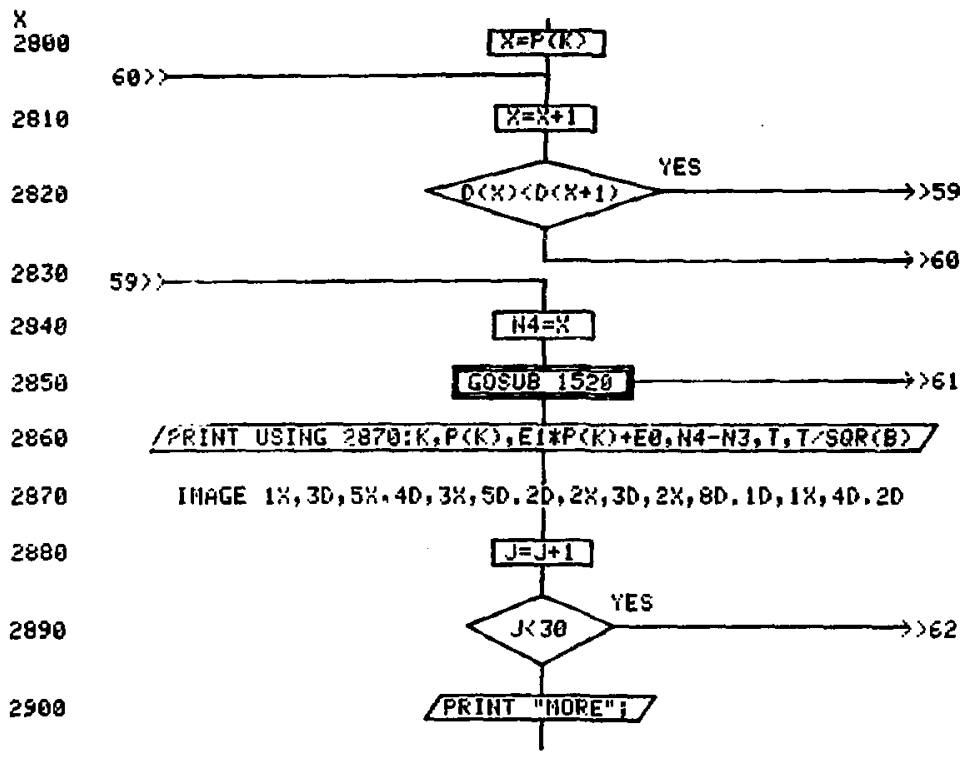

$y$ 


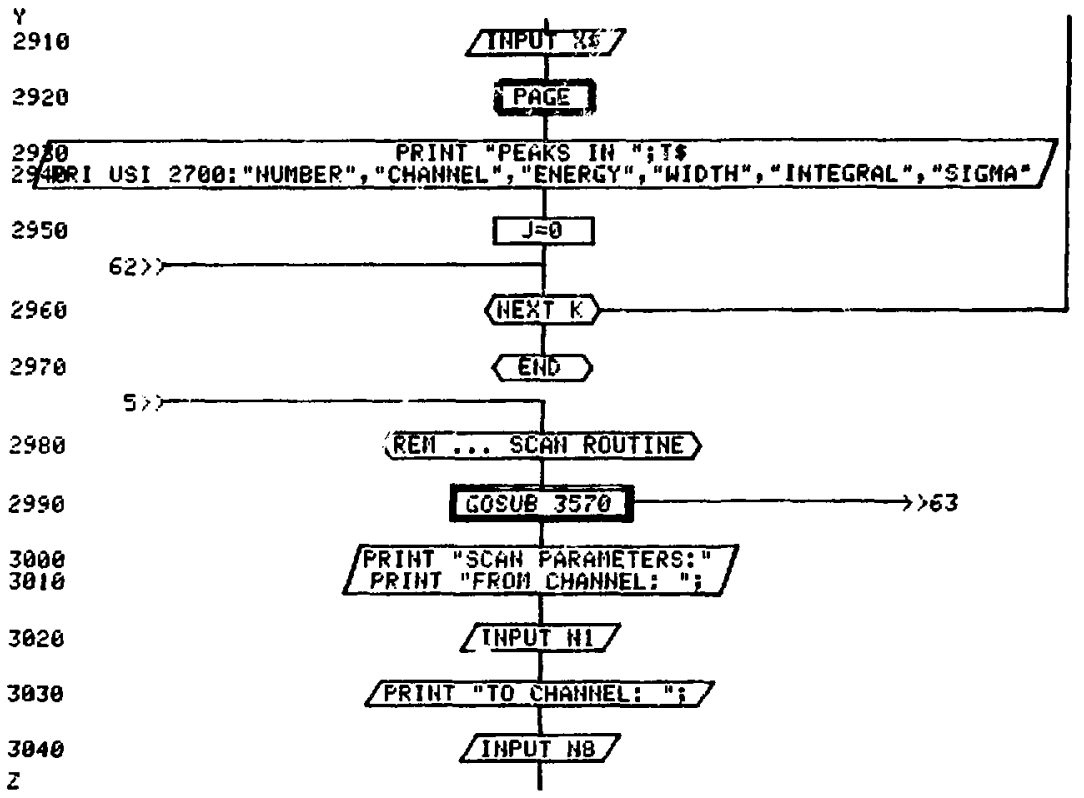


2 3050 PRINT TINCKEFENT: ?

3060

3070

3989

3090

3100

3110

$64 ;$

74

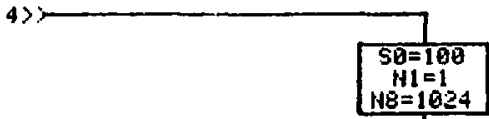

44

$312 \overline{0}$

3130
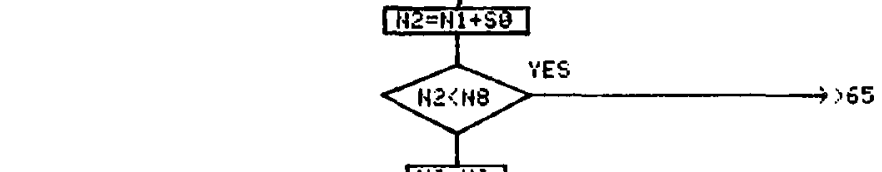

\section{0}

65

112=NE

3140

3150

3160

GosUB 550

PRIAT "ENTER CIHKOFIOR RETURN "I

a

IIIFIT I\$ 
4

3170

3180

3190

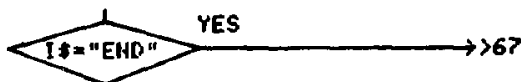

$3 \geq 00$

68:

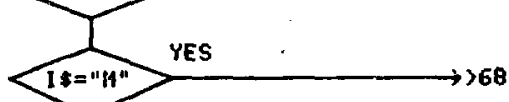

VES

I\$<> II I"

$\rightarrow>69$

$\rightarrow 70$

3210

GOSUB 2040

$\rightarrow>71$

3220

$[: 2=1 \sqrt{2}+1$

3230

70)

1 YES

$\mathrm{HZ}=\mathrm{NB}$

$\rightarrow>72$

3240

3250

3260

$S B=V_{G L}(I)$

b

\section{H1 $=12-1$}

69?

I 
RETURA

3290

3300

3310

3329

3330

3340

3350

3368

3370

3380

3390

REM ... EPERGY CALIQRATE

GosU8 3570

PRTIAT "LOW CHANAEL, ENERGY "I

IIPUT $5, E 5$

FRIPT "HIEH CHANHEL, EHERG'"

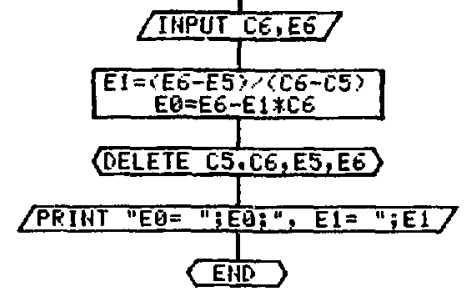

c 
c

3400

3410

3420

3436

3440

3458

3460

3470

3480

3490

3500

3516

3520

d
17)

REII ... GO BACK TO IFO PROGRAM

Gusute $34+6$

PRINT "THSERT PROGRAII TAPE (RETURH)"

IIPUT स्ञ

FIND ?

$9 ?$

REM ... GO TO PEAK SEARCH AUTO

GDSDB 3570

PRIHT "IHSERT PROGRAM TAPE (RETURIS"

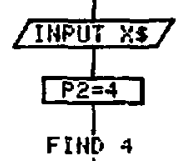




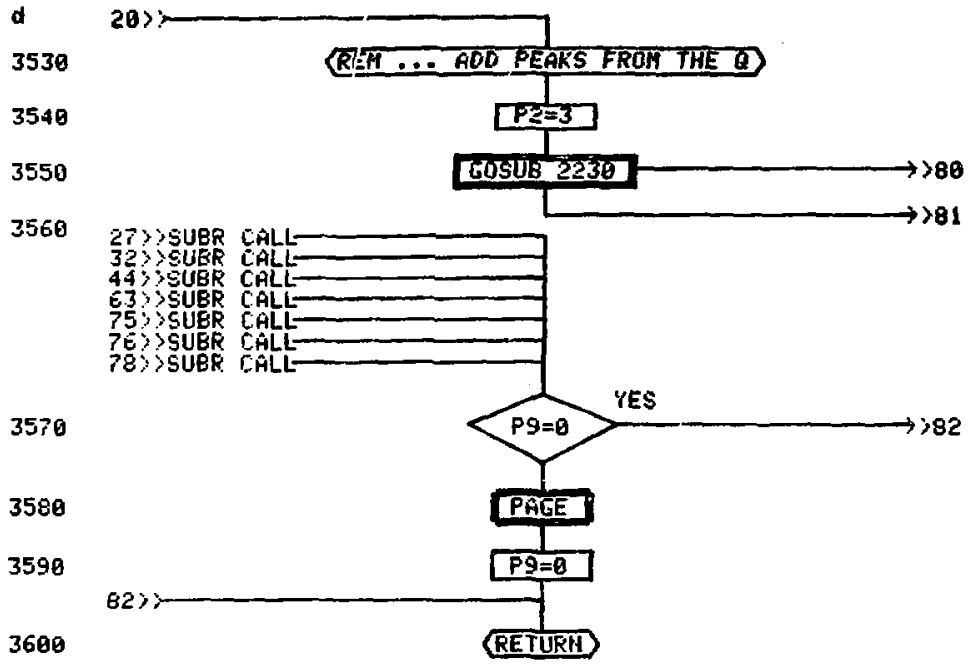

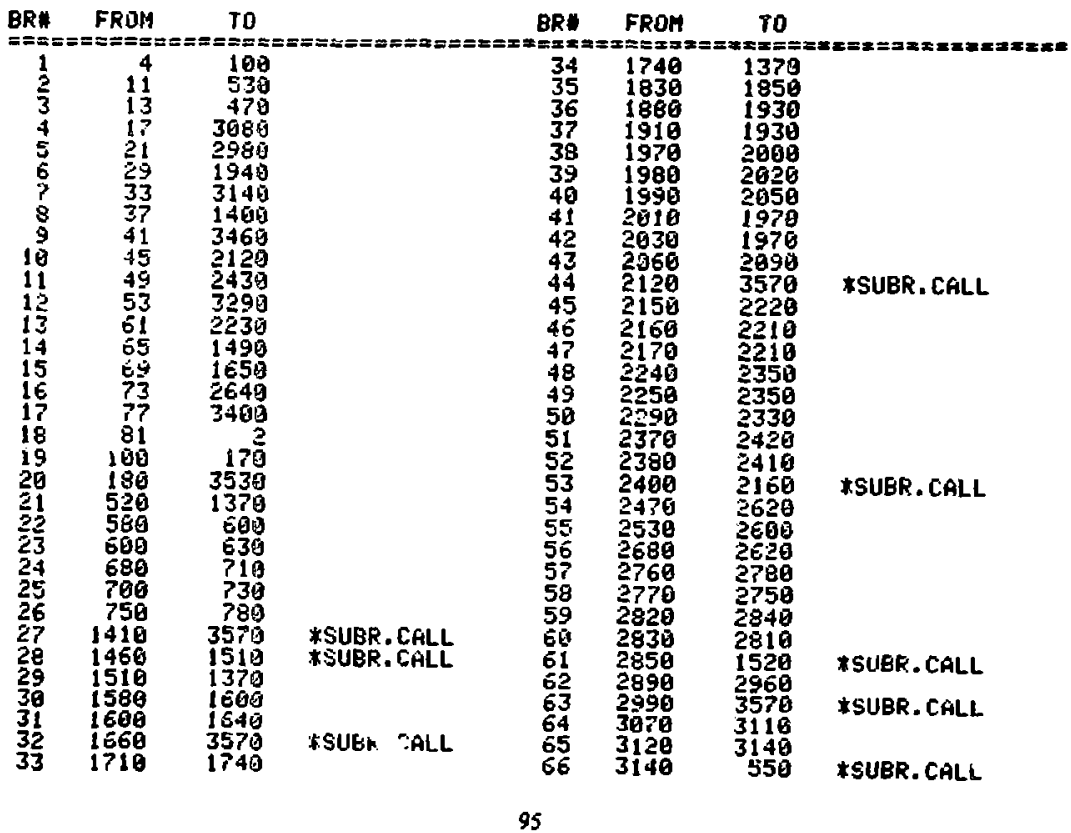




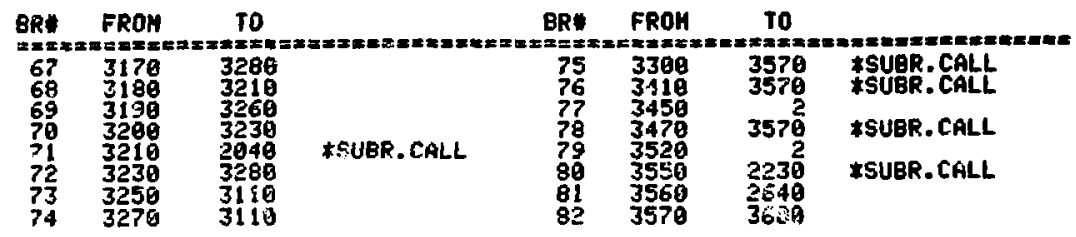

$\theta$

\#*\#* KEY 1 \#\#**

4

13

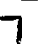

100

110

126

130

140

150

160

REM THIS IS A TEST PROGRAM TO LOCATE PEAKS IH A HPEE REH SPECTRAL DATA FILE AHO CLASSIFY THE PEAKS LOCATED REIA BY SIFHA LEUEL. OHLY THE 100 HIGHEST SIGHA PEAKS

REM ARE REPORTED. CTHE PEAK STORAGE SPACE IN THE AMALYSIS REN PROERGI ALLOWS FOR A MAXIMUUH OF 160 PEAKS.)

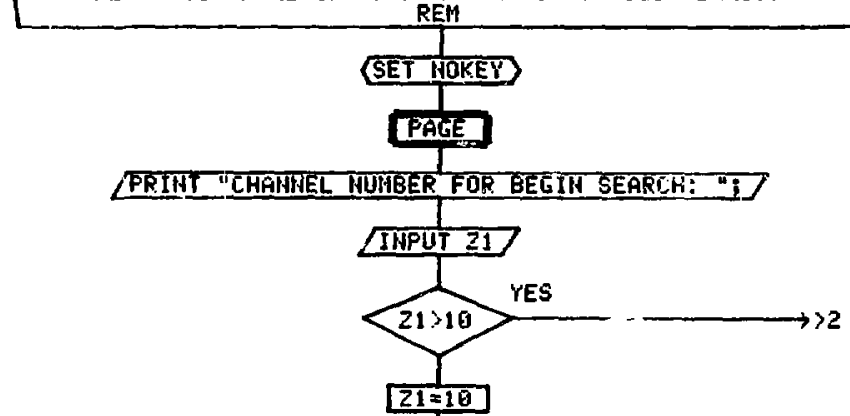

210

2)

220

PRINT "CHANHEL NUMBER FOR END OF SEARCH: "I

A 


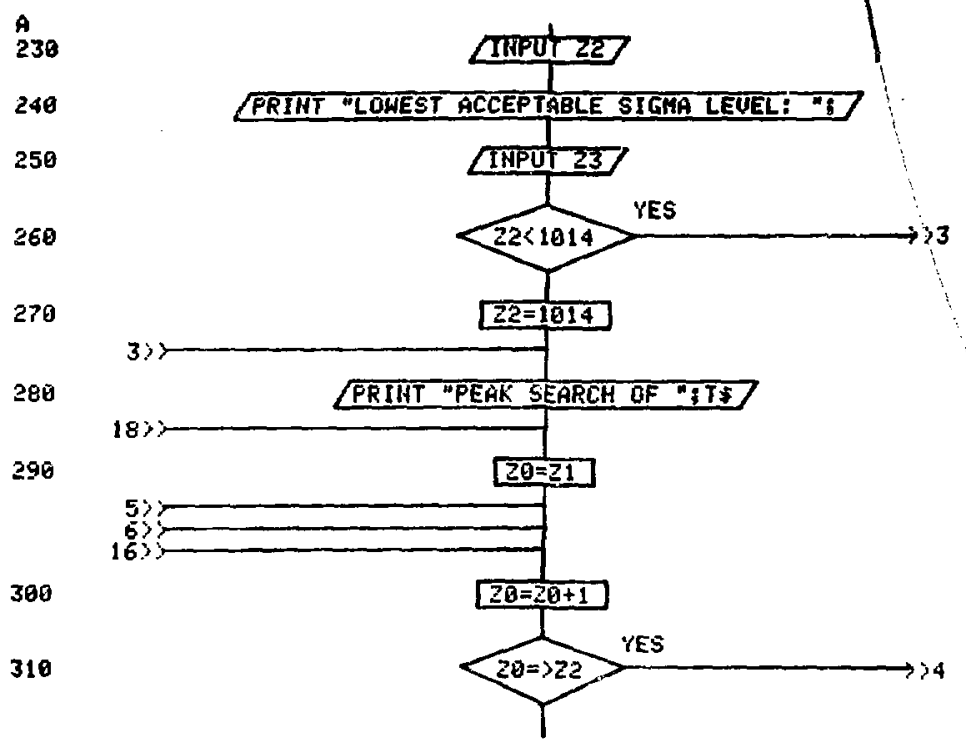

$B$ 


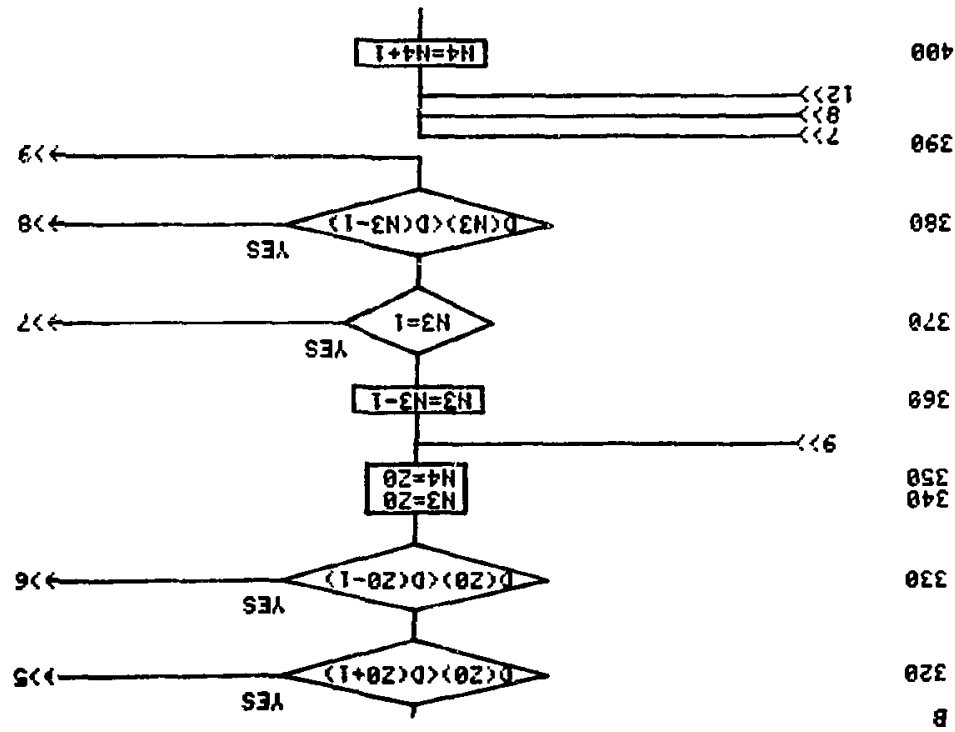


C

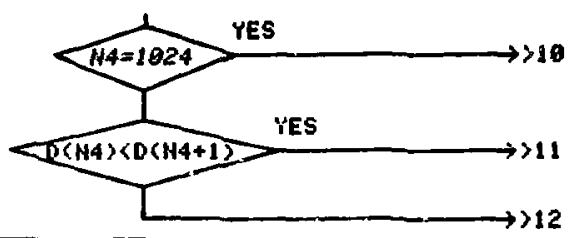

430

446

450

460

FOR I=N3 TO 14

470

$T=T+b(S)$

480

MEXT I

496

$B=(D(H 3)+D(H A)=2 *(N 4-H 3+1)$ $T=0$

(1)

510

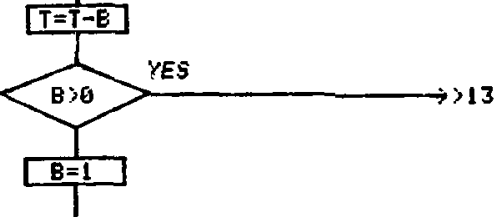

D 


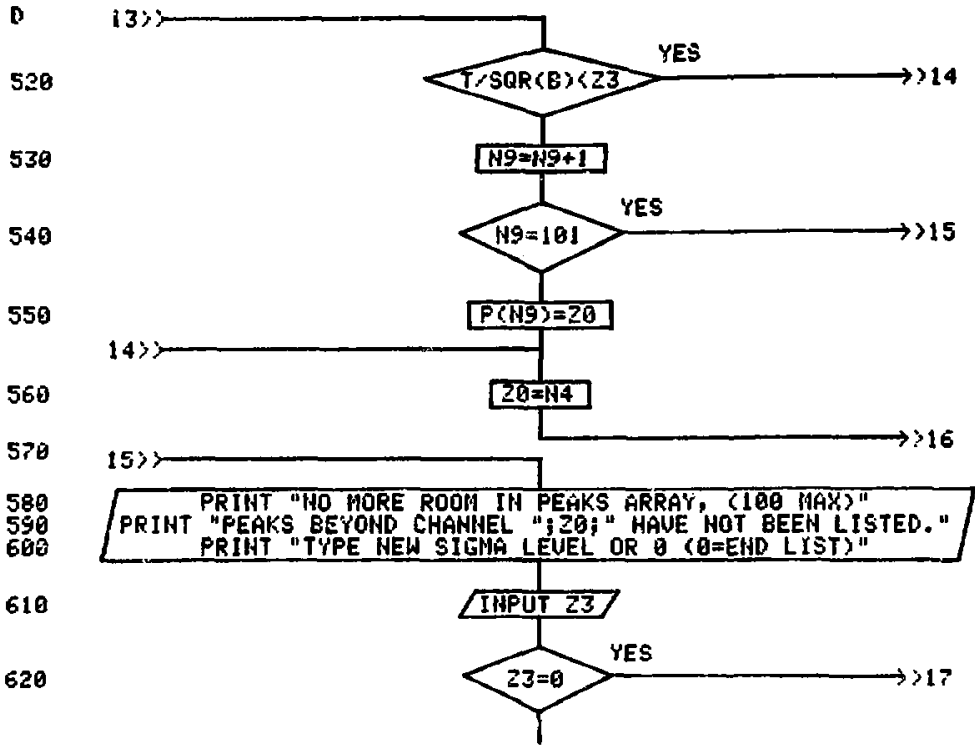

E 


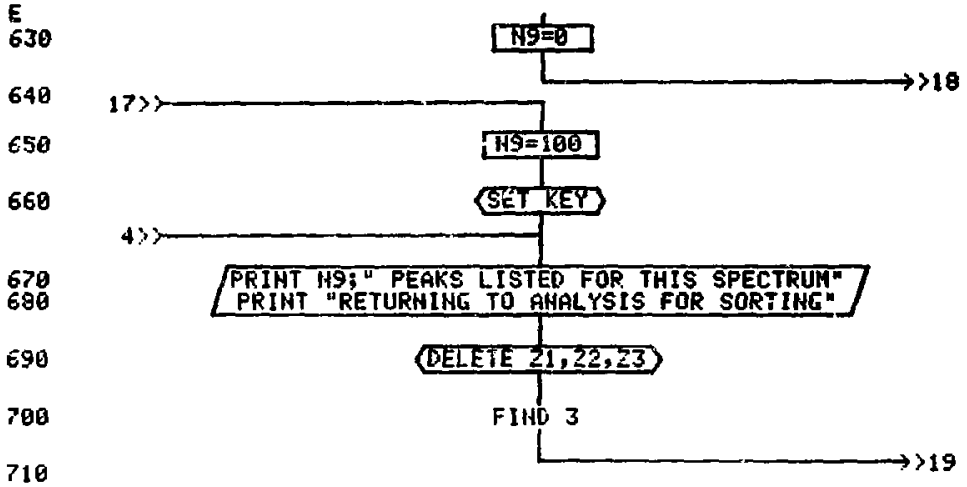

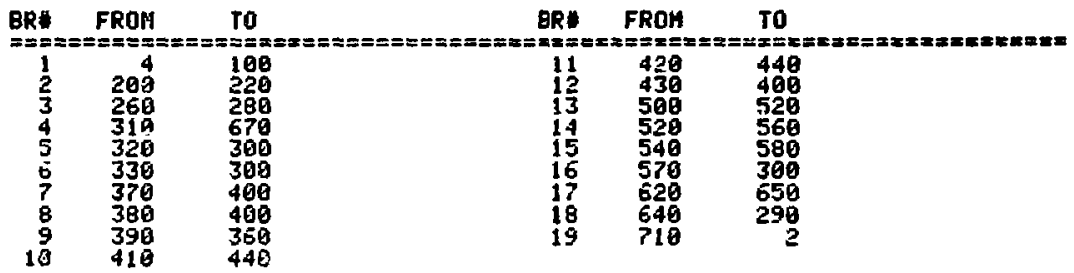


$\theta$

3610

PAGE

3626

ARITT "ITSERT LIBRARY TAPE CRETURH)";

3630

3649

PRINT "LIERARY FILE RUMRER: ID

3650

IFFUTF

3660

3670

FOR IE 10 TO

3685

READ Q33:

3690

BE: 1

3700

PRIKT "QUADRAIT COEALLI: ":

3710

3720

3730

A

IHPUT 0

PRINT "SUBTRAHEHD FPCTOR: ";

IMPUT F 
A

3740

3759

3760

3770

PRIHT "KINUEND QUADRANT: ":

3780

IMPUTE

3790

$k=(k-1,+256$

3800

PRIHT "DIFFEREMCE QUADRAHT: ":

3810

3820

3830

3840

3850

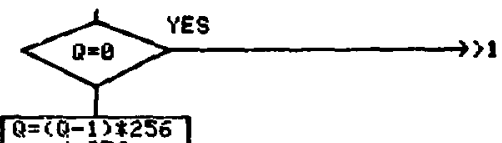

$$
j=256
$$

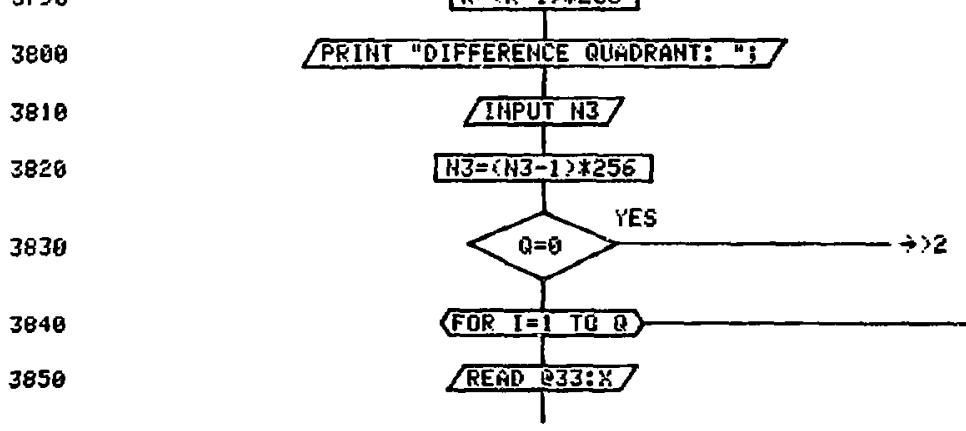

B 